\title{
SWITCHGRASS RESPONSES TO MANGANESE AVAILABILITY
}

A Dissertation
Presented to
The Faculty of the Graduate School
At the University of Missouri
In Partial Fulfillment
Of the Requirements for the Degree
Delix Fritschi, Dissertation Supervisor
YING GUO
By Philosophy

MAY 2019 
The undersigned, appointed by the dean of the Graduate School, have examined the Dissertation entitled

\title{
SWITCHGRASS RESPONSES TO MANGANESE AVAILABILITY
}

\author{
Presented by YING GUO
}

A candidate for the degree of

Doctorate of Philosophy in Plant Insect and Microbial Sciences

and hereby certify that, in their opinion, it is worthy of acceptance.

Dr. Felix Fritschi

Dr. Craig Roberts

Dr. Jeanne Mihail

Dr. Peter P. Motavalli 


\section{DEDICATION}

I would like to dedicate this dissertation to my family and my husband, Zhengbin Liu and my children, Wangshu Liu and Allysa Liu for their love, support and encouragement throughout my PhD study and life. 


\section{ACKNOWLEDGEMENTS}

Firstly, I give the deepest appreciation to my supervisor, Dr. Felix Fritschi, for giving me the opportunity to pursue a $\mathrm{PhD}$ degree. This dissertation would not have been possible without his patience, encouragement, guidance and helpful advice during difficult moments. He also taught me that a PhD student should learn to solve the problems they meet in study, life and research projects. The joy and enthusiasm he shows in research and teaching inspire me how to become a researcher or plant scientist in the future.

I thank my committee member, Dr. Roberts, for his guidance in my development of a research philosophy. He used several practical cases or stories to help me understand how to become an excellent scientist or professor in the future. I express my gratitude to Dr. Mihail for her excellent plant anatomy class and writing class. Both classes have been so useful for my TEM image analysis in my $\mathrm{PhD}$ project and for the writing of this dissertation. I also thanks her for her assistance and guidance in my project for the plant stress agent class. I owe the greatest gratitude to Dr. Motavalli for his awesome soil science and plant nutrient classes and guidance in the knowledge of soil science.

I extend my greatest gratitude and respect to my lab members, Shengjun Liu, Hua Bai, Anh Nguyen, Brandon Davis, Jessica Biever, Hussien Almtarfi, Matt Herritt, Micheal Maw, Matthew James Smith, Alvaro Sanz Saez de Jauregui, Arun Prabhu Dhanapal, Gabriel Esparza, Maria Murillo, Sarah Dixon, Lauren Ragel; thanks for your help in setting up experimental systems, shoot and root harvesting, taking measurements in my project. I thank Yebei Li for helping creating perfect graphs by using SigmaPlot 
software. I also thank Fei Gao for running RT-PCR to confirm expression of our genes of interest. I express my appreciates to Shannon King for her help in dissertation writing.

Finally, I thank my family for their love, support, and encouragement. But I would like to especially thank my mother in law, Yuanxiang Ding, who helped me take care of my kids here and in China. And most of all, to my husband Zhengbin Liu, thanks for his understanding, support, encouragement and suggestions in writing my dissertation. He tried his best to make me comfortable during the difficult times of my $\mathrm{PhD}$ studies. Overall, without them, this project and thesis would not have been completed or written.

If there is anyone reading this that has a memory of helping me during my $\mathrm{PhD}$ studies and research, or I have missed, I apologize and thank you. 


\section{TABLE OF CONTENTS}

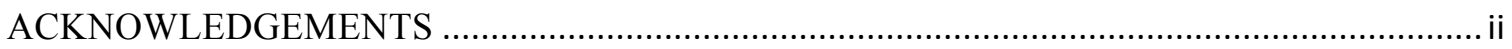

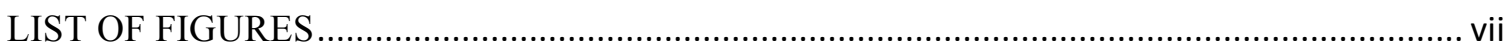

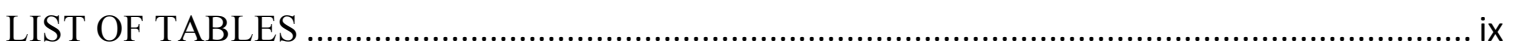

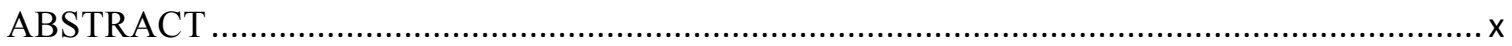

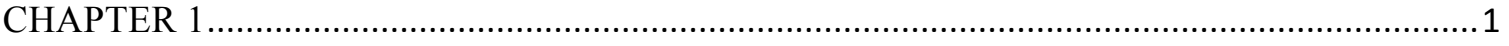

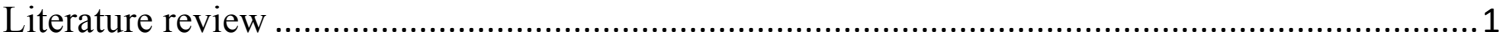

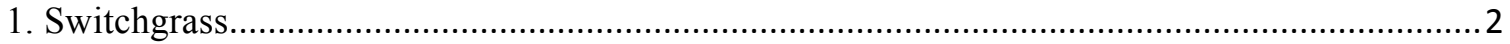

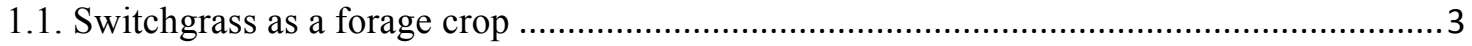

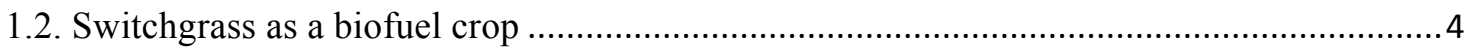

1.3. Switchgrass as a phytoremediation and conservation crop.............................................. 5



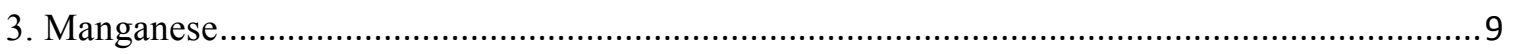

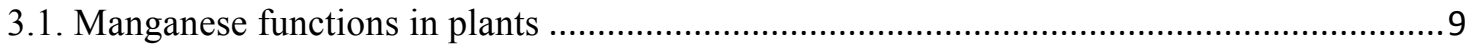

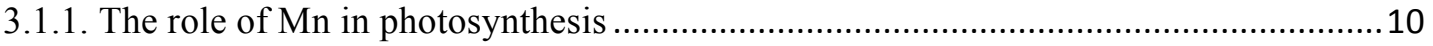

3.1.2. Role of $\mathrm{Mn}$ in plant respiration and nitrogen assimilation.......................................11

3.1.3. Function of $\mathrm{Mn}$ in the production of secondary metabolites ......................................12

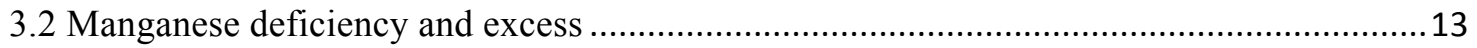

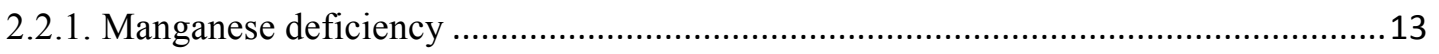

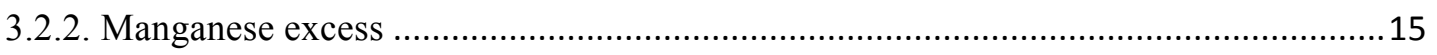

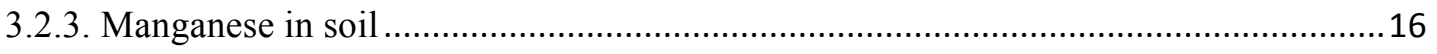

3.2.4. Manganese requirement for switchgrass.................................................................



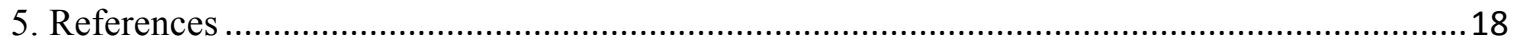

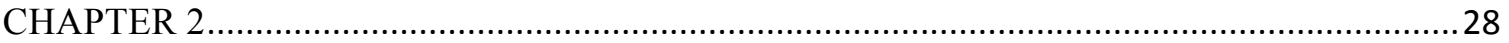

Influence of manganese availability on switchgrass and pearl millet biomass production............28

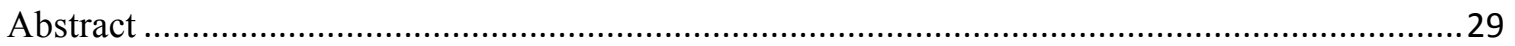

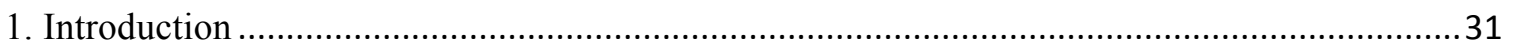

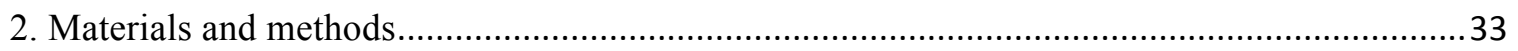

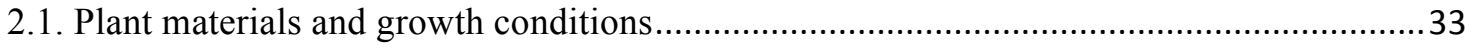

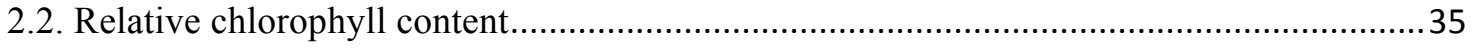




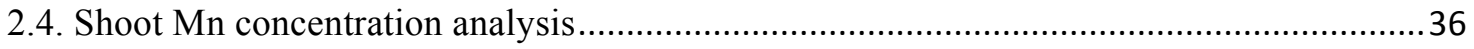

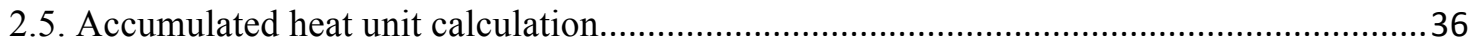

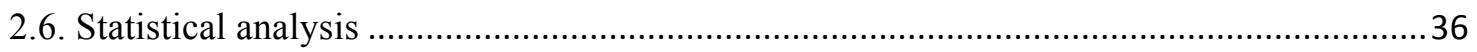

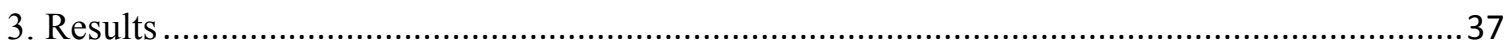

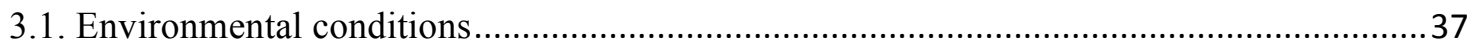

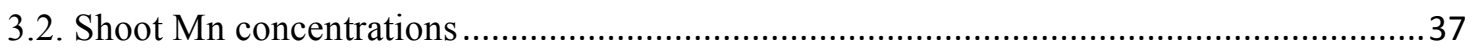

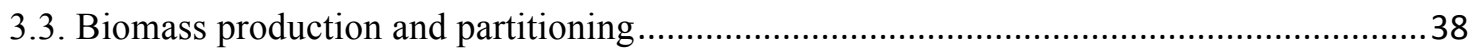

3.4 Tiller number, and plant height, and relative chlorophyll content ....................................40

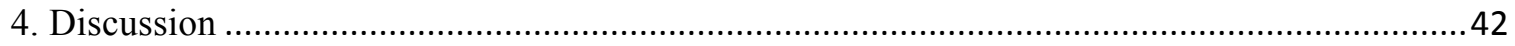

4.1. Limited response of switchgrass biomass production to Mn availability ..........................42

4.2. Shoot Mn concentration for optimum biomass production of switchgrass.........................45

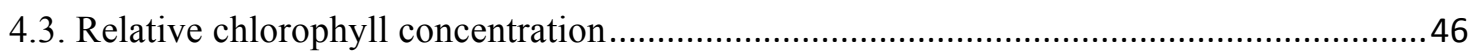

4.4. Switchgrass might have a different response mechanism than pearl millet to low $\mathrm{Mn}$

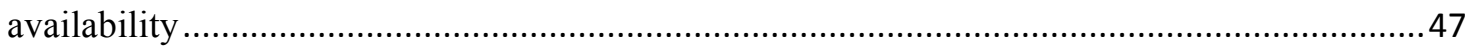

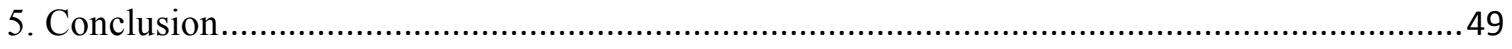

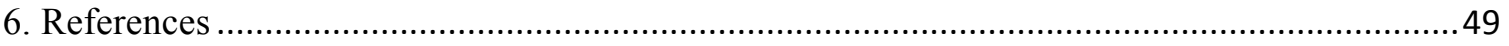

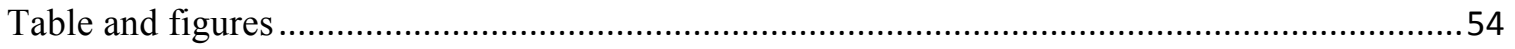



Influence of manganese availability on photosynthesis-related characteristics in switchgrass and

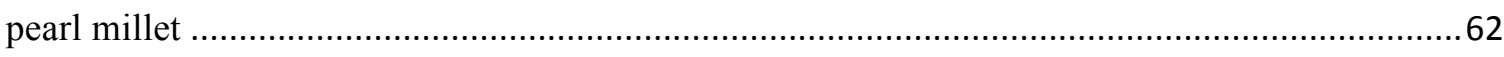

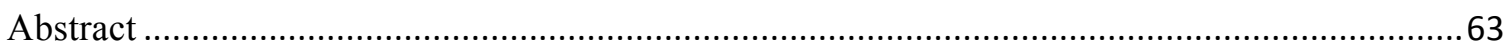

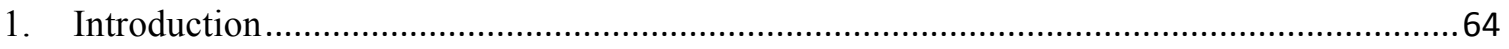

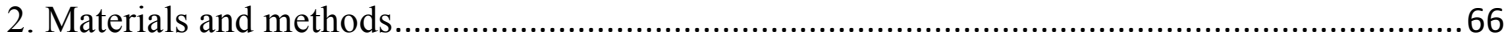

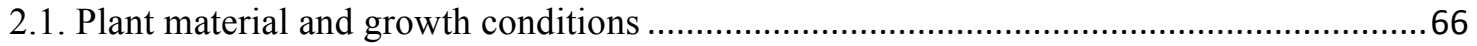

2.2. Chlorophyll fluorescence and gas exchange measurements ..........................................67

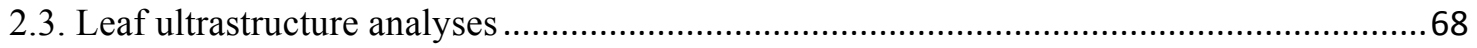

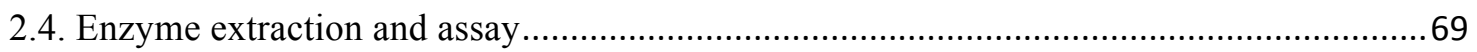

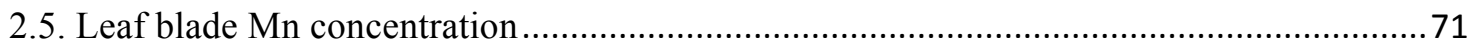

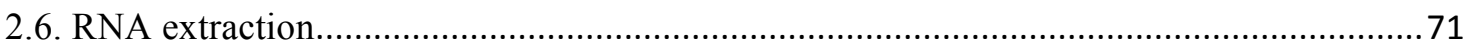

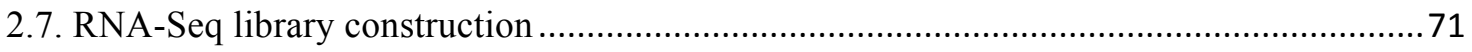

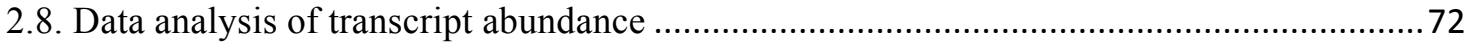

2.9. Real-time quantitative reverse transcription-PCR …..................................................... 73

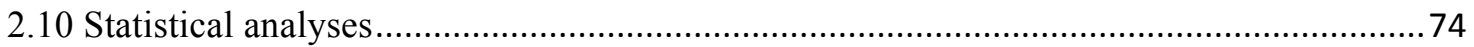




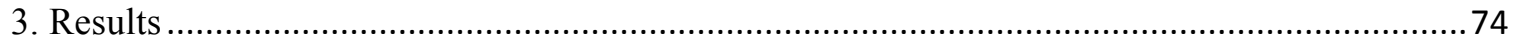

3.1. Photosynthetic rate and stomatal conductance ................................................................ 74

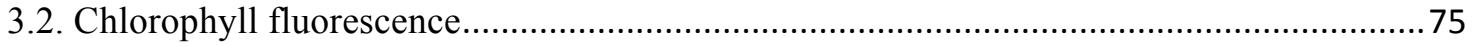

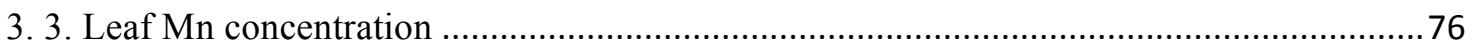

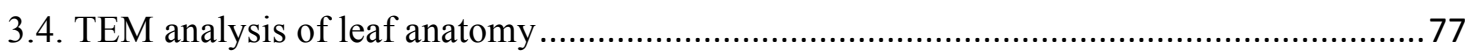

3.5. Validation of expression of selected genes by qPCR …................................................ 78

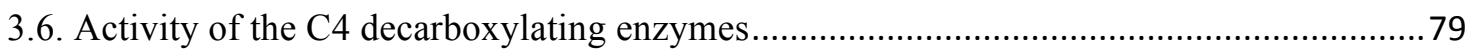

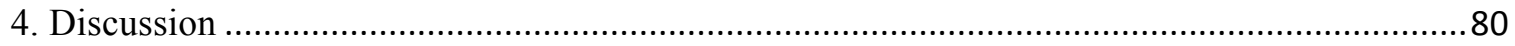

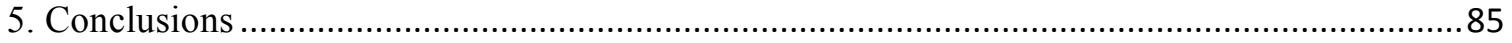

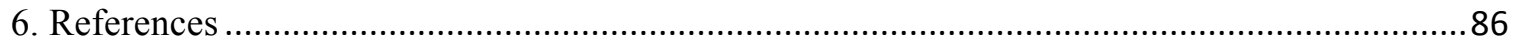

Figures

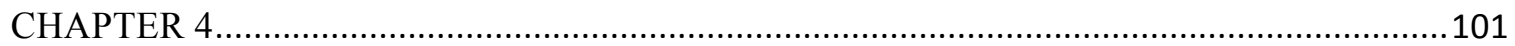

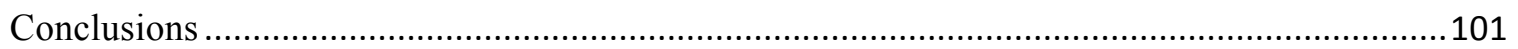

Appendix. Global transcript abundance analysis in switchgrass and pearl millet leaves ............104

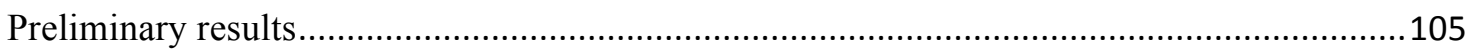

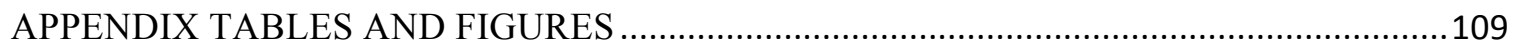

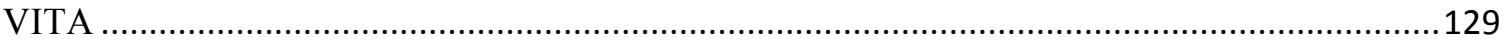




\section{LIST OF FIGURES}

Figure 2-1. Average weekly precipitation and average weekly temperatures for 2014, 2015, and 2016 at the Bradford Research Center.....

Figure 2-2. Shoot Mn concentrations of two switchgrass genotypes, Alamo and Cave-in-

Rock (CIR), and the pearl millet genotype KGraze. .56

Figure 2-3. Total biomass and biomass fractions of two switchgrass genotypes, Alamo and Cave-in-Rock (CIR), and the pearl millet genotype KGraze......

Figure 2-4. Root-shoot ratios of two switchgrass genotypes, Alamo and Cave-in-Rock (CIR), and the pearl millet genotype KGraze.

Figure 2-5. Number of tillers per plant for two switchgrass genotypes, Alamo and Cavein-Rock (CIR), and the pearl millet genotype KGraze.

Figure 2-6. Plant height for two switchgrass genotypes, Alamo and Cave-in-Rock (CIR), and the pearl millet genotype KGraze.

Figure 2-7. SPAD-502 chlorophyll meter reading of leaves for two switchgrass genotypes, Alamo and Cave-in-Rock (CIR), and the pearl millet genotype KGraze.....61

Figure 3-1. Leaf photosynthetic rate of two switchgrass genotypes, Alamo and Cave-inrock (CIR), and the pearl millet genotype KGraze.

Figure 3-2. Stomatal conductance of two switchgrass genotypes, Alamo and Cave-in-rock (CIR), and the pearl millet genotype KGraze.

Figure 3-3. Fv/Fm ratios of two switchgrass genotypes, Alamo and Cave-in-rock (CIR), and the pearl millet genotype KGraze.

Figure 3-4. Minimal chlorophyll fluorescence (Fo) of two switchgrass genotypes, Alamo and Cave-in-rock (CIR), and the pearl millet genotype KGraze.

Figure 3-5. Maximum chlorophyll fluorescence (Fm) of two switchgrass genotypes, Alamo and Cave-in-rock (CIR), and the pearl millet genotype KGraze.....

Figure 3-6. Leaf Mn concentrations of two switchgrass genotypes, Alamo and Cave-inrock (CIR), and the pearl millet genotype KGraze in 2016.

Figure 3-7. Transmission electron micrographs of chloroplasts with starch granules in leaves of two switchgrass genotypes Alamo, Cave-in-rock and the pearl millet genotype KGraze in 2016.

Figure 3-8. Anatomical changes of chloroplasts in mesophyll cells (MC) and bundle sheath cells (BSC) of two switchgrass genotypes, Alamo and Cave-in-rock (CIR), and the pearl millet genotype KGraze in 2016.

Figure 3-9. Gene expression levels of PSII, MDH, NADP-ME, NAD-ME, PEPCK and PEPC in two switchgrass genotypes leaves, Alamo and Cave-in-rock in 2016. 
Figure 3-10. Enzyme activity in leaves of two switchgrass genotypes, Alamo and Cavein-rock (CIR), and the pearl millet genotype KGraze in 2016 ................................... 100

Appendix. Figure 3-1. Classification of Raw Reads. ................................................... 120

Appendix. Figure 3-2. Percent of reads mapped to genome regions (EHMLeaf1).........121

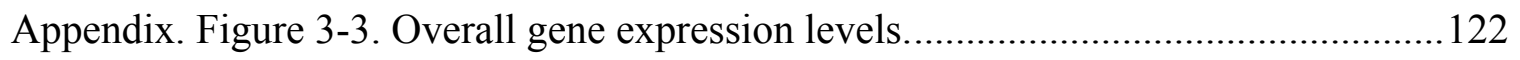

Appendix. Figure 3-4. Pearson correlation between samples. .......................................123

Appendix. Figure 3-5. Volcano plot of the overall distribution of different expression

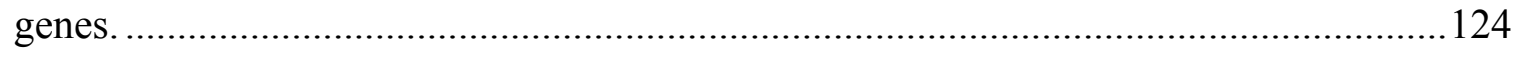

Appendix. Figure3-6. Venn diagram of differentially expressed genes........................125

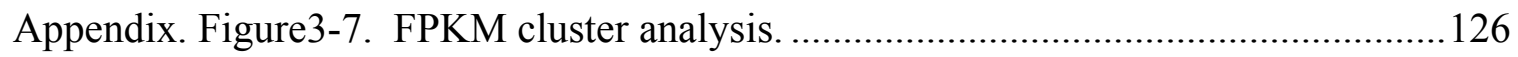

Appendix. Figure 3-8. Gene ontology analysis of gene expression differences. ............127

Appendix. Figure 3-9. KEGG enrichment scatter plot of DEGs, EL vs LL as an example to show the gene expression changes at different growth stages. 


\section{LIST OF TABLES}

Table 2-1. Chemical compositions of growth media used for experiments conducted in 2014, 2015, and 2016.

Appendix Table 2-1. Shoot Mn concentration of switchgrass (Alamo and Cave-in-rock) and pearl millet (KGraze) grown with nutrient solutions containing different Mn concentrations.

Appendix Table 2-2. Total biomass, shoot biomass, and root + rhizome biomass of two switchgrass cultivars grown with nutrient solutions containing different $\mathrm{Mn}$ concentrations.

Appendix Table 2-3. Total biomass, shoot biomass, and root (including rhizomes for switchgrass), of two switchgrass cultivars and the pearl millet KGraze grown with nutrient solutions containing different $\mathrm{Mn}$ concentrations in 2016.

Appendix Table 2-4. Root-shoot ratio of two two switchgrass cultivars and the pearl millet KGraze grown with nutrient solutions containing different Mn concentrations...112

Appendix Table 2-5. Tiller numbers of two switchgrass cultivars and the pearl millet KGraze grown with nutrient solutions containing different Mn concentrations.

Appendix Table 2-6. Plant height of two switchgrass cultivars and the pearl millet KGraze grown with nutrient solutions containing different Mn concentrations.

Appendix Table 2-7. SPAD-502 chlorophyll meter reading of two switchgrass cultivars grown with nutrient solutions containing different $\mathrm{Mn}$ concentrations.

Appendix Table 2-8. SPAD-502 chlorophyll meter reading of two switchgrass cultivars and the pearl millet KGraze grown with nutrient solutions containing different $\mathrm{Mn}$ concentrations in 2016 .

Appendix. Table 3-1. Primer sequences of selected genes for RT-PCR ..........................117

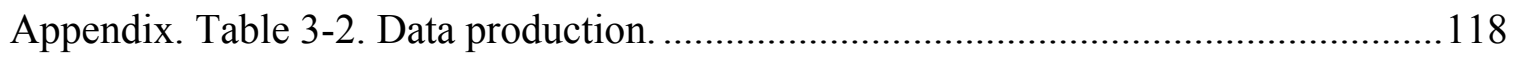

Appendix. Table 3-3. $M D H$ gene is involved in the top 4 most significant enrichment pathways 


\begin{abstract}
Manganese $(\mathrm{Mn})$ is an essential micronutrient and has a broad range of functions for all plant growth and reproduction. It plays a crucial role in NAD-ME C4 photosynthesis, including as a constituent of the water splitting protein of photosystem II (PSII) and as an activator of NAD-ME which catalyzes the release of $\mathrm{CO}_{2}$ from malate in bundle sheath cells (BSC). Switchgrass (Panicum virgatum L.), a perennial NAD-ME C4 grass, is native to much of the United States. Switchgrass is also considered as a promising biofuel species for sustainable production of bioenergy feedstock. As a NADME C4 species, switchgrass may have a high requirement for Mn for optimum growth. However, little is known about switchgrass responses to Mn availability at present. To study the influence of $\mathrm{Mn}$ on biomass production and photosynthetic characteristics, one lowland ('Alamo') and one upland ('Cave-in-Rock') switchgrass ecotype were grown in 19-L pots filled with either washed sand, vermiculite, or perlite, and fertilized with nutrient solutions with $\mathrm{Mn}$ concentrations ranging from 0 to $200 \mu \mathrm{M}$ under field conditions in three consecutive years. In the last year (perlite), pearl millet (Pennisetum glaucum L. R. Br.) ('KGraze') was also grown.
\end{abstract}

Shoot Mn concentration was highly responsive to increasing Mn in the nutrient solution in all experiments and for all entries. When grown in washed sand and vermiculite, no Mn treatment effects on biomass production were found for either switchgrass ecotype. In perlite, a significant decrease in biomass production grown in the $0 \mu \mathrm{M}$ Mn treatment compared to $10-25 \mu \mathrm{M}$ Mn treatments was only observed for Alamo and KGraze, and not for Cave-in-Rock. Late in the season, relative chlorophyll contents of both switchgrass ecotypes were significantly lower in the $0 \mu \mathrm{M}$ Mn treatment than 
other treatments, but, in KGraze, relative chlorophyll content was low early in the season, increased throughout the season, resulting in a less pronounced, but still significant $\mathrm{Mn}$ treatment effect, at late stages.

Leaf Mn concentration of all entries increased with increasing Mn concentration in the nutrient solution. In switchgrass, leaf Mn concentration was significantly greater early compared to late in the season in the absence of $\mathrm{Mn}$ in the nutrient solution; however, this was not the case for pearl millet. In switchgrass, the absence of Mn in the nutrient solution significantly decreased photosynthetic rates and maximum PSII efficiency $\left(\mathrm{F}_{\mathrm{v}} / \mathrm{F}_{\mathrm{m}}\right)$ late in the season. In contrast, in pearl millet the effect of $0 \mu \mathrm{M} \mathrm{Mn}$ in the nutrient solution on net photosynthesis and $\mathrm{F}_{\mathrm{v}} / \mathrm{F}_{\mathrm{m}}$ was more pronounced early in the season. Chloroplast ultrastructure in mesophyll and bundle sheath cells were only affected by Mn availability in the lowland switchgrass ecotype. Manganese availability did not influence NAD-ME, NADP-ME and PEPCK activities in switchgrass, but NADME and PEPCK activities were reduced in pearl millet early in the season in the absence of $\mathrm{Mn}$ in the nutrient solution. Based on these results, Mn limitation for the oxygen evolving compex of PSII rather than for NAD-ME was the primary limitation of low Mn availability on net photosynthesis. Overall, switchgrass and pearl millet exhibited distinct temporal responses to limited Mn availabillity. 


\section{CHAPTER 1}

Literature review 


\section{Switchgrass}

Switchgrass (Panicum virgatum L.), a perennial warm-season C4 grass, is native in most of North America Tallgrass Prairie (Weaver, 1968) except for areas west of the Rocky Mountains and north of $55^{\circ} \mathrm{N}$ latitude. Switchgrass tolerates diverse growing conditions and is highly productive from arid sites to brackish marshes and open woods (Hitchcock 1951).

Switchgrass has been classified into two distinct ecotypes: upland and lowland ecotypes (Moser and Vogel, 1995), based on plant morphology and adaptation. Upland ecotypes (e.g. 'Cave-in-rock') occur in upland areas that are dry and cool in the northern USA, whereas lowland ecotypes (e.g. 'Alamo') are mainly adapted to flood plains of the southern USA and other areas that receive run-off water (Porter, 1966). Generally, upland ecotypes are either octoploids or tetraploids, characterized by short and narrow stems and leaves. They usually are less productive than lowland ecotypes and are more susceptible to damage by pests and diseases (Sanderson et al., 1996). However, upland ecotypes can tolerate to drought and cold. Lowland ecotypes are usually tetraploid, and plants of this ecotype usually have a longer, wider leaves and large, thick stems. Additionally, they are tall with high biomass potential and a later heading date than upland ecotypes and tend to be more pest and disease tolerance (Sanderson et al., 1996).

In earlier agronomic studies, switchgrass was generally considered as one of several "native," "warm-season," or "range" grasses (Parrish and Fike, 2005; Cornelius, 1944). Not until the 1970s, was it more commonly studied and managed as a crop in monoculture (Parrish and Fike, 2005; Balasko and Smith, 1971; Berg, 1971). Early agronomic research mainly focused on aspects related to forage yield and forage value 
(Anderson, 2000). These studies suggested that switchgrass can be productive, protective of the environment, and profiTable for farmers in the Great Plains, Midwest, South, and Southeast. In the 1980s, switchgrass gained attention as a potential bioenergy feedstock, and more recently, renewed interest in bioenergy feedstock also provided new momentum for research on switchgrass as a source of biomass for energy. Several characteristics make switchgrass a promising biofuel crop: it is native and widely adapted in North America, it has relatively high yield potential compared to other species in varied growth conditions, its agricultural input requirements are low, and it is relatively easy to establish from seed (McLaughlin and Kzsos, 2005; Parrish and Fike, 2005; Sims et al., 2006; Sanderson et al., 2006; Parrish et al., 2008; Thomson et al., 2009). Overall, switchgrass is an adaptable and versatile plant as it can be used as forage, a bioenergy feedstock, for phytoremediation and conservation (Dunn et al., 1993).

\subsection{Switchgrass as a forage crop}

Early interest in switchgrass was focused on forage production, and much research focused on intake (Burns and Sollenberger, 2002), nutritive value, and toxicology of switchgrass. As a forage crop, switchgrass often is grazed (Anderson, 2000; Balasko et al., 1984; Jung et al., 1978; Moore et al., 2004; Parrish and Fike, 2005), but can also be used for making hay (Balasko et al., 1984; McLaughlin et al., 2004b; Sanderson et al., 2000) and silage (Burns et al., 1993). Switchgrass is recognized as a good forage for cattle, but it was shown to be toxic for horses, sheep, and goats because saponins in switchgrass can cause photosensitivity and liver damage in these animals (Lee et al., 2001; Johnson et al., 2006; Stegelmeier et al., 2007). In current forage research, switchgrass is not only managed as a pure-grass sward, but is also managed in silvopasture or agroforestry settings (Lin et al., 1999; Pitman, 2000) 


\subsection{Switchgrass as a biofuel crop}

Since petroleum, coal, and natural gas are non-renewable resources, new renewable sources of energy are needed. In both American and global scales, the utilization of energy crops as a source of renewable fuels may contribute to a more sustainable energy economy. In addition, production of crops for biofuel can represent a new source of income for American farmers and should benefit the agricultural economy. Renewable energy from biomass, including that from perennial grasses such as switchgrass, has the potential to reduce dependency on fossil fuels and the costs of imported oils in the US.

After screening more than 30 herbaceous plant species during 1980s (Wright 1994), switchgrass has received much attention as a biofuel feedstock (McLaughlin, 2004a; Greene et al., 2004; Sims et al., 2006; Fike et al., 2007; Parrish et al., 2008; Thomson et al., 2009). In early 1990s, the U.S. Department of Energy (DOE) chose switchgrass as a target crop for biomass energy, and switchgrass is considered a promising biofuel species for sustainable production of large amounts of bioenergy feedstock (McLaughlin and Kszos, 2005).

For energy production, switchgrass can be burned to generate power, but may also be fermented to ethanol, thus producing a liquid fuel. The quality of switchgrass for fuel is associated with the concentration of energy, primarily derived from the cell walls and particularly from lignin and cellulose. In addition, the contents of certain mineral elements (e.g. potassium, sodium, chlorine, silica) need to be considered because they can decrease conversion efficiency and increase maintenance costs by causing corrosion, slagging, and fouling of the boilers and other components of the power plant (Sanderson et al, 1996; McLaughlin et al., 2005). For co-firing, an ideal quality of switchgrass should 
contain a high concentration of lignin and cellulose, however, total ash, chloride, and other undesirable elements should be minimal (Lemus et al., 2002).

While much has been learned about switchgrass, primarily as a forage, but more recently also as a bioenergy crop, more research is needed. Primary needs include best management practices (e.g., establishment, fertilizer requirements, cutting frequency), genetics and breeding (particularly for biomass yield), physiological characteristics (utilization of nutrients, response to water and nutrient stress, etc.), and propagation techniques (Parrish and Fike, 2005).

\subsection{Switchgrass as a phytoremediation and conservation crop}

In addition to the above usages as forage and biofuel feedstock, switchgrass can be used for soil erosion control (Ichizen et al., 2001; Self-Davis et al., 2003), and has value in streamside buffers or vegetative filters (Dillaha et al., 1989) because of its extensive root system and the morphology of stiff stems. Recently, switchgrass has received attention as a phytoremediation crop, because of its potential for secreting BXcompounds (e.g. 2, 4-dihydroxy-1, 4-benzoxazin-3-one-glucoside (GIBOA-GIc)), which can enhance the degradation of atrazine (Willett et al., 2013).

\section{C4 photosynthesis in switchgrass}

Plants are able to convert solar energy to chemical energy by photosynthesis. Photosynthesis includes two main steps: the light reactions (photophosphorylation) and the carbon reduction reactions (Calvin cycle). Vascular plants can be classified into three groups based on their photosynthesis: C3 photosynthesis, C4 photosynthesis, and crassulacean acid metabolism (CAM) plants. In C3 plants, the first stable carbon 
compound resulting from photosynthesis is a $3-\mathrm{C}$ molecule whereas it is a 4-C molecule in $\mathrm{C} 4$ plants.

In CAM plants, stomata open during the night, allowing $\mathrm{CO}_{2}$ to enter and be converted to the bicarbonate ion $\left(\mathrm{HCO}_{3}^{-}\right)$by carbonic anhydrase (CA). Then the $\mathrm{HCO}_{3}^{-}$and phosphoenolpyruvate (PEP) are combined to produce oxaloacetate (OAA) through catalysis of PEP-carboxylase (PEPC). In the next step, OAA is reduced to malate by malate dehydrogenase (MDH) and the malate is moved to vacuoles for storage. During the day, the stored malate is released from vacuoles and decarboxylated to release $\mathrm{CO}_{2}$ for Calvin cycle reactions by nicotinamide-adenine dinucleotide phosphate malic enzyme (NADP-ME) in chloroplasts (Edwards and Walker, 1983).

In C4 plants, photosynthetic processes span two different cell types: mesophyll cells (MC) and bundle sheath cells (BSC). Bundle sheath cells are arranged as a single ring surrounding the vascular bundle followed by a concentric ring of specialized $\mathrm{MC}$, an arrangement termed Kranz anatomy (Laetsch, 1974)).

In $\mathrm{C} 4$ plants, $\mathrm{CO}_{2}$ fixation is a two-step process. The first step occurs in $\mathrm{MC}$ where PEPC reacts with $\mathrm{HCO}_{3}{ }^{-}$to produce OAA which is the first 4-C molecule in $\mathrm{C} 4$ photosynthesis (Edwards and Black, 1971). Oxaloacetate is converted to either malate by reduction or aspartate (Asp) by transamination, then malate or Asp diffuse into neighboring BSC through plasmodesmata. In BSC, decarboxylation of malate or Asp is catalyzed by one of three key decarboxylating enzymes, nicotinamide-adenine dinucleotide malic enzyme (NAD-ME), NADP-ME or PEP-carboxykinase (PEP-CK). The $\mathrm{CO}_{2}$ that is released is fixed by Rubisco in the $\mathrm{C} 3$ cycles (Calvin cycle) (Andrews, et al., 1973). 
Historically, based on the predominant decarboxylation enzymes present in the BSC, C4 plants were divided into three different metabolic subtypes: NAD-ME, NADPME, and PEP-CK type (Hatch, 1987; Edwards and Black, 1971; Hatch and Kagawa, 1974; Burnell, 1986). In BSC, the decarboxylation reactions catalyzed by NAD-ME take place in mitochondria, by NADP-ME in chloroplasts, and by PEP-CK in the cytosol. The differences among the three $\mathrm{C} 4$ photosynthetic pathways, including intercellular organic molecule movement and decarboxylating enzymes involved are summarized in Figure 11.

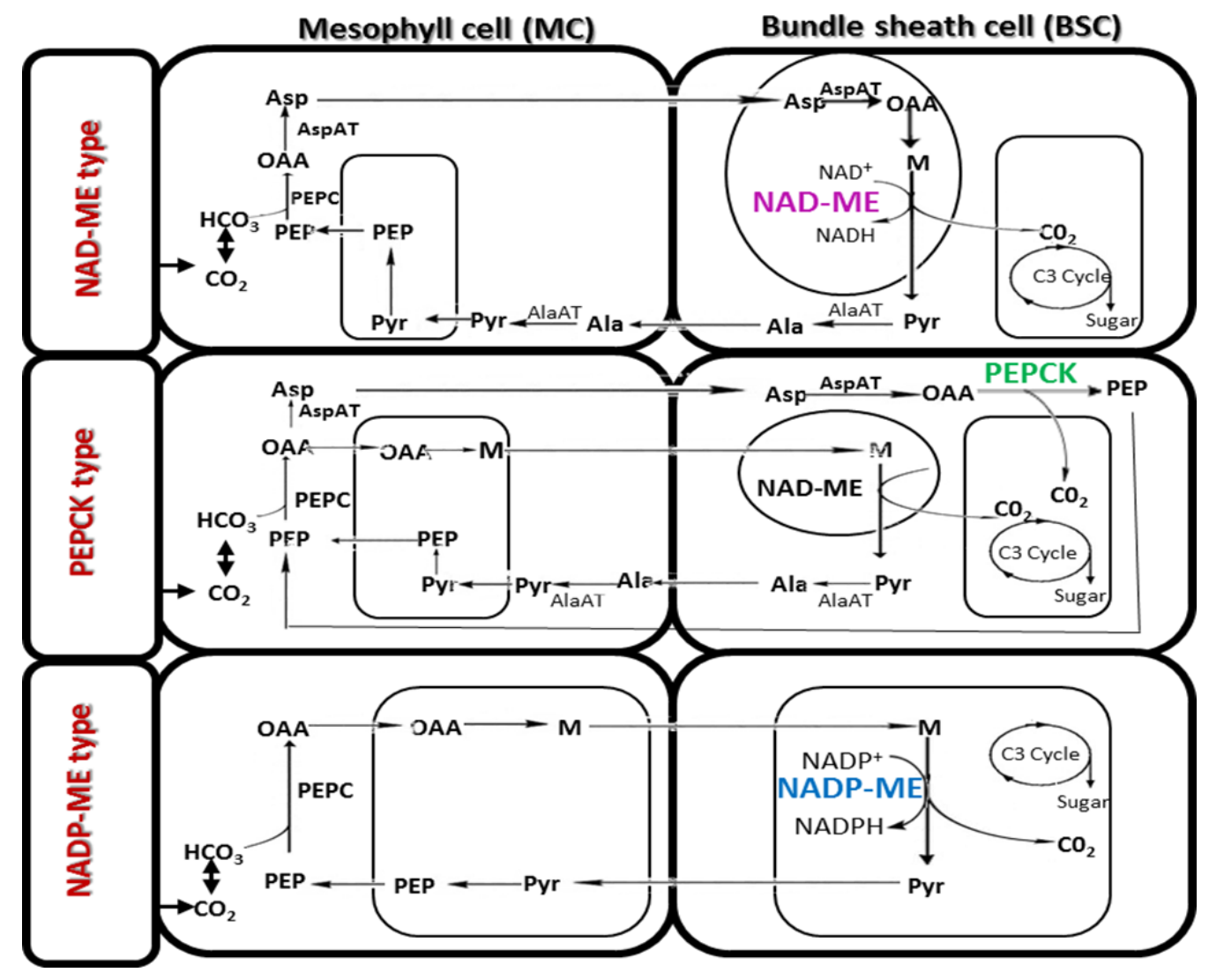

Figure 1-1. Movement of organic compounds between the mesophyll and bundle sheath cells and the specific compound decarboxylated to release $\mathrm{CO}_{2}$ for Calvin cycle reactions 
in C4 plants. OAA, oxaloacetate; M, Malate; Asp, Aspartate; PEP, phosphoenolpyruvate; Pyr, pyruvate; Ala, aspartate; PEPC, phosphoenolpyruvate carboxylase; AspAT, Aspartate aminotransferase; NAD-ME, NAD-malic acid; NADP-ME, NADP-malic acid; PEPCK, PEP carboxykinase. Re-drawn from Furbank (2011).

However, several studies have indicated that some flexibility in C4 photosynthetic pathways exists within a leaf (Furbank, 2011; Wang et al., 2014; Rao et al., 2016a; Rao et al., 2016b); specifically that NADP-ME and PEPCK types might coexist. Similarly, NAD-ME and PEPCK subtypes can also coexist. So far, no pure PEPCK-type C4 species has been discovered (Sage, 2004; Rao, et al 2016) because the robust model analysis of "pure PEPCK type" indicates the energy requirements in BSC and MC are unbalanced (Wang et al., 2014). Previous results demonstrated that the PEP-CK pathway is involved in BSC of maize leaves mainly performing NADP-ME type C4 pathway (Chapman and Hatch, 1981; Wingler et al., 1999; Pick et al., 2011). Furthermore, a similar phenomenon has also been found in Flaveria bidentis, an NADP-ME dicot species (Meister et al., 1996). PEP-CK enzyme activity has also been reported for other NADP-ME and NADME species (Walker et al., 1997; Wingler et al., 1999; Bräutigam et al., 2011; Pick et al., 2011; Sommer et al., 2012; Christin et al., 2013; Muhaidat and McKown, 2013).

Additionally, the flexibility between the three subtypes might be controlled by environmental and developmental conditions (Sommer et al., 2012; Wang et al., 2014; Sharwood et al., 2014). Sharwood et al. (2014), pointed out that flexible partitioning of C4 acid decarboxylation activity between NADP-ME and PEP-CK will take place in maize under salinity and shade conditions. Cleome gynandra, a dicot crop, is known to 
perform NAD-ME type C4 photosynthesis and a mixed NAD-ME and PEPCK type was observed in its older leaves (Sommer et al., 2012).

Interestingly, as a NAD-ME C4 plant, switchgrass was reported to uset the PEPCK pathway and the NAD-ME pathway in young leaves (Rao et al., 2016b). NADME, NADP-ME and PEPCK activities have been reported in leaves at different developmental stages of switchgrass. Moreover, recent data from three switchgrass cDNA libraries revealed six expressed sequence tags (EST) that closely matched PEPCK from more mature leaf tissue of maize and sorghum (Tobias et al., 2008). These results indicated that $\mathrm{C} 4$ photosynthetic flexibility may exist in switchgrass leaves at different stages, and it is possible that this flexibility might be induced by environmental or developmental aspects.

\section{Manganese}

\subsection{Manganese functions in plants}

Manganese, an essential nutrient element, is necessary for normal growth and development of plants. Unlike other essential trace elements such as $\mathrm{Cu}, \mathrm{Zn}, \mathrm{Fe}$ and $\mathrm{Mo}$ which often are integral components of enzymes, Mn usually acts as an activator of enzymes and can be replaced by other metals (e.g. Mg). To date, three main Mncontaining enzymes have been reported, including the Mn-containing superoxide dismutase (Mn-SOD), the photosynthetic Mn-containing oxygen evolving complex, and Mn-containing acid phosphatases (Burnell, 1988). As an activator, Mn is important for a wide variety of enzymes. These enzymes include those which catalyze oxidationreduction reactions, hydrolysis, group transfers, and decarboxylation (Burnell, 1988). Hence, $\mathrm{Mn}$ is important for many metabolic processes in plants, mainly in photosynthesis 
(Hatch and Kagawa, 1974; Burnell, 1986; Pfeffer et al., 1986; Goussias et al., 2002; Papadakis et al., 2007; Lavres et al., 2009; Millaleo et al., 2010; Tewari et al., 2013), as well as respiration, nitrogen assimilation, and production of secondary metabolites (Burnell, 1988).

\subsubsection{The role of $M n$ in photosynthesis}

In the photosynthetic process, Mn mainly plays an irreplaceable role as a constituent of the oxygen evolving protein complex of photosystem II (PSII), which catalyzes the water-splitting reaction to produce oxygen and provide electrons for the photosynthetic electron transport chain (Nickelsen and Rengstl, 2013). This role of Mn has been exploited to diagnose Mn efficiency and deficiency by chlorophyll a (Chl a) fluorescence in winter barley (Hebbern et al., 2005; Husted et al., 2009; Schmidt et al., 2013). Under Mn deficiency, the $F_{v} / F_{m}$ ratio, a Chl a fluorescence associated parameter, can be significantly decreased (Schmidt et al., 2013). Therefore, the $F_{v} / F_{m}$ ratio can be used as a relatively simple and non-destructive tool to diagnose Mn deficiency in winter barley (Hebbern et al., 2005; Husted and et al., 2009; Leplat, 2015). In addition, since manganese can activate specific enzymes that catalyze chlorophyll biosynthesis, it is also essential for the biosynthesis of chlorophyll.

In the $\mathrm{C} 4$ photosynthetic process, Mn also can activate several photosynthetic enzymes. Mitochondrial NAD-ME is specifically dependent on $\mathrm{Mn}^{2+}$ for activity (Hatch and Kagawa, 1974; Burnell, 1986). NADP-ME is able to use either $\mathrm{Mn}^{2+}$ or $\mathrm{Mg}^{2+}$, however, it has a higher affinity for $\mathrm{Mn}^{2+}$ and a higher activity with $\mathrm{Mg}^{2+}$ at their optimum concentrations (Johson and Hatch, 1970). PEP-CK is activated not only by $\mathrm{Mn}^{2+}$ (Burnell, 1986), but also by $\mathrm{Mg}^{2+}$ (Chen, et al., 2002). In addition, PEPC, a primary 
carboxylating enzyme in $\mathrm{C} 4$ plants, is dependent on divalent metal cations, such as $\mathrm{Mg}^{2+}$ or $\mathrm{Mn}^{2+}$, for activity. Under saturating conditions, maize PEPC enzyme has the same activity with $\mathrm{Mg}^{2+}$ as with $\mathrm{Mn}^{2+}$ (O'Leary et al, 1981). However, DL-2-phosphomalate, an analog of the PEPC-product complex, has a stronger inhibition on PEPC activity when $\mathrm{Mn}^{2+}$ is present than in the presence of $\mathrm{Mg}^{2+}\left(\mathrm{O}^{\prime}\right.$ Leary, 1982). In addition, it has been reported that $\mathrm{Mn}^{2+}$ can replace $\mathrm{Mg}^{2+}$ to alter the oxygenase activity of RUBPcarboxylase/oxygenase (Wildner and Henkel, 1978; Christeller and Laing, 1979). Thus, in many cases, $\mathrm{Mn}^{2+}$ ions can be replaced by $\mathrm{Mg}^{2+}$ ions or vice versa (Burnell, 1988).

Since Mn is required for NAD-ME activity, NAD-ME C4 plants have an absolute requirement for Mn (Hatch and Kagawa, 1974; Burnell, 1986). Therefore, while Mn deficiency may significantly affect leaf photosynthetic activity, dry matter accumulation, forage and grain yield of all plants, NAD-ME C-4 plants may be especially affected. For annual plants, previous research indicated that the Mn requirement of NAD-ME C4 plants was significantly higher than that of NADP-ME C4 plants and C3 plants. Furthermore, photosynthetic rate responses of NAD-ME C4 plants to Mn availability were similar to their biomass responses (Kering et al., 2009).

\subsubsection{Role of Mn in plant respiration and nitrogen assimilation}

Manganese plays an important role as major cofactor of enzymes in the tricarboxylic acid cycle (TCA) (Burnell, 1988). For example, Mn can serve as activator of NAD isocitrate dehydrogenase (EC1.1.1.41) which catalyzes the reaction in which isocitrate loses a molecule of carbon dioxide and then undergoes oxidation to form alphaketoglutarate. However, in this case, $\mathrm{Mn}^{2+}$ can be replaced by $\mathrm{Mg}^{2+}$ (Coultate and Dennis, 1969). In addition, Mn also participates in ATP synthesis (Pfeffer et al., 1986), and the 
biosynthesis of proteins, acyl lipids and fatty acids (Constantopoulos, 1970; Ness and Woolhouse, 1980). These compounds can be used to start and to participate in the respiration process.

Manganese is indirectly involved in the nitrate and nitrite reduction steps through its influence on photosynthetic electron transport (Burnell, 1988; Ducic and Polle, 2005). In addition, glutamine synthetase (EC 6.3.1.2) is a key enzyme that catalyzes ATPdependent assimilation of ammonia, and $\mathrm{Mn}$ is essential for activing glutamine synthetase (EC 6.3.1.2) as a cofactor, instead of $\mathrm{Mg}^{2+}$ (O'neal and Joy., 1974; Burnell., 1988). In addition, $\mathrm{Mn}^{2+}$ indirectly influences symbiotic $\mathrm{N}$ fixation because $\mathrm{Mn}$ can limit root nodule formation by affecting indole acetic acid (IAA) level by its effect on IAA oxidase activity (Burnell, 1988).

\subsubsection{Function of $M n$ in the production of secondary metabolites}

The shikimic acid pathway is a link between carbohydrate metabolism and secondary metabolism (Jenson, 1986). This pathway leads to the biosynthesis of aromatic amino acids (e.g. tyrosine), and various secondary products, such as lignin and flavonoids (Burnell, 1988; Wilkinson and Ohki, 1988; Lidon et al., 2004). Manganese plays a primary role in the activation of several enzymes of the shikimic acid pathway. The first committed step of the shikimic acid pathway involves the synthesis of deoxy-Darabinoheptulosonate-7-phosphate (DAHP). The synthesis of DAHP requires two markedly distinct DAHP-synthases, DAHP-synthase-Mn (DS-Mn) and DAHP-synthaseCo (DS-Co) (Ganson, et al., 1986; Ganson and Jensen., 1987). The activity of DS-Mn can be stimulated by, but does not require $\mathrm{Mn}^{2+}$, and DS-Co requires $\mathrm{Co}^{2+}, \mathrm{Mg}^{2+}$ or $\mathrm{Mn}^{2+}$ for activity. 
Phenylalanine ammonialyase (PAL) is an important enzyme in the metabolism of phenolics in plants and its activity can be induced by low concentration of $\mathrm{Mn}^{2+}$ (Engelsma, 1972). The final step of synthesis of lignin requires $\mathrm{H}_{2} \mathrm{O}_{2}$ (Stafford, 1974) and the formation of $\mathrm{H}_{2} \mathrm{O}_{2}$ is stimulated by monophenols and $\mathrm{Mn}^{2+}$ (Gross, et al., 1977). Manganese, as a cofactor of IAA oxidase, also participated in hormone activation (IAA) (Burnell, 1988; Millaleo, et al., 2010). In addition, the biosynthetic pathway of isoprenoids also requires $\mathrm{Mn}^{2+}$ (Lidon et al., 2004).

\subsection{Manganese deficiency and excess}

Manganese is an essential micronutrient in most organisms. As described above, in plants, it participates in the structure of proteins and activator of enzymes. Its deficit and excess are dangerous for metabolic process of plants (Mukhopadhyay and Sharma, 1991; Buchanan et al., 2015). Thus, there are two main roles of in the plant biochemical processes: as an essential micronutrient and as a toxic element (Kochian et al., 2004; Ducic and Polle, 2005).

\subsubsection{Manganese deficiency}

Manganese deficiency has a great effect on plant photosynthesis, because it affects the water-splitting system of photosystem II (PSII), which provides the necessary electrons for photosynthesis (Nickelsen and Rengstl, 2013). Manganese deficiency can significantly decrease the concentration of total chlorophyll, as well as chlorophyll a and chlorophyll b (Tewari et al., 2013). Manganese deficiency also influences leaf anatomy and chloroplast ultrastructure. Manganese deficiency not only can result in disorganization of leaf mesophyll cells, mainly of palisade parenchyma cells, but it can also decrease the number of mesophyll chloroplasts per cellular area and their length in 
plant leaves (Papadakis et al., 2007; Lavres et al., 2009). Moreover, manganese deficiency can increase the percentages of starch grains and plastoglobuli per chloroplast in orange leaves (Papadakis et al., 2007). Generally, the critical deficiency level of Mn for most plant species is in the range of 10-20 $\mathrm{mg} \mathrm{Mn} \mathrm{kg}^{-1}$ dry matter of mature leaves (Broadley et al., 2012), $25 \mathrm{mg} \mathrm{Mn} \mathrm{kg}{ }^{-1}$ for warm-season turfgrass based on plant tissue analysis, and $40 \mathrm{mg} \mathrm{Mn} \mathrm{kg}^{-1}$ dry matter for bahiagrass (Pessarakli, 2007; NRC, 2000)

Even though there are numerous studies focusing on the effect of Mn deficiency on plant growth, to date, Mn deficiency still remains an unsolved nutritional problem affecting crop production worldwide (Reuter et al., 1988; Hebbern et al., 2005; Yang et al., 2007), and Mn deficiency can limit plant growth in many states in the USA (Berger, 1962)(Fig.1-2) 


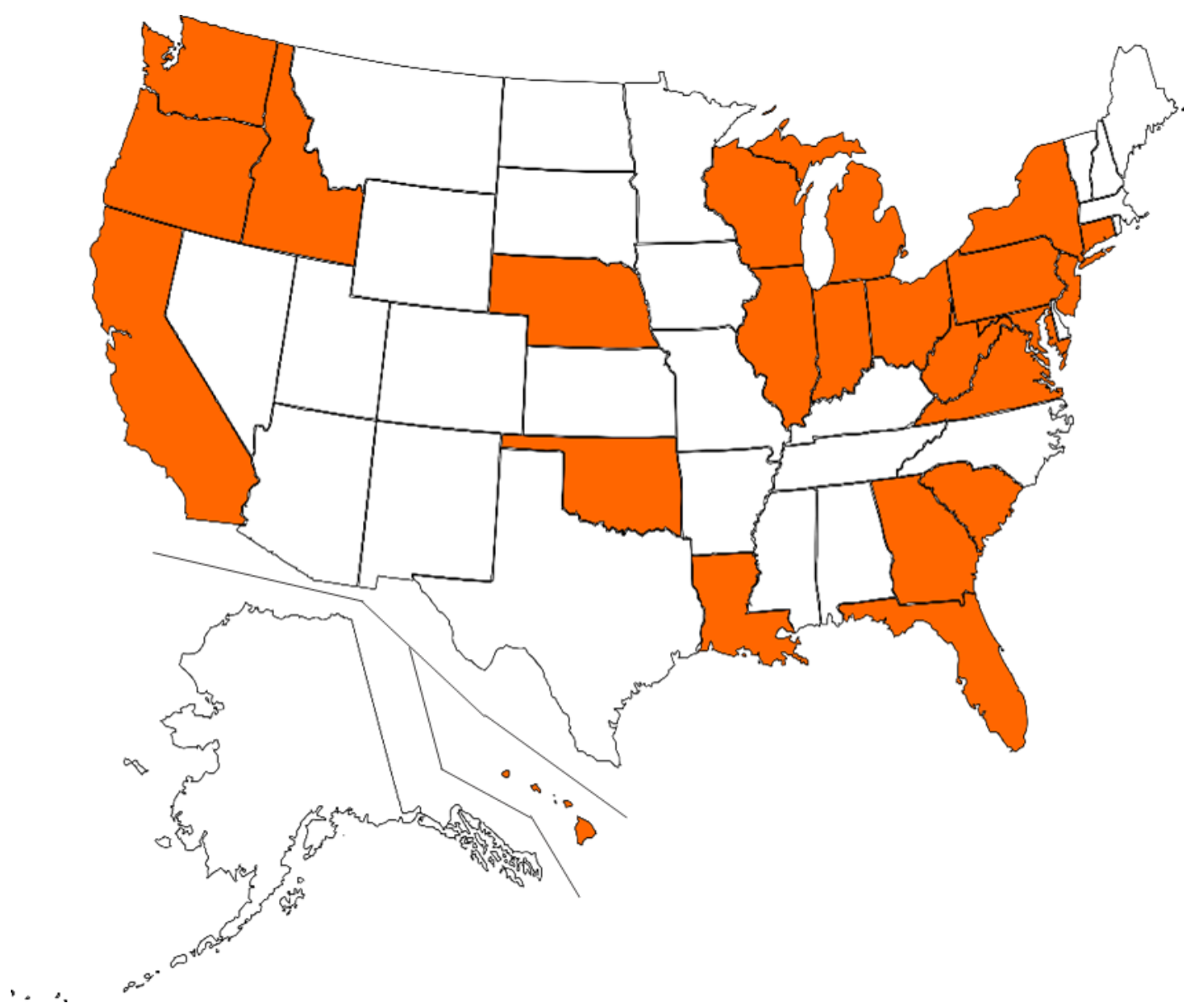

Figure 1-2. Manganese deficiency in USA. Redrawn from Berger, K. C. (1962). Orange color indicated the states that has been reported Mn deficiency.

\subsubsection{Manganese excess}

The level of normal or adequate Mn concentrations of leaves differs between species and ranges widely, from 30-500 mg Mn kg- dry matter (Clarkson, 1988). Manganese toxicity can be an important factor limiting plant growth, particularly in soil with low $\mathrm{pH}$ (acidic soil). Critical levels with respect to toxicity have been reported to range from 200 to $5300 \mathrm{mg} \mathrm{Mn} \mathrm{kg}{ }^{-1} \mathrm{Mn}$ dry matter (Edwards and Asher, 1982). Most studies have focussed on the damage of excess Mn on photosynthesis. For example, Mn toxicity can decrease photosynthetic capacity by inhibiting the activity of OEC of PSII 
(Amao and Ohashi, 2008), by interfering with thylakoid stacking (Lidon and Teixeira, 2000), and by inhibiting chlorophyll synthesis (Clairmont et al., 1986; Tewari et al., 2013). Inhibition of chlorophyll synthesis is probably mediated by influencing the Ferequiring step following the insertion of $\mathrm{Mg}$ into the tetrapyrrole ring (Chereskin and Castelfranco, 1982; Clairmont et al., 1986). In addition, excess Mn also caused oxidative stress and altered absorption, translocation and utilization of other mineral elements $(\mathrm{Ca}$, Mg, Fe and P) (Ducic and Polle, 2005; Lei et al., 2007).

\subsubsection{Manganese in soil}

In soil, $\mathrm{Mn}$ is mainly present in divalent $\left(\mathrm{Mn}^{2+}\right)$, trivalent $\left(\mathrm{Mn}^{3+}\right)$ and tetravalent

$\left(\mathrm{Mn}^{4+}\right)$ forms, $\mathrm{Mn}^{2+}$ being the primary form absorbed by plants. After $\mathrm{Mn}^{2+}$ is released into soil solution, it becomes available to the plants. $\mathrm{Mn}^{2+}$ reaches the root surface through transport by mass flow and diffusion and is taken up by the roots.

Soil conditions impact Mn availability to plants (Millaleo et al., 2010). For example, the $\mathrm{pH}$ is an important factor influencing Mn bioactivity in soil. A higher $\mathrm{pH}$ (up to 8.0) dramatically decreases Mn availability and can lead to Mn deficiency in plants. In contrast, a lower $\mathrm{pH}$ (below 5.5) increases Mn availability and may lead to $\mathrm{Mn}$ toxicity in plants (Marschner, 1995; Gherardi and Rengel, 2004; Porter et al., 2004; Ducic and Polle, 2005; Humphries et al., 2007). In order to reduce Mn toxicity to plants, lime can be used to increase soil $\mathrm{pH}$ and thus decrease soluble Mn (Hue and Mai, 2002), but in slightly acidic soils, liming may result in Mn deficiency. For example, applying lime on a fragipan soil in southwest Missouri and on a claypan soil in central Missouri dramatically decreased leaf $\mathrm{Mn}$ concentrations in tall fescue (Hamilton, 2006). 
Additionally, soil moisture and temperature, organic matter and other nutrients and heavy metals also influence Mn availability in soil (Laha and Luthy, 1990).

Fertilizer management and other crop management practices also influence $\mathrm{Mn}$ availability for plant uptake. For example, phosphorus (P) application increased $\mathrm{Mn}$ uptake in wheat plants (Johnson and Jackson, 1964) and tall fescue (McClain, 2007). On the other hand, plant availability of Mn may be improved by application of ammoniacal $\mathrm{N}$ fertilizer and sulfur (S) to high $\mathrm{pH}$ soils by lowering the $\mathrm{pH}$ (Norvell, 1988). Glyphosate [N- (phosphonomethyl) glycine], commonly known as Roundup ${ }^{\circledR}$, is a wide spectrum herbicide that kills most plants, and is commonly used to control weeds in genetically modified Roundup Ready ${ }^{\circledR}$ plants. Some cations including Mn may be chelated when Roundup ${ }^{\circledR}$ is applied to Roundup Ready ${ }^{\circledR}$ crops (Bailey et al., 2002, Bernards et al., 2005). Roundup ${ }^{\circledR}$ can reduce $\mathrm{Fe}$ and Mn uptake in plants by producing poorly soluble glyphosate-metal complexes in plant tissues (Eker et al., 2006). Mobility of Mn within the plants can be impaired by glyphosate-cation complexes and result in chlorosis. Therefore, Roundup Ready ${ }^{\circledR}$ corn and soybean cultivars may require higher Mn fertilization than non-Roundup Ready ${ }^{\circledR}$ cultivars. In addition, environmental conditions may also affect Mn availability in soil. For example, hot, dry summers and warm waterlogged conditions can increase soluble and exchangeable Mn in soil (Sparrow and Uren, 1987; Conyers et al., 1997).

\subsubsection{Manganese requirement for switchgrass}

All plants require Mn for growth, but since NAD-ME is thought to have an absolute requirement for Mn, NAD-ME type C4 plants may require more Mn for growth and reproduction than non-NAD-ME plants. Thus, as an NAD-ME C4 plant, switchgrass 
photosynthesis and growth may be responsive to higher Mn availability. However, only limited information is available on the Mn requirements of switchgrass. To date, $\mathrm{Mn}$ requirements for optimum photosynthesis and growth in switchgrass remain underexplored, and it is unknown whether switchgrass responds to Mn deficiency by shifting decarboxylation enzyme activity. In addition, the effect of manganese on leaf anatomy and chloroplast ultrastructure have not been investigated.

\section{Dissertation Goals and Objectives}

The goal of this research was to develop a better understanding of switchgrass responses to Mn availability. In particular, the objectives were to:

1) Quantify the effect of Mn availability on switchgrass growth and photosynthesis.

2) Identify physiological, biochemical, and anatomical impacts of Mn deficiency on switchgrass.

\section{References}

Amao, Y., and Ohashi, A. 2008. Effect of Mn ion on the visible light induced water oxidation activity of photosynthetic organ grana from spinach. Catalysis Communications, 10(2), 217-220.

Anderson, B.E. 2000. Use of warm-season grasses by grazing livestock. In: Native Warm-season Grasses Research Trends and Issues, 147-157.

Andrews, T. J., Lorimer, G., and Tolbert, N. E. 1973. Ribulose diphosphate oxygenase. I. Synthesis of phosphoglycolate by fraction-1 protein of leaves. Biochemistry, 12(1), 11-18.

Bailey, W. A., Poston, D. H., Wilson, H. P., and Hines, T. E. 2002. Glyphosate interactions with manganese 1. Weed Technology, 16(4), 792-799. 
Balasko, J. A., Burner, D. M., and Thayne, W. V. 1984. Yield and quality of switchgrass grown without soil amendments. Agronomy Journal, 76(2), 204-208.

Balasko, J. A., and Smith, D. 1971. Influence of temperature and nitrogen fertilization on the growth and composition of switchgrass (Panicum virgatum L.) and timothy (Phleum pratense L.) at anthesis. Agronomy Journal, 63(6), 853-857.

Berg, C. C. 1971. Forage yield of switchgrass (Panicum virgatum) in Pennsylvania. Agronomy Journal, 63(5), 785-786.

Berger, K. C. 1962. Micronutrient shortages, micronutrient deficiencies in the United States. Journal of Agricultural and Food Chemistry, 10(3), 178-181.

Bernards, M. L., Thelen, K. D., andPenner, D. 2005. Glyphosate efficacy is antagonized by manganese 1 . Weed Technology, 19(1), 27-34.

Bräutigam, A., Kajala, K., Wullenweber, J., Sommer, M., Gagneul, D., Weber, K. L., and Westhoff, P. 2011. An mRNA blueprint for C4 photosynthesis derived from comparative transcriptomics of closely related $\mathrm{C} 3$ and $\mathrm{C} 4$ species. Plant Physiology, 155(1), 142-156.

Broadley, M., Brown, P., Cakmak, I., Ma, J. F., Rengel, Z., and Zhao, F. 2012. Beneficial elements. In Marschner's mineral nutrition of higher plants (pp. 191-248). Academic Press.

Buchanan, B. B., Gruissem, W., and Jones, R. L. (Eds.). 2015. Biochemistry and molecular biology of plants. John Wiley and Sons.

Burns, J. C., Fisher, D. S., and Pond, K. R. 1993. Ensiling characteristics and utilization of switchgrass preserved as silage. Postharvest Biology and Technology, 3(4), 349-359.

Burns, J. C., and Sollenberger, L. E. 2002. Grazing behavior of ruminants and daily performance from warm-season grasses. Crop Science, 42(3), 873-881.

Burnell, J. N. 1988. The biochemistry of manganese in plants. In Manganese in soils and plants (pp. 125-137). Springer Netherlands.

Burnell, J. N. 1986. Purification and properties of phosphoenolpyruvate carboxykinase from C4 plants. Functional Plant Biology, 13(5), 577-587.

Clairmont, K. B., Hagar, W. G., and Davis, E. A. 1986. Manganese toxicity to chlorophyll synthesis in tobacco callus. Plant Physiology, 80(1), 291-293.

Clarkson, D. T. 1988. The uptake and translocation of manganese by plant roots. In Manganese in soils and plants (pp. 101-111). Springer Netherlands.

Chapman, K. S. R., and Hatch, M. D. 1981. Aspartate decarboxylation in bundle sheath cells of Zea mays and its possible contribution to $\mathrm{C} 3$ photosynthesis. Functional Plant Biology, 8(2), 237-248. 
Chen, Z. H., Walker, R. P., Acheson, R. M., and Leegood, R. C. 2002. Phosphoenolpyruvate carboxykinase assayed at physiological concentrations of metal ions has a high affinity for CO2. Plant Physiology, 128(1), 160-164.

Chereskin, B. M., and Castelfranco, P. A. 1982. Effects of iron and oxygen on chlorophyll biosynthesis. Plant Physiology, 69(1), 112-116.

Christeller, J. T., and Laing, W. A. 1979. Effects of manganese ions and magnesium ions on the activity of soya-bean ribulose bisphosphate carboxylase/oxygenase. Biochemical Journal, 183(3), 747-750.

Christin, P. A., Osborne, C. P., Chatelet, D. S., Columbus, J. T., Besnard, G., Hodkinson, T. R., and Edwards, E. J. 2013. Anatomical enablers and the evolution of C4 photosynthesis in grasses. Proceedings of the National Academy of Sciences, 110(4), 1381-1386.

Constantopoulos, G. 1970. Lipid metabolism of manganese-deficient algae: I. Effect of manganese deficiency on the greening and the lipid composition of Euglena gracilis Z. Plant physiology, 45(1), 76-80

Conyers, M. K., Uren, N. C., Helyar, K. R., Poile, G. J., and Cullis, B. R. 1997. Temporal variation in soil acidity. Australian Journal of Soil Research, 35(5), 1115-1129.

Cornelius, D.R. 1944. Revegetation in the tall grass prairie region. Journal of the American Society of Agronomy 36:393-400

Coultate, T. P., and Dennis, D. T. 1969. Regulatory properties of a plant NAD: isocitrate dehydrogenase. The FEBS Journal, 7(2), 153-158.

Dillaha, T. A., Reneau, R. B., Mostaghimi, S., and Lee, D. 1989. Vegetative filter strips for agricultural nonpoint source pollution control. Trans. Amer. Soc. Agric. Eng. 32: 513-519.

Ducic, T., and Polle, A. 2005. Transport and detoxification of manganese and copper in plants. Brazilian Journal of Plant Physiology, 17(1), 103-112.

Dunn, C. P., Stearns, F., Guntenspergen, G. R., and Sharpe, D. M. 1993. Ecological benefits of the conservation reserve program. Conservation Biology, 7(1), 132139

Edwards, G., and Walker, D. 1983. C3, C4: mechanisms, and cellular and environmental regulation, of photosynthesis. Univ of California Press. 462

Edwards, D. G., and Asher, C. J. 1982. Tolerance of crop and pasture species to manganese toxicity. In Plant nutrition 1982: proceedings of the ninth International Plant Nutrition Colloquium, Warwick University, England, August 22-27, 1982/edited by A. Scaife. Slough, UK: Commonwealth Agricultural Bureaux, c1982.

Edwards, G. E., and Black, C. C. 1971. Isolation of mesophyll cells and bundle sheath cells from Digitaria sanguinalis (L.) Scop. leaves and a scanning microscopy study of the internal leaf cell morphology. Plant Physiology, 47(1), 149-156. 
Eker, S., Ozturk, L., Yazici, A., Erenoglu, B., Romheld, V., and Cakmak, I. 2006. Foliarapplied glyphosate substantially reduced uptake and transport of iron and manganese in sunflower (Helianthus annuus L.) plants. Journal of Agricultural and Food Chemistry, 54(26), 10019-10025.

Engelsma, G. 1972. A possible role of divalent manganese ions in the photoinduction of phenylalanine ammonia-lyase. Plant physiology, 50(5), 599-602.

Fike, J. H., Parrish, D. J., Alwang, J., and Cundiff, J. S. 2007. Challenges for deploying dedicated, large-scale, bioenergy systems in the USA. CAB Reviews, 2(064), 128.

Furbank, R. T. 2011. Evolution of the C4 photosynthetic mechanism: are there really three C4 acid decarboxylation types? Journal of Experimental Botany, 62: 31033108 .

Ganson, R. J., d'Amato, T. A., and Jensen, R. A. 1986. The two-isozyme system of 3deoxy-D-arabino-heptulosonate 7-phosphate synthase in Nicotiana silvestris and other higher plants. Plant physiology, 82(1), 203-210.

Ganson, R. J., and Jensen, R. A. 1987. Response of cytosolic-isozyme and plastidisozyme levels of 3-deoxy-D-arabino-heptulosonate 7-phosphate synthase to physiological state of Nicotiana silvestris in suspension culture. Plant physiology, 83(3), 479-482.

Gherardi, M. J., and Rengel, Z. 2004. The effect of manganese supply on exudation of carboxylates by roots of lucerne (Medicago sativa). Plant and Soil, 260(1-2), 271282.

Goussias, C., Boussac, A., and Rutherford, A. W. 2002. Photosystem II and photosynthetic oxidation of water: an overview. Philosophical Transactions of the Royal Society of London B: Biological Sciences, 357(1426), 1369-1381.

Greene, J. D., Nystrom, L. E., Engell, A. D., Darley, J. M., and Cohen, J. D. 2004. The neural bases of cognitive conflict and control in moral judgment. Neuron, 44(2), $389-400$.

Gross, G. G., Janse, C., and Elstner, E. F. 1977. Involvement of malate, monophenols, and the superoxide radical in hydrogen peroxide formation by isolated cell walls from horseradish (Armoracia lapathifolia Gilib.). Planta, 136(3), 271-276.

Hamilton, E. J. 2006. Elemental concentration changes in soil and stockpiled tall fescue leaves after liming (Doctoral dissertation, University of Missouri--Columbia).

Hatch, M. D., and Kagawa, T. 1974. Activity, location and role of NAD malic enzyme in leaves with C4-pathway photosynthesis. Functional Plant Biology, 1(3), 357-369.

Hatch, M. D. 1987. C4 photosynthesis: a unique blend of modified biochemistry, anatomy and ultrastructure. Biochimica et Biophysica Acta (BBA)-Reviews on Bioenergetics, 895(2), 81-106. 
Hebbern, C. A., Pedas, P., Schjoerring, J. K., Knudsen, L., and Husted, S. 2005. Genotypic differences in manganese efficiency: field experiments with winter barley (Hordeum vulgare L.). Plant and Soil, 272(1-2), 233-244.

Hitchcock, A.S. 1951. Manual of the grasses of the United States, $2^{\text {nd }}$ edition. A.S. Chase (rev). USDA Misc. Pub. 200:1051. U.S. Gov. Print. Officce, Washington, DC.

Hue, N. V., and Mai, Y. 2002. Manganese toxicity in watermelon as affected by lime and compost amended to a Hawaiian acid Oxisol. HortScience, 37(4), 656-661.

Humphries, J., Stangoulis, J., and Graham, R. 2007 Manganese. In: A. Barker, D. Pilbeam(eds). Handbook of Plant Nutrition, Taylor and Francis, USA, pp. 351366.

Husted, S., Laursen, K. H., Hebbern, C. A., Schmidt, S. B., Pedas, P., Haldrup, A., and Jensen, P. E. 2009. Manganese deficiency leads to genotype-specific changes in fluorescence induction kinetics and state transitions. Plant Physiology, 150(2), 825-833.

Ichizen, N., Nishio, T., Liu, G., Li, D., and Huang, J. 2001. Relation between management systems and soil erosion and screening of perennial gramineous plants for vegetation recovery in hilly land in loess plateau. J. Weed Sci. and Tech. 46: 97-103

Jensen, R. A. 1986. The shikimate/arogenate pathway: link between carbohydrate metabolism and secondary metabolism. Physiologia Plantarum, 66(1), 164-168.

Johnson, A. L., Divers, T. J., Freckleton, M. L., McKenzie, H. C., Mitchell, E., Cullen, J. M., and McDonough, S. P. 2006. Fall panicum (Panicum dichotomiflorum) hepatotoxicosis in horses and sheep. Journal of veterinary internal medicine, 20(6), 1414-1421.

Johnson, H. S., and Hatch, M. D. 1970. Properties and regulation of leaf NADP-malate dehydrogenase and malic enzyme in plants with the $\mathrm{C} 4$ dicarboxylic acid pathway of photosynthesis. Biochem. J, 119, 273-280.

Johnson, R. E., and Jackson, W. A. 1964. Calcium uptake and transport by wheat seedlings as affected by aluminum. Soil Science Society of America Journal, 28(3), 381-385.

Jung, G. A., Gross, C. F., Kocher, R. E., Burdett, L. R., and Sharp, W. C. 1978. Warmseason range grasses extend beef cattle forage [Grazing management]. Science in Agriculture.

Kering, M. K., Lukaszewska, K., and Blevins, D. G. 2009. Manganese requirement for optimum photosynthesis and growth in NAD-malic enzyme C-4 species. Plant and Soil, 316(1-2), 217-226.

Kochian, L., Hoekenga, O., Piñeros, M. 2004. How do crops plants tolerate acid soils? Mechanisms of aluminum tolerance and phosphorus efficiency. Annu. Rev. Plant Biolog. 55, 459-93 
Laetsch, W. M. 1974. The C4 syndrome: a structural analysis. Annual review of plant physiology, 25(1), 27-52.

Laha, S., and Luthy, R. G. 1990. Oxidation of aniline and other primary aromatic amines by manganese dioxide. Environmental Science and Technology, 24(3), 363-373.

Lavres J. J., Malavolta, E., Nogueira, N. D. L., Moraes, M. F., Reis, A. R., Rossi, M. L., and Cabral, C. P. 2009. Changes in anatomy and root cell ultrastructure of soybean genotypes under manganese stress. Revista Brasileira de Ciência do Solo, 33(2), 395-403.

Lee, S. T., Stegelmeier, B. L., Gardner, D. R., and Vogel, K. P. 2001. The isolation and identification of steroidal sapogenins in switchgrass. Journal of natural Toxins, 10 (4), 273-281.

Lei, Y., Korpelainen, H., and Li, C. 2007. Physiological and biochemical responses to high Mn concentrations in two contrasting Populus cathayana populations. Chemosphere, 68(4), 686-694.toxins, 10(4), 273-281.

Lemus, R., Brummer, E. C., Moore, K. J., Molstad, N. E., Burras, C. L., and Barker, M. F. 2002. Biomass yield and quality of 20 switchgrass populations in southern Iowa, USA. Biomass and Bioenergy, 23(6), 433-442.

Leplat, F. 2015. Identification of manganese use efficiency candidate genes in winter barley (Hordeum vulgare): GWAS on Chlorophyll a Fluorescence and ICP-OES. In Plant and Animal Genome XXIII Conference. Plant and Animal Genome.

Lin, C. H., McGraw, R. L., George, M. F., and Garrett, H. E. 1999. Shade effects on forage crops with potential in temperate agroforestry practices. Agrofor. Syst. 44: 109-119

Lidon, F. C., Barreiro, M. G., and Ramalho, J. C. 2004. Manganese accumulation in rice: implications for photosynthetic functioning. Journal of Plant Physiology, 161(11), 1235-1244.

Lidon, F.C, Teixeira, M.G. 2000. Rice tolerance to excess Mn: Implications in the chloroplast lamellae and synthesis of a novel Mn protein. Plant Physiol. Biochem. $38,969-978$.

Marschner, H. 1995 Mineral Nutrition of Higher Plants. Academic Press, San Diego, p 889.

McClain, W. E. 2007. Phosphorus nutrition in tall fescue: From stockpiling to seed production (Doctoral dissertation, University of Missouri--Columbia), 118-138.

McLaughlin, S. B., and Kszos, L. A. 2005. Development of switchgrass (Panicum virgatum) as a bioenergy feedstock in the United States. Biomass and Bioenergy, 28(6), 515-535.

McLaughlin, M. R., Fairbrother, T. E., and Rowe, D. E. 2004a. Forage yield and nutrient uptake of warm-season annual grasses in a swine effluent spray field. Agronomy Journal, 96(6), 1516-1522. 
McLaughlin, M. R., Fairbrother, T. E., and Rowe, D. E. 2004b. Nutrient uptake by warmseason perennial grasses in a swine effluent spray field. Agronomy Journal, 96(2), 484-493.

Meister, M., Agostino, A., and Hatch, M. D. 1996. The roles of malate and aspartate in C4 photosynthetic metabolism of Flaveria bidentis (L.). Planta, 199(2), 262-269.

Millaleo, R., Reyes-Díaz, M., Ivanov, A. G., Mora, M. L., and Alberdi, M. 2010. Manganese as essential and toxic element for plants: transport, accumulation and resistance mechanisms. Journal of Soil Science and Plant Nutrition, 10(4), 470481.

Moore, K. J., White, T. A., Hintz, R. L., Patrick, P. K., and Brummer, E. C. 2004. Sequential grazing of cool-and warm-season pastures. Agronomy Journal, 96(4), 1103-1111.

Moser, L. E., and Vogel, K. P. 1995. Switchgrass, big bluestem, and indiangrass. Forages, 1, 409-420.

Muhaidat, R., and McKown, A. D. 2013. Significant involvement of PEP-CK in carbon assimilation of C4 eudicots. Annals of botany, 111(4), 577-589.

Mukhopadhyay, M. J., and Sharma, A. 1991. Manganese in cell metabolism of higher plants. The Botanical Review, 57(2), 117-149.

National Research Council (NRC). 2000. Nutrient requirements of beef cattle, 7th ed. Washington, D.C.: National Academy Press.

Ness, P. J., and Woolhouse, H. W. 1980. RNA synthesis in Phaseolus chloroplasts: I. Ribonucleic acid synthesis in chloroplast preparations from Phaseolus vulgaris L. leaves and solubilization of the RNA polymerase. Journal of Experimental Botany, 31(1), 223-233.

Nickelsen, J., and Rengstl, B. 2013. Photosystem II assembly: from cyanobacteria to plants. Annual Review of Plant Biology, 64, 609-635.

Norvell, W. A. 1988. Inorganic reactions of manganese in soils. In Manganese in soils and plants, 33, 37-58. Springer Netherlands.

O'Leary, M. H. 1982. Phosphoenolpyruvate carboxylase: an enzymologist's view. Annual Review of Plant Physiology, 33(1), 297-315.

O'Leary, M. H., Rife, J. E., and Slater, J. D. 1981. Kinetic and isotope effect studies of maize phosphoenolpyruvate carboxylase. Biochemistry, 20(25), 7308-7314.

O'Neal, D., and Joy, K. W. 1974. Glutamine Synthetase of Pea Leaves: Divalent Cation Effects, Substrate Specificity, and Other Properties 1. Plant Physiology, 54(5), 773. 
Papadakis, I. E., Bosabalidis, A. M., Sotiropoulos, T. E., and Therios, I. N. 2007. Leaf anatomy and chloroplast ultrastructure of Mn-deficient orange plants. Acta Physiologiae Plantarum, 29(4), 297-301.

Parrish, D. J., and Fike, J. H. 2005. The biology and agronomy of switchgrass for biofuels. BPTS, 24(5-6), 423-459.

Parrish, D. J., Fike, J. H., Bransby, D. I., and Samson, R. 2008. Establishing and managing switchgrass as an energy crop. Forage and Grazinglands, (February).

Pessarakli, M. (Ed.). 2007. Handbook of turfgrass management and physiology. CRC Pitman, W. D. 2000. Adaptation of tall-grass prairie cultivars to West Louisiana. J. Range Manage. 53: 47-51. press. 211

Pfeffer, P. E., Tu, S. I., Gerasimowicz, W. V., and Cavanaugh, J. R. 1986. In vivo31P NMR studies of corn root tissue and its uptake of toxic metals. Plant Physiology, 80(1), 77-84.

Pick, T. R., Bräutigam, A., Schlüter, U., Denton, A. K., Colmsee, C., Scholz, U., and Weber, A. P. 2011. Systems analysis of a maize leaf developmental gradient redefines the current $\mathrm{C} 4$ model and provides candidates for regulation. The Plant Cell, 23(12), 4208-4220.

Porter, C.L. 1966. An analysis of variations between upland and lowland switchgrass, $P$. virgatum L., in central Oklahoma. Ecology 47:980-992

Porter, G. S., Bajita-Locke, J. B., Hue, N. V., andStrand, D. 2004. Manganese solubility and phytotoxicity affected by soil moisture, oxygen levels, and green manure additions. Communications in Soil Science and Plant Analysis, 35(1-2), 99-116.

Rao, X., and Dixon, R. A. 2016a. The differences between NAD-ME and NADP-ME subtypes of $\mathrm{C} 4$ photosynthesis: more than decarboxylating enzymes. Frontiers in Plant Science, 7, 1525.

Rao, X., Lu, N., Li, G., Nakashima, J., Tang, Y., and Dixon, R. A. 2016b. Comparative cell-specific transcriptomics reveals differentiation of $\mathrm{C} 4$ photosynthesis pathways in switchgrass and other $\mathrm{C} 4$ lineages. Journal of Experimental Botany, 67(6), 1649-1662.

Reuter, D. J., Cartwright, B., Judson, G. J., McFarlane, J. D., Maschmedt, D. J., and Robinson, J. B. 1988. Trace elements in South Australian agriculture. Department of Agriculture South Australia Technical Report, 139.

Sage, R. F., and McKown, A. D. 2006. Is C4 photosynthesis less phenotypically plastic than C3 photosynthesis? Journal of Experimental Botany, 57(2), 303-317.

Sage, R. F. 2004. The evolution of C4 photosynthesis. New phytologist, 161(2), 341-370.

Sanderson, M. A., Reed, R. L., McLaughlin, S. B., Wullschleger, S. D., Conger, B. V., Parrish, D. J., ... and Hussey, M. A. 1996. Switchgrass as a sustainable bioenergy crop. Bioresource Technology, 56(1), 83-93. 
Sanderson, M. A., Moore, K. J., and Anderson, B. E. 2000. Cutting management of native warm-season perennial grasses: morphological and physiological responses. In Native warm-season grasses: research trends and issues. Proceedings of the Native Warm-Season Grass Conference and Expo, Des Moines, IA, USA, 12-13 September 1996. 133-146. Crop Science Society of America.

Sanderson, M. A., Adler, P. R., Boateng, A. A., Casler, M. D., and Sarath, G. 2006. Switchgrass as a biofuels feedstock in the USA. Canadian Journal of Plant Science, 86(5), 1315.

Schmidt, S. B., Pedas, P., Laursen, K. H., Schjoerring, J. K., and Husted, S. 2013. Latent manganese deficiency in barley can be diagnosed and remediated on the basis of chlorophyll a fluorescence measurements. Plant and Soil, 372(1-2), 417-429.

Self-Davis, M. L., Moore, P. A., Daniel, T. C., Nichols, D. J., Sauer, T. J., West, C. P., Aiken, G. E., and Edwards, D. R. 2003. Forage species and canopy cover effects on runoff from small plots. J. Soil Water Conserv. 58: 349- 359.

Sharwood, R. E., Sonawane, B. V., and Ghannoum, O. 2014. Photosynthetic flexibility in maize exposed to salinity and shade. Journal of Experimental Botany, 65(13), 3715-3724.

Sims, R. E., Hastings, A., Schlamadinger, B., Taylor, G., and Smith, P. 2006. Energy crops: current status and future prospects. Global Change Biology, 12(11), 20542076.

Sommer, M., Bräutigam, A., and Weber, A. P. M. 2012. The dicotyledonous NAD malic enzyme C4 plant Cleome gynandra displays age dependent plasticity of $\mathrm{C} 4$ decarboxylation biochemistry. Plant Biology, 14(4), 621-629.

Sparrow, L. A., andUren, N. C. 1987. Oxidation and reduction of Mn in acidic soils: effect of temperature and soil pH. Soil Biology and Biochemistry, 19(2), 143-148.

Stafford, H. A. 1974. The metabolism of aromatic compounds. Annual Review of Plant Physiology, 25(1), 459-486.

Stegelmeier, B. L., Elmore, S. A., Lee, S. T., James, L. F., Gardner, D. R., Panter, K. E., ... and Wierenga, T. L. 2007. Switchgrass (Panicum virgatum) Toxicity in Rodents, Sheep, Goats and Horses. Poisonous Plants: Global Research and Solutions, Panter, K. (Ed.). CABI Publishing, New York, USA, 113-117.

Tewari, R. K., Kumar, P., andSharma, P. N. 2013. Oxidative stress and antioxidant responses of mulberry (Morus alba) plants subjected to deficiency and excess of manganese. Acta Physiologiae Plantarum, 35(12), 3345-3356.

Thomson, A. M., Izaurralde, R. C., West, T. O., Parrish, D. J., Tyler, D. D., and Williams, J. R. 2009. Simulating potential switchgrass production in the United States. PNNL-19072. 
Tobias, C. M., Sarath, G., Twigg, P., Lindquist, E., Pangilinan, J., Penning, B. W. and Lazo, G. R. 2008. Comparative genomics in switchgrass using 61,585 highquality expressed sequence tags. The Plant Genome, 1(2), 111-124.

Vogel, K.P. 2004. Switchgrass. p. 561-588 In: L.E. Moser et al., eds. Warm-season (C4) Grasses. ASA-CSSA-SSSA, Madison, WI.

Walker, R. P., Acheson, R. M., Técsi, L. I., and Leegood, R. C. 1997. Phosphoenolpyruvate carboxykinase in $\mathrm{C} 4$ plants: its role and regulation. Functional Plant Biology, 24(4), 459-468.

Wang, Y., Bräutigam, A., Weber, A. P., and Zhu, X. G. 2014. Three distinct biochemical subtypes of C4 photosynthesis? A modelling analysis. Journal of Experimental Botany, 65: 3567-3578.

Weaver, J. E. 1968. Prairie plants and their environment. A fifty-year study in the midwest. Prairie plants and their environment. A fifty-year study in the midwest.

Wildner, G. F., and Henkel, J. 1978. Differential reactivation of ribulose 1, 5bisphosphate oxygenase with low carboxylase activity by Mn2+. FEBS Letters, 91(1), 99-103.

Wilkinson, R. E., and Ohki, K. 1988. Influence of manganese deficiency and toxicity on isoprenoid syntheses. Plant Physiology, 87(4), 841-846.

Willett, C. D., Lerch, R. N., Lin, C. H., Goyne, K. W., Leigh, N. D., and Roberts, C. A. 2013. Identification of an atrazine-degrading benzoxazinoid in Eastern Gamagrass (Tripsacum dactyloides). Journal of Agricultural and Food Chemistry, 61(34), 8026-8033.

Wingler, A., Walker, R. P., Chen, Z. H., and Leegood, R. C. 1999. Phosphoenolpyruvate carboxykinase is involved in the decarboxylation of aspartate in the bundle sheath of maize. Plant Physiology, 120(2), 539-546.

Wright, L. L. 1994. Production technology status of woody and herbaceous crops. Biomass and Bioenergy, 6(3), 191-209.

Yang, X. E., Chen, W. R., and Feng, Y. 2007. Improving human micronutrient nutrition through biofortification in the soil-plant system: China as a case study. Environmental Geochemistry and Health, 29(5), 413-428. 


\section{CHAPTER 2}

Influence of manganese availability on switchgrass and pearl millet biomass production 


\begin{abstract}
Manganese $(\mathrm{Mn})$ is an essential micronutrient and has a broad range of functions in plants. It plays key roles in photosynthetic processes, including as a constituent of the water splitting complex of photosystem II (PSII), and, in NAD-ME type C4 plants, as an activator of NAD-ME which catalyzes the release of $\mathrm{CO}_{2}$ from malate in bundle sheath cells (BSC). However, little is known about the Mn requirements of switchgrass (Panicum virgatum L.) at present. To study Mn requirements for optimum growth and biomass production, a lowland ('Alamo') and an upland ('Cave-in-Rock') switchgrass ecotype were grown in 19-L pots filled with either washed sand, vermiculite, or perlite, and fertilized with nutrient solutions with Mn concentrations ranging from 0 to $200 \mu \mathrm{M}$ under field conditions in three consecutive years. In the last year (perlite), pearl millet (_Pennisetum glaucum L. R. Br.) ('KGraze') was also grown. Shoot Mn concentration was highly responsive to increasing $\mathrm{Mn}$ concentration in the nutrient solution in all experiments and for all entries. When grown in washed sand and vermiculite, switchgrass tissue Mn concentrations remained above those normally considered deficient, even for the $0 \mu \mathrm{M}$ Mn treatment, and no Mn treatment effects on biomass production were found for either ecotype. In perlite, end-of-season shoot $\mathrm{Mn}$ concentrations were below $5 \mathrm{mg} \mathrm{kg}^{-1}$ in all entries when no $\mathrm{Mn}$ was supplied in the nutrient solution, but a significant decrease in biomass production compared to $10-25 \mu \mathrm{M}$ Mn treatments was only observed for Alamo and KGraze, but not for Cave-in-Rock. Relative chlorophyll contents of both switchgrass ecotypes were significantly lower in the $0 \mu \mathrm{M}$ Mn treatment than other treatments late in the season. In KGraze, relative chlorophyll content was lowest early in the season in the $0 \mu \mathrm{M}$ Mn treatment and
\end{abstract}


increased throughout the season, resulting in less pronounced, but still significant differences compared to the other Mn treatments, at late stages. Overall, results indicated that switchgrass and pearl millet respond differently to low Mn availability and that even low levels of shoot tissue Mn concentrations allow switchgrass to maintain biomass production. 


\section{Introduction}

Switchgrass (Panicum virgatum L.) is a perennial NAD-malic enzyme (NADME) type C4 grass. Switchgrass is considered a promising species for sustainable production of large amounts of bioenergy feedstock. Traditionally, switchgrass has been used as a forage crop for animal grazing and hay production (Balasko et al., 1984; Jung et al., 1978; Anderson, 2000; Sanderson et al., 2000; Moore et al., 2004; McLaughlin, 2004; Parrish and Fike, 2005), but because of its' potential as a bioenergy feedstock, research on switchgrass has increased in recent years (McLaughlin et al., 2004, 2005; Sims et al., 2006; Fike et al., 2007; Parrish et al., 2008; Thomson et al., 2009).

Earlier research on switchgrass mainly focused on management for forage productivity and quality (Anderson et al., 1983; Anderson et al., 1988), including animal intake (Burns and Sollenberger, 2002), nutritive value, and toxicology of switchgrass (Lee et al., 2001; Guretzky et al., 2011). Several studies also investigated fertility requirements and fertilizer responses with respect to forage productivity and quality (Vogel et al., 2002). However, the utility of the fertilizer recommendations for forage production and forage quality may be limited for optimization of switchgrass production for bioenergy (Sanderson, et al., 2006). Studies examining fertilizer responses of switchgrass for bioenergy production primarily focus on $\mathrm{N}$, and $\mathrm{P}$ and $\mathrm{K}$ requirements ( Muir et al., 2001; Thomason et al., 2005; Lemus et al., 2008; Kering et al., 2013), whereas studies on micronutrient requirements are relatively limited (Bardhan et al., 2017).

Manganese (Mn), an essential micronutrient, is a component of the oxygen evolving complex of photosystem II (PSII) (Amao and Ohashi, 2008; Nickelsen and 
Rengstl, 2013), is a constituent of superoxide dismutase (MnSOD), and an activator of numerous enzymes in several metabolic process (Marshner, 1995), especially in photosynthesis (Hatch and Kagawa, 1974; Goussias et al., 2002; Millaleo et al., 2010).

In NAD-ME plants, Mn plays a crucial role in activing NAD-ME which catalyzes the decarboxylation of malate in the mitochondria bundle sheath cells (Hatch and Kagawa, 1974; Burnell, 1986).Studies by Hatch and Kagawa (1974) indicate that NADME has an absolute requirement for Mn. Given previous research about the particular importance of Mn for NAD-ME, Kering et al. (2009) compared Mn requirements of selected NAD-ME, NADP-ME, and C3 plants under controlled conditions using hydroponic culture. Their research demonstrated that young pearl millet (Pennisetum glaucum L. R. Br. ) and purple amaranth (Amaranthus hypochondriacus L.), NAD-ME C4 plant representatives, have a higher Mn requirement for optimum biomass production and photosynthesis than wheat (Triticum aestivum L.) and squash (Cucurbita pepo L.), C3 representatives, and NADP-ME C4 plants maize (Zea mays L.) and sorghum (Sorghum bicolor L.). Therefore, since switchgrass traditionally has been classified as an NADME C4 grass, its Mn requirements for optimum biomass may also exceed those of other non-NAD-ME C4 species. However, Mn requirements of switchgrass have not been tested explicitly and only limited information is available on the Mn requirement for optimum growth and biomass production of switchgrass, even though Mn availability can limit plant growth in parts of the USA (Berger, 1962).

To test if switchgrass has a high requirement for $\mathrm{Mn}$ for optimum biomass production, a lowland ('Alamo') and upland ('Cave-in-Rock') switchgrass ecotype, and, as reference, pearl millet cultivar ('KGraze'), were grown in different Mn treatments in 
pots under field conditions in three years; and biomass accumulation and partitioning were characterized.

\section{Materials and methods}

\subsection{Plant materials and growth conditions}

Three pot experiments were carried out at MU Bradford Research Center, Columbia, Missouri from 2014-2016. Two switchgrass genotypes, Alamo and Cave-inRock, were used in this research. Alamo, a lowland ecotype, produces heavy foliage and has late season maturity. Cave-in-Rock, an upland ecotype, has an early season maturity. One pearl millet cultivar, KGraze, was used as a reference crop in the 2016 experiment.

Switchgrass seeds were pre-germinated in germination paper rolls that were placed in $1 \mathrm{~L}$ beakers with $500 \mathrm{ml} 0.2 \mathrm{mM} \mathrm{CaSO} 4$ solution for a period of $72 \mathrm{~h}$ (Cave-inRock) or $96 \mathrm{~h}$ (Alamo) in an incubator at $28^{\circ} \mathrm{C}$. Germinating seeds were planted to seedling trays consisting of 72 cells filled with organic potting medium (Premier Pro-Mix BX, Premier horticulture), vermiculite, or perlite in 2014, 2015, and 2016, respectively. The trays with the seedlings were placed in a greenhouse and were grown for an additional 30 to 41 days prior to transplanting into the pots in the field. During this time, seedling were watered with complete nutrient solution, except for Mn, which consisted of $2.5 \mathrm{mM} \mathrm{NH}_{4} \mathrm{NO}_{3}, 2.0 \mathrm{mM} \mathrm{KCl}, 2.0 \mathrm{mM} \mathrm{CaCl}_{2} \cdot 2 \mathrm{H}_{2} \mathrm{O}, 0.5 \mathrm{mM} \mathrm{MgSO} 4 \cdot 7 \mathrm{H}_{2} \mathrm{O}, 2.0$ $\mathrm{mM} \mathrm{KNO}_{3}, 0.08 \mathrm{mM} \mathrm{K}_{2} \mathrm{HPO}_{4}, 0.32 \mathrm{mM} \mathrm{KH_{2 }} \mathrm{PO}_{4}, 0.025 \mathrm{mM}$ FeSeq330, $2.3 \mu \mathrm{M} \mathrm{H}_{3} \mathrm{BO}_{3}$, $0.6 \mu \mathrm{MnSO}_{4} \cdot 7 \mathrm{H}_{2} \mathrm{O}, 0.10 \mu \mathrm{M} \mathrm{NaMoO}{ }_{4} \cdot 2 \mathrm{H}_{2} \mathrm{O}, 0.11 \mu \mathrm{M} \mathrm{NiCl} 2 \cdot 6 \mathrm{H}_{2} \mathrm{O}, 0.15 \mu \mathrm{M}$ $\mathrm{CuSO}_{4} \cdot 5 \mathrm{H}_{2} \mathrm{O}$. The solution $\mathrm{pH}$ was adjusted to 5.6 with $\mathrm{NaOH}$ and nutrient solution was applied every other day. 
Once seedlings reached the 3-4 leaf stage with vigorous growth seedlings were selected for uniformity and transplanted into 19-liter pots filled with growth medium. In 2014, pots were filled with $25 \mathrm{~kg}$ of dry, washed river sand, in 2015 with $2 \mathrm{~kg}$ of dry vermiculite, and in 2016 with $2 \mathrm{~kg}$ perlite. Seedlings were transplanted to the pots in the field 41 (19 June), 30 (1 July), and 40 (16 June) days post germination in 2014, 2015, and 2016, respectively. In 2016, six pearl millet seeds were directly sown in each pot on the day of switchgrass transplanting and thinned to three uniform seedlings after the first leaf was fully developed. During the pot filling process, subsamples of sand, vermiculate, and perlite, respectively, were collected for nutrient analyses. In 2016, samples of rain water and deionized water used to make the nutrient solution were also collected and analyzed. Nutrient analyses of these samples were carried out by the University of Missouri Soil and Plant Testing Laboratory, and the result are shown in Table 2-1.

Plants were fertigated with the above-described nutrient solution without Mn every day between 8:00 and 9:00 am for the first 6 (2014), 2 (2015), and 10 (2016) days following transplanting to the pots in the field. After this initial period, Mn application treatments were established using $\mathrm{MnSO}_{4}$ as the $\mathrm{Mn}$ source. The above-described nutrient solution was modified to contain 0, 25, 50, 75 and $100 \mu \mathrm{M} \mathrm{Mn}$ in 2014, 0, 25, $50,75,100$ and $200 \mu \mathrm{M}$ Mn in 2015, and 0, 2, 5, 10, 25 and $75 \mu \mathrm{M} \mathrm{Mn}$ in 2016. Nutrient build-up in the pots was prevented by excess fertigation as well as open top pots (with drainage holes) exposed to precipitation, allowing pots to be flushed. Environmental data were obtained from Missouri Historical Agricultural Weather Database located within the Columbia-Bradford Research and Extension Center (Boone County) of the experiment. 


\subsection{Relative chlorophyll content}

Relative chlorophyll content was measured with a SPAD-502 chlorophyll meter (Konica Minolta, Osaka, Japan) on the middle third of recently fully expanded leaves at 82 and 78 day after Mn treatment initiation (DAMT) in 2014 and 2015, respectively. In 2016 , the measurements were taken on recently fully expanded leaves at $24,38,53$, and 67 DAMT for Cave-in-rock and KGraze, and one more measurement was taken at 85 DAMT for Alamo. Five readings were collected per experimental unit (pot) and the average was used for statistical analysis.

\subsection{Plant harvest}

Tillers were counted and plant height was measured at final harvest time. For switchgrass, once tiller numbers were counted and plant height was measured, plants were harvested by replication. To this end, tillers were cut at $10 \mathrm{~cm}$ above the media surface, placed in paper bags, and oven dried. Roots including rhizomes were removed from the pots and washed and rinsed repeatedly with tap water to remove all the media, bagged, and oven dried. Harvests occurred after 142 DAMT (November 13, 2014), 113 DAMT (October 22, 2015), or 109 DAMT (October 13, 2016). All plant tissues were dried at $70^{\circ} \mathrm{C}$ for 3 days and weighed. To obtain separate dry matter data for rhizomes and roots, these tissues were separated from each other after drying and prior to weighing. After weighing, shoot samples were ground through a $2 \mathrm{~mm}$ screen in a Whiley Mill (Tomas Scientific, Swedesboro, NJ) and a subsample was further ground through a $1 \mathrm{~mm}$ screen with a Cyclone Mill (Udy Corporation, Fort Collins, CO). Pearl millet was harvested at 109 DAMT. Stems were cut at $10 \mathrm{~cm}$ above the media level, and separated from leaves, and panicles, and roots were removed from the pots and washed. 
Samples were dried at $70^{\circ} \mathrm{C}$, and weighed. Seeds were removed from the panicles and weighed separately, while the rachis was weighed with the stem. Stem and leaf samples were ground separately as described for the pearl millet samples.

\subsection{Shoot Mn concentration analysis}

Subsamples of ground shoot (switchgrass) and stem and leaf tissues (pearl millet) were submitted to the Agriculture Diagnostic Laboratory at the University of Arkansas for nutrient analysis. Samples were analyzed by inductively coupled plasma optical emission spectroscopy (Spectro ARCOS ICP-OES-SOP, FHS16, Kleve, Germany). Shoot Mn concentration of pearl millet was calculated on the basis of stem and leaf dry matter and stem and leaf tissue Mn concentrations.

\subsection{Accumulated heat unit calculation}

The accumulated heat units were calculated by below equation: The accumulated heat units $=\Sigma(($ Daily high temperature + Daily low temperature $) \div 2-$ threshold temperature). For switchgrass the threshold is $50^{\circ} \mathrm{F}\left(10^{\circ} \mathrm{C}\right)$ (McLaughlin et al., 1999), and $54{ }^{\circ} \mathrm{F}\left(12^{\circ} \mathrm{C}\right)$ for pearl millet (Hannaway and Larson, 2004).

\subsection{Statistical analysis}

The experiments were arranged in a randomized complete block design (RCBD) with five replications in 2014 and 2015, and six replications in 2016. Analysis of variance was conducted using the PROC GLM model in SAS version 9.4 (SAS Institute, 2013), treating genotype, Mn treatment and interaction as fixed effects, and replication as random effects. Mean separation was conducted using Fisher's Protected Least Significant Difference at $\mathrm{p}<0.05$ level. 


\section{Results}

\subsection{Environmental conditions}

Weather data from years 2014, 2015, and 2016 were recorded at the Bradford Research Center near Columbia, MO. Both precipitation and temperatures differed among the three years, in part also as a result of the different transplanting and harvest dates (Fig. 2-1). Cumulative precipitation during the experimental period was $545 \mathrm{~mm}$ in 2014, $278 \mathrm{~mm}$ in 2015, and $582 \mathrm{~mm}$ for switchgrass and $582 \mathrm{~mm}$ for pearl millet in 2016 . Heat unit accumulations were 1306 in 2014, 1290 in 2015, and in 2016, 1390 for switchgrass and 1146 for pearl millet.

\subsection{Shoot Mn concentrations}

As expected, shoot Mn concentration increased with increasing Mn concentration in the nutrient solution in Alamo, Cave-in-Rock, and KGraze (Fig. 2-2; Appendix Table 2-1). Shoot Mn concentrations of Alamo and Cave-in-Rock did not differ within Mn treatment in 2014 and 2015, except for a greater Mn concentration in CIR in the $0 \mu \mathrm{M}$ treatment in 2014, and lower concentration in $25 \mu \mathrm{M}$ treatment in 2015. In 2016, Alamo had lower shoot Mn concentration than Cave-in-Rock in treatments with Mn concentrations ranging from $2-25 \mu \mathrm{M}$, and lower than KGraze in 2 and $25 \mu \mathrm{M} \mathrm{Mn}$ treatments. Shoot $\mathrm{Mn}$ concentration in the $0 \mu \mathrm{M}$ Mn treatment were highest in 2014, intermediate in 2015, and lowest in $2016(\mathrm{P}<0.05)$, which is consistent with the highest, intermediate, and lowest concentrations of $\mathrm{Mn}$ in the sand, vermiculate, and perlite media that were used in these three years, respectively (Table 2-1). 


\subsection{Biomass production and partitioning}

Although shoot Mn concentration was highly responsive to Mn treatment, the effect of Mn treatment on total biomass production at the end of the experiments was either absent or minimal in all experiments (Fig. 2-3; Appendix Table. 2-2; Appendix Table. 2-3). Total biomass of Cave-in-Rock was similar across all Mn treatments in each of the three years. Similarly, total biomass of Alamo was not influenced by Mn treatments in 2014 and 2015, and only in the $0 \mu \mathrm{M}$ Mn treatment was it significantly lower than in the 10 and $25 \mu \mathrm{M}$ Mn treatments in 2016. Total biomass produced by KGraze was less in the 0 and $2 \mu \mathrm{M}$ Mn treatments than in the $10 \mu \mathrm{M}$ Mn treatment, and did not differ from the 25 and $75 \mu \mathrm{M}$ Mn treatments (Fig. 2-3; Appendix Table. 2-2; Appendix Table. 2-3). The significant Mn treatment effects was observed in 2016 for Alamo and KGraze were associated with much lower tissue Mn concentrations in the 0 Mn treatment in this year than in 2014 and 2015 (Fig. 2-2; Appendix Table. 2-1;).

Separate analysis of switchgrass shoot, root, and rhizome biomass did not reveal any significant effects of Mn treatments for any of these fractions in 2014 and 2015 for either ecotype (Fig. 2-3; Appendix Table. 2-2; Appendix Table. 2-3). While this was also true for all fractions of Cave-in-Rock and root biomass of Alamo in 2016, significant Mn treatment effects on Alamo rhizome and shoot biomass fractions were observed. Alamo rhizome biomass was significantly lower in 0 and $2 \mu \mathrm{M}$ Mn treatments than in the $5 \mu \mathrm{M}$ Mn treatment, which did not differ from the $>5 \mu \mathrm{M}$ Mn treatments (Fig.2-3; Appendix Table. 2-2; Appendix Table. 2-3). Alamo shoot biomass was lower in the $0 \mu \mathrm{M} \mathrm{Mn}$ treatment than in $\geq 10 \mu$ treatments. KGraze reached maximum total biomass and shoot biomass (excluding seed) in the $10 \mu \mathrm{M}$ Mn treatment for which they were significantly greater than in the 0 and $2 \mu \mathrm{Mn}$ treatments, but did not differ from all other treatments 
(Fig.2-3; Appendix Table. 2-2; Appendix Table. 2-3). The maximum KGraze seed dry weight was observed in the 10 and $25 \mu \mathrm{M}$ Mn treatments which were did not differ from 2, 5, and $75 \mu \mathrm{M} \mathrm{Mn}$ treatments, but were greater than in the $0 \mu \mathrm{M} \mathrm{Mn}$ treatment (Fig.2-3; Appendix Table. 2-2; Appendix Table. 2-3).

Alamo produced greater shoot biomass and total biomass than Cave-in-Rock in all three years and across all Mn treatments (Fig. 2-3; Appendix Table. 2-2, Appendix Table 2-3). Across all years and Mn treatments, shoot biomass and total biomass of Alamo were 1.7 and 1.5 fold greater than for Cave-in Rock. Additionally, Alamo also produced more total biomass than KGraze in all Mn treatments, averaging approximately 1.6-fold that of KGraze across all Mn treatments. With the exception of the 0 and 100 $\mu \mathrm{M}$ Mn treatments in 2015, in which Alamo produced more root biomass than Cave-inrock, no differences in root biomass were found between the two ecotypes in the first two years (Fig. 2-3; Appendix Table. 2-2; Appendix Table. 2-3). However, in 2016, Alamo produced more root biomass in all Mn treatments (2.1-fold, average across all $\mathrm{Mn}$ treatments) than Cave-in-rock (Fig. 2-3; Appendix Table. 2-2; Appendix Table. 2-3).

Root-shoot ratio is often influenced by nutrient availability and stress conditions. However, in this study, Mn treatment did not influence root-shoot ratios of any of the entries, except for the 2016, $5 \mu \mathrm{M}$ Mn treatment Cave-in-Rock which was had a lower root-shoot ratio than any of the $2 \mu \mathrm{M}$ Mn treatment (Fig. 2-3; Appendix Table. 2-4). The Root-shoot ratio of Cave-in-rock was significantly greater than for Alamo in all Mn treatments in 2014 (Fig. 2-3; Appendix Table. 2-4). In contrast, root-shoot ratios in 2015 and 2016 were not different between the two ecotypes, and were more similar to the rootshoot ratio observed for Alamo than for that of Cave-in-Rock in 2014. KGraze root-shoot 
ratios were much smaller than those of both switchgrass ecotypes, averaging only 0.14 compared to 0.46 (average of both ecotypes) (Fig. 2-3; Appendix Table. 2-4).

\subsection{Tiller number, and plant height, and relative chlorophyll content}

Tiller number was not influenced by Mn treatment in either switchgrass ecotype in any of the three years, except for Cave-in-Rock in 2014 when tiller number was lowest in the $100 \mu \mathrm{M}$ Mn treatment (Figure 2-4; Appendix Table. 2-5). In contrast, Mn addition $(\geq 2 \mu \mathrm{M})$ increased the tillers number of KGraze (Fig.2-4; Appendix Table. 2-5), but addition above $2 \mu \mathrm{M}$ Mn did not further increase tiller number. In 2014 and 2015, there is no difference in tillers between two switchgrass ecotype, except for Cave-in-rock in 2015 has higher tiller numbers than Alamo in the $200 \mu \mathrm{M}$ Mn treatment. However, KGraze in 2016 acquired highest tiller number among species ((Fig.2-4; Appendix Table. 2-5).

Plant height at final harvest was not influenced by $\mathrm{Mn}$ treatment, expect for Alamo in 2016, when it was lower in the $0 \mu \mathrm{M}$ Mn treatment than in the 10 and $25 \mu \mathrm{M}$ Mn treatments (Fig.2-5; Appendix Table 2-6). In 2014 and 2015, Alamo had higher plant height than Cave-in-rock in all $\mathrm{Mn}$ treatments expect for the 100 and $200 \mu \mathrm{M} \mathrm{Mn}$ treatments in 2015 when the plant heights of the two ecotypes were similar (Fig.2-5; Appendix Table. 2-6).

In order to detect the leaf greenness, the chlorophyll SPAD value were measured. In 2014 and 2015, single chlorophyll SPAD readings conducted at 82 DAMT and 78 DAMT, respectively, were not affected by Mn treatment (Fig.2-6; Appendix Table 2-7; Appendix Table 2-8). In 2016, SPAD meter readings were conducted 24, 38, 53, and 67 DAMT for all entries, and one additional time at 85 DAMT for Alamo. For the two switchgrass ecotypes, no significant effects of Mn treatment were observed early on (24 
and 38 DAMT), but SPAD values decreased in the $0 \mu \mathrm{M}$ Mn treatment by 53 DAMT and later for both Alamo and Cave-in-Rock (Fig.2-7; Appendix Table 2-7; Appendix Table 28). The decline in SPAD values that was observed in the $0 \mu \mathrm{M}$ treatment as the season progressed was not evident in the remaining treatments, and thus resulted in significantly lower values in the $0 \mu \mathrm{M}$ treatment than in $\geq 2 \mu \mathrm{M}$ Mn treatments. In contrast, SPAD meter readings of KGraze were significantly lower in the $0 \mu \mathrm{M}$ Mn treatment than all the other Mn treatments throughout the growing season (Fig.2-7; Appendix Table 2-7; Appendix Table 2-8). In all Mn treatments, KGraze SPAD values increased over the course of the growing season.

Cave-in-rock SPAD values were greater than those of Alamo in all Mn treatments in 2014. In 2015, the trend was the same, but the difference was only significant in the 75 and $100 \mu \mathrm{M}$ Mn treatments (Appendix Table 2-7). Periodic SPAD meter readings conducted in 2016 did not reveal any differences between Alamo and Cave-in-rock across all Mn treatments at early stages (24 DAMT and 38DAMT), but revealed greater SPAD values in Cave-in-rock than in Alamo at 67 DAMT. Interestingly, KGraze SPAD values in the $0 \mu \mathrm{Mn}$ treatment exhibited an opposite trend to those of the two switchgrass genotypes in the same treatment. That is, in the beginning (24 DAMT and 38 DAMT), switchgrass SPAD values in this treatment were higher than those of KGraze, but SPAD values at 67DAMT were greater in KGraze than in switchgrass (Fig. 2-7; Appendix Table $2-8)$. 


\section{Discussion}

\subsection{Limited response of switchgrass biomass production to Mn availability}

The NAD-ME catalyzing the decarboxylation of malate in the mitochondria of bundle sheath cells in C4 plants requires Mn as an activator (Hatch and Kagawa, 1974). Previous research with pearl millet and purple amaranth, annual monocot and annual dicot representatives of NAD-ME C4 plants, indicated that these species require high levels of Mn for optimum biomass production during early stage development (10-14 days after start of Mn treatments) (Kering et al., 2009). However, these studies were conducted in controlled conditions using a series of hydroponic experiments, and results have not been verified, either under high light intensity conditions that prevail in the field, nor for extended growth into reproductive growth stages.

Based on the results from Kering et al. (2009), we hypothesized that switchgrass, a perennial NAD-ME C4 grass may also have a higher Mn requirement for optimum growth and biomass production. Experiments were conducted in sand-filled pots (sand Mn: $2.59 \mathrm{ppm}$ ) with one upland and one lowland switchgrass ecotype which were fertigated with the Mn nutrient solutions ranging from 0 to $100 \mu \mathrm{M}$, which is the same range that was used in the hydroponic study by Kering et al. (2009). Although shoot Mn concentration increased significantly with greater nutrient solution Mn concentration, it did not have a beneficial effect on growth as no differences in plant height and total biomass in response to $\mathrm{Mn}$ treatment were observed for either ecotype. Thus, the experiment was repeated in the next season using vermiculite, which had a much lower Mn concentration than the sand used previously (0.017 ppm vs. $2.590 \mathrm{ppm} \mathrm{Mn}$ ), and extending the range of $\mathrm{Mn}$ concentration in the nutrient solution from 0 to $200 \mu \mathrm{M}$. 
Again, while shoot Mn concentration increased 7-fold from the $0 \mu \mathrm{M}$ to the $200 \mu \mathrm{M} \mathrm{Mn}$ treatment, neither plant height nor total biomass responded to an increasing $\mathrm{Mn}$ concentration in the nutrient solution. On average between the two ecotypes, shoot $\mathrm{Mn}$ concentration in the $0 \mu \mathrm{M} \mathrm{Mn}$ treatment was $66 \mathrm{mg} \mathrm{kg}^{-1}$ when grown in vermiculate and $115 \mathrm{mg} \mathrm{kg}^{-1}$ when grown in sand. Even though shoot Mn concentration was strongly reduced in the vermiculite system, levels were still more than the $25-50 \mathrm{mg} \mathrm{kg}^{-1}$ dry leaf tissue reported for turfgrass (Jones, 1980; Hull, 2001). Since neither the expansion of the Mn treatment ranges to $200 \mu \mathrm{M}$ Mn, nor the use of a vermiculate instead of sand resulted in a switchgrass response, a third experiment was conducted with perlite $(0.008 \mathrm{ppm} \mathrm{Mn})$ in an attempt to generate shoot lower $\mathrm{Mn}$ concentrations. Indeed, shoot $\mathrm{Mn}$ concentration in the $0 \mu \mathrm{M} \mathrm{Mn}$ treatment were reduced to an average of $3.345 \mathrm{mg} \mathrm{kg}-1$ in the two switchgrass ecotypes. Additionally, the $2 \mu \mathrm{M}$ and $5 \mu \mathrm{M}$ Mn treatment also resulted in shoot $\mathrm{Mn}$ concentrations with $41 \mathrm{mg} \mathrm{kg}^{-1}$, still lower than those found in the 0 $\mu \mathrm{M}$ Mn treatment in vermiculite. Despite the very low shoot Mn concentration (2.89 mg $\left.\mathrm{kg}^{-1}\right)$ in the $0 \mu \mathrm{M} \mathrm{Mn}$ treatment, no significant effect of Mn treatment on Cave-in-Rock plant height or biomass production was observed in the perlite system. However, plant height and biomass production of Alamo were limited by Mn availability in the $0 \mu \mathrm{M} \mathrm{Mn}$ treatment compared to the 10 and $25 \mu \mathrm{M}$ Mn treatments. Thus, 10 to $25 \mu \mathrm{M} \mathrm{Mn}$ concentration required for maximum biomass production of Alamo grown in perlite was well below the 50-100 $\mu \mathrm{M}$ Mn concentration in the nutrient solution that was reported by Kering et al. (2009) to be needed to maximize early biomass production of NAD-ME C4 plants pearl millet and amaranth. Indeed, Kering et al.(2009) also found that higher Mn addition caused (50 $\mu \mathrm{M} \mathrm{Mn}$ ) up to $257 \%$ and $239 \%$ increase shoot dry weight and total 
biomass of pearl millet at early stage (10-14 days after the first photosynthetic leaf fully expanded), respectively. In contrast, Cave-in-Rock biomass production was not influenced by a broad range of nutrient solution Mn concentrations, whether grown in sand, vermiculite, or perlite. A small increase in shoot (11\%) and total (8\%) biomass production was observed for Alamo when grown in perlite with $10 \mu \mathrm{M}$ Mn as compared to $0 \mu \mathrm{M} \mathrm{Mn}$ in the nutrient solution. Thus, the results obtained with these upland and lowland switchgrass ecotypes did not support the hypothesis that all NAD-ME type C4 plants have a requirement for high Mn availability for maximum biomass production.

Given the lack of response of Alamo and Cave-in-Rock in the sand and vermiculite experiments, the pearl millet KGraze was added as an entry for the perlite experiment. A positive response in KGraze biomass production was observed in response to $\mathrm{Mn}$ in the nutrient solution, and the response was more pronounced than for Alamo. KGraze shoot and total biomass increased by $27 \%$ and $25 \%$, respectively in the $10 \mu \mathrm{M} \mathrm{Mn}$ treatment compared to 0 and $2 \mu \mathrm{M}$ Mn treatments. As for Alamo, maximum biomass of KGraze was produced in the $10 \mu \mathrm{M}$ Mn treatment, which again is much lower than the 50 to $100 \mu \mathrm{M}$ Mn concentration required to maximize biomass production of pearl millet grown in hydroponic culture in controlled environment conditions (Kering et al., 2009).

Additionally, Mn addition had no effect on root dry weight of all plants included in this study at late stage. This response is different to Kering et al (2009) study in which Mn addition significantly increased root dry weight of pearl millet at early stage, especially for high Mn concentrations in growth chamber. These different responses of roots to $\mathrm{Mn}$ addition indicated that the response of root dry weight to Mn addition might 
depend on growth condition (field and growth chamber) and growth stage (late and early stage).

\subsection{Shoot Mn concentration for optimum biomass production of switchgrass}

In all experiments, the shoot $\mathrm{Mn}$ concentration increased in parallel with $\mathrm{Mn}$ concentrations in the nutrient solutions (Fig. 2-2; Appendix Table 2-1). However, as indicated above, increased shoot Mn concentration was not associated with increased biomass production in any of the experiments for Cave-in-Rock, and only in the perlite system for Alamo and KGraze. Shoot Mn concentrations ranged from 87 to $248 \mathrm{mg} \mathrm{kg}^{-1}$ in Alamo and from 143 to $266 \mathrm{mg} \mathrm{kg}^{-1}$ in Cave-in-Rock when grown in sand, and from 75 to $515 \mathrm{mg} \mathrm{kg}^{-1}$ in Alamo and from 57 to $441 \mathrm{mg} \mathrm{kg}^{-1}$ in Cave-in-Rock when grown in vermiculite. The upper end of these ranges are comparable to the previously reported 294 - $470 \mathrm{mg} \mathrm{kg}^{-1}$ shoot Mn concentrations that were associated with maximum biomass production of pearl millet, but well below the $750-1424 \mathrm{mg} \mathrm{kg}^{-1}$ shoot $\mathrm{Mn}$ that maximized purple Amaranth biomass production (Kering et al., 2009). Interestingly, the minimum shoot Mn concentrations required to maximize biomass production of Alamo and KGraze grown in the perlite system were only $54 \mathrm{mg} \mathrm{kg}^{-1}$ and $66 \mathrm{mg} \mathrm{kg}^{-1}$, respectively, less than a quarter of those reported to maximize biomass production in pearl millet seedlings. These results indicated that the optimum shoot Mn concentration for growth and biomass production are dependent on crop species, genotypes, growth stages and growth conditions.

Since these shoot $\mathrm{Mn}$ concentrations were sufficient to maximize Alamo and KGraze biomass production in the perlite experiment, the absence of a Mn response in the sand and vermiculite systems was not surprising as the lowest shoot Mn 
concentrations ( $0 \mu \mathrm{M}$ Mn treatment) of Alamo were $87 \mathrm{mg} \mathrm{kg}^{-1}$ and $75 \mathrm{mg} \mathrm{kg}^{-1}$ and those of Cave-in-Rock were $143 \mathrm{mg} \mathrm{kg}^{-1}$ and $58 \mathrm{mg} \mathrm{kg}^{-1}$, respectively. For many plants, the range for critical deficiency level of $\mathrm{Mn}$ is $10-20 \mathrm{mg} \mathrm{Mn} \mathrm{kg}^{-1}$ dry matter of mature leaves (Broadley et al., 2012). For warm-season turfgrasses, $25 \mathrm{mg} \mathrm{kg}^{-1}$ has been indicated as the critical level for tissue Mn concentration, and for the NAD-ME C4 bahiagrass (Paspalum notatum Flügge), $40 \mathrm{mg} \mathrm{Mn} \mathrm{kg}^{-1}$ is considered to be the critical level (Pessarakli, et al., 2007; NRC, 2000). Interestingly, the shoot Mn concentrations of Alamo, CIR and KGraze grown in the perlite system with $0 \mu \mathrm{mol}$ Mn nutrient solution were only 3.80, 2.89 and $3.64 \mathrm{mg} \mathrm{Mn} \mathrm{kg}^{-1}$ shoot dry weight (Table2-2). Therefore, all of these shoot Mn concentration were less than the critical deficiency levels reported in previous studies, and, in the case of Cave-in-Rock, still did not reduce biomass production compared to the other Mn treatments.

\subsection{Relative chlorophyll concentration}

Relative chlorophyll concentration was assessed with a SPAD meter, but did not reveal any Mn treatment effects in Alamo and Cave-in-Rock grown in the sand and vermiculite systems. Repeated SPAD meter readings over the course of the growing season revealed a contrasting response between the two switchgrass ecotypes and the pearl millet when grown in the perlite system. While not different at the beginning of the season, relative chlorophyll levels were lower in the $0 \mu \mathrm{M}$ Mn treatment in the two switchgrass ecotypes later in the season (Fig. 2-7; Appendix Table 2-7; Appendix Table 2-8). In contrast, in KGraze, relative chlorophyll levels were significantly lower in the 0 $\mu \mathrm{M} \mathrm{Mn}$ treatment than the remaining treatments throughout the season. Interestingly, 
relative chlorophyll levels increased over time in KGraze in all Mn treatments whereas chlorophyll levels were not as responsive in time in $\geq 2 \mu \mathrm{M}$ Mn treatments in switchgrass.

The low relative chlorophyll concentrations during early growth of KGraze in the $0 \mu \mathrm{M}$ Mn treatment were consistent with chlorosis that was observed in early stages, as was also reported by Kering et al. (2009). However, as the season progressed, visible symptoms disappeared and SPAD meter readings increased and reached values $>40$. These data suggest that pearl millet is particularly sensitive to Mn availability during early growth but is able to adapt to low Mn availability in later growth stages. Overall, these observations are in agreement with those of Kering et al. (2009) that early growth of pearl millet is sensitive to Mn availability.

In contrast, switchgrass relative chlorophyll concentrations were not impacted by low Mn availability during early growth, but lower SPAD meter readings in the latter half of the season indicate that $\mathrm{Mn}$ availability started to impact leaf physiology. Indeed, no visible Mn deficiency symptoms were observed in the switchgrass ecotypes grown in 0 $\mu \mathrm{mol}$ Mn treatment, but some lighter green young leaves were observed at late stages. These results suggest important differences in switchgrass and pearl millet physiology with respect to low Mn availability.

\subsection{Switchgrass might have a different response mechanism than pearl millet to low Mn availability}

While C4 plants have traditionally been grouped into NAD-ME, NADP-ME, and PEPCK subtypes, it is now clear that the different $\mathrm{C} 4$ photosynthetic pathways can coexist (Wang et al., 2014; Liu and Osborne, 2014; Sharwood et al., 2014; Rao et al., 2016). It should be noted, that the flexibility among the three subtypes might be 
controlled by environmental and developmental conditions (Sommer et al., 2012; Wang et al., 2014; Sharwood et al., 2014). Sharwood et al. (2014), found that flexible partitioning of $\mathrm{C} 4$ acid decarboxylation activity between NADP-ME and PEP-CK will take place when maize is exposed to salinity and shade. Cleome gynandra, a dicot crop, is known to perform NAD-ME type C4 photosynthesis, but both NAD-ME and PEPCK activity have been observed in older leaves (Sommer et al., 2012). Additionally, several C4 plants have been shown to conduct C3 photosynthesis along the leaf blade and at different leaf ages and positions and during seedling stage (Dai et al., 1995; Ghannoum et al., 1998). Dai et al. (1995) pointed out that younger, senescing, and lower position maize leaves were similar to $\mathrm{C} 3$ plants.

While categorized as an NAD-ME C4 plant, PEPCK activity has been observed in young switchgrass leaves (Rao et al., 2016), and NAD-ME, NADP-ME and PEPCK activities have been reported in switchgrass at different developmental stages (Prendergast et al., 1987; Rao et al., 2016). Thus, it is possible that switchgrass and pearl millet may be able to shift the emphasis among C4 pathways away from the NAD-ME requiring pathway when Mn availability is limited, and thus minimize impact on growth. Alternatively, although not consistent with previous literature that documented an absolute requirement of NAD-ME for Mn (Hatch and Kagawa, 1974), the possibility that Mn may be substituted by other nutrients, possibly Mg, may need to be reexamined.

Serious Mn deficiency was observed at the early stage of pearl millet growth, however, this response was less pronounced at the late stage. Similarly, pearl millet in photosynthesis and biomass production has a higher requirement for $\mathrm{Mn}$ at seedling stage. Since, NADP-ME and PEPCK pathways do no have an essential requirement for 
$\mathrm{Mn}$, the flexibility and co-existence in $\mathrm{C} 4$ photosynthetic pathways might be a possible tolerance mechanism of swtichgrass and pearl millet to low manganese availability.

\section{Conclusion}

Switchgrass and pearl millet growth responses to increasing levels of $\mathrm{Mn}$ availability in the nutrient solution were minimal. Even small amounts of $\mathrm{Mn}$ in the nutrient solution were sufficient to maximize biomass production. Switchgrass and pearl millet responses to low Mn availability differed during early growth, suggesting that the two species may have different tolerance mechanisms to low Mn availability.

\section{References}

Amao, Y., and Ohashi, A. 2008. Effect of Mn ion on the visible light induced water oxidation activity of photosynthetic organ grana from spinach. Catalysis Communications, 10(2), 217-220.

Anderson, B., and Matches, A. G. 1983. Forage Yield, Quality, and Persistence of Switchgrass and Caucasian Bluestem 1. Agronomy Journal, 75(1), 119-124.

Anderson, B., Ward, J. K., Vogel, K. P., Ward, M. G., Gorz, H. J., and Haskins, F. A. 1988. Forage quality and performance of yearlings grazing switchgrass strains selected for differing digestibility. Journal of Animal Science, 66(9), 2239-2244.

Anderson, B.E. 2000. Use of warm-season grasses by grazing livestock. In: Nativ. warmseason grasses Res. trends issues, $147-157$.

Balasko, J. A., Burner, D. M., and Thayne, W. V. 1984. Yield and quality of switchgrass grown without soil amendments. Agronomy Journal, 76(2), 204-208.

Bardhan, S., Chattopadhyay, A. K., Jose, S., and Chandrasoma, J. 2017. Impact of boron additions in marginal soils for growth of corn, wheat, soybean, and switchgrass. Agricultural Sciences, 7,155-159.

Berger, K. C. 1962. Micronutrient shortages, micronutrient deficiencies in the United States. Journal of Agricultural and Food Chemistry, 10(3), 178-181. 
Broadley, M., Brown, P., Cakmak, I., Ma, J. F., Rengel, Z., and Zhao, F. 2012. Beneficial elements. In Marschner's mineral nutrition of higher plants (pp. 191-248). Academic Press.

Burnell, J. N. 1986. Purification and properties of phosphoenolpyruvate carboxykinase from C4 plants. Functional Plant Biology, 13(5), 577-587.

Burns, J. C., and Sollenberger, L. E. 2002. Grazing behavior of ruminants and daily performance from warm-season grasses. Crop Science, 42(3), 873-881.

Chen, Z. H., Walker, R. P., Acheson, R. M., and Leegood, R. C. 2002. Phosphoenolpyruvate carboxykinase assayed at physiological concentrations of metal ions has a high affinity for CO2. Plant Physiology, 128(1), 160-164.

Dai, Z., Ku, M.S.B. Edwards, G. B. 1995 C4 photosynthesis. The effects of leaf development on the CO2-concentrating mechanism and photorespiration in maize. - Plant Physiol. 107: 815-825.

Dever, L. V., Pearson, M., Ireland, R. J., Leegood, R. C., and Lea, P. J. 1998. The isolation and characterisation of a mutant of the $\mathrm{C} 4$ plant Amaranthus edulis deficient in NAD-malic enzyme activity. Planta, 206(4), 649-656.

Fike, J. H., Parrish, D. J., Alwang, J., and Cundiff, J. S. 2007. Challenges for deploying dedicated, large-scale, bioenergy systems in the USA. CAB Reviews, 2(064), 128.

Ghannoum, O., Siebke, K., von Caemmerer, S., Conroy, J.P. 1998. The photosynthesis of young Panicum C4 leaves is not C3-like. - Plant Cell Environ. 21, 1123-1131.

Goussias, C., Boussac, A., and Rutherford, A. W. 2002. Photosystem II and photosynthetic oxidation of water: an overview. Philosophical Transactions of the Royal Society of London B: Biological Sciences, 357(1426), 1369-1381.

Guretzky, J. A., Biermacher, J. T., Cook, B. J., Kering, M. K., and Mosali, J. 2011. Switchgrass for forage and bioenergy: harvest and nitrogen rate effects on biomass yields and nutrient composition. Plant and Soil, 339(1-2), 69-81.

Hannaway, D. B., and Larson, C. 2004. Forage fact sheet: pearl millet (Pennisetum americanum). Corvallis: Oregon State University.

Hatch, M. D., and Kagawa, T. 1974. Activity, location and role of NAD malic enzyme in leaves with C4-pathway photosynthesis. Functional Plant Biology, 1(3), 357-369.

Hebbern, C. A., Pedas, P., Schjoerring, J. K., Knudsen, L., and Husted, S. 2005. Genotypic differences in manganese efficiency: field experiments with winter barley (Hordeum vulgare L.). Plant and Soil, 272(1-2), 233-244.

Hull, R. J. 2001. Manganese usage by turfgrasses. TurfGrass Trends, 10(9), 6-13.

Jung, G. A., Gross, C. F., Kocher, R. E., Burdett, L. R., and Sharp, W. C. 1978. Warmseason range grasses extend beef cattle forage [Grazing management]. Science in Agriculture 25: 6 
Jones, Jr., J.R. 1980. Turf analysis. Golf Course Management. 48(1):29-32.

Kering, M. K., Butler, T. J., Biermacher, J. T., Mosali, J., and Guretzky, J. A. 2013. Effect of potassium and nitrogen fertilizer on switchgrass productivity and nutrient removal rates under two harvest systems on a low potassium soil. Bioenergy Research, 6(1), 329-335.

Kering, M. K., Lukaszewska, K., and Blevins, D. G. 2009. Manganese requirement for optimum photosynthesis and growth in NAD-malic enzyme C-4 species. Plant and Soil, 316(1-2), 217-226.

Lee, S. T., Stegelmeier, B. L., Gardner, D. R., and Vogel, K. P. 2001. Main content area The isolation and identification of steroidal sapogenins in switchgrass. Journal of natural toxins, 10(4), 273-281.

Lemus, R., Brummer, E. C., Burras, C. L., Moore, K. J., Barker, M. F., and Molstad, N. E. 2008. Effects of nitrogen fertilization on biomass yield and quality in large fields of established switchgrass in southern Iowa, USA. Biomass and Bioenergy, 32(12), 1187-1194.

Leplat, F. 2015. Identification of manganese use efficiency candidate genes in winter barley (Hordeum vulgare): GWAS on Chlorophyll a Fluorescence and ICP-OES. In Plant and Animal Genome XXIII Conference. Plant and Animal Genome.

Leplat, F., Jensen, J., and Madsen, P. 2016. Genomic Prediction of Manganese Efficiency in Winter Barley. The plant genome, 9(2).

Lidon, F. C., and Teixeira, M. G. 2000. Oxyradicals production and control in the chloroplast of Mn-treated rice. Plant Science, 152(1), 7-15.

Liu, H., and Osborne, C. P. 2014. Water relations traits of C4 grasses depend on phylogenetic lineage, photosynthetic pathway, and habitat water availability. Journal of experimental botany, 66(3), 761-773.

Marshner, H. 1995: Mineral nutrition of higher plants. Academic press, London

McLaughlin, M. R., Fairbrother, T. E., and Rowe, D. E. 2004. Forage yield and nutrient uptake of warm-season annual grasses in a swine effluent spray field. Agronomy journal, 96(6), 1516-1522.

McLaughlin, S. B., and Kszos, L. A. 2005. Development of switchgrass (Panicum virgatum) as a bioenergy feedstock in the United States. Biomass and Bioenergy, 28(6), 515-535.

McLaughlin, S., Bouton, J., Bransby, D., Conger, B., Ocumpaugh, W., Parrish, D., and Wullschleger, S. 1999. Developing switchgrass as a bioenergy crop. Perspectives on new crops and new uses, 56, 282-299.

Millaleo, R., Reyes-Díaz, M., Ivanov, A. G., Mora, M. L., and Alberdi, M. 2010. Manganese as essential and toxic element for plants: transport, accumulation and resistance mechanisms. Journal of soil science and plant nutrition, 10(4), 470-481. 
Moore, K. J., White, T. A., Hintz, R. L., Patrick, P. K., and Brummer, E. C. 2004. Sequential grazing of cool-and warm-season pastures. Agronomy Journal, 96(4), 1103-1111.

Muir, J. P., Sanderson, M. A., Ocumpaugh, W. R., Jones, R. M., and Reed, R. L. 2001. Biomass production of 'Alamo'switchgrass in response to nitrogen, phosphorus, and row spacing. Agronomy Journal, 93(4), 896-901.

Nickelsen, J., and Rengstl, B. 2013. Photosystem II assembly: from cyanobacteria to plants. Annual review of plant biology, 64, 609-635.

National Research Council (NRC). 2000. Nutrient requirements of beef cattle, 7th ed. Washington, D.C.: National Academy Press.

Parrish, D. J., and Fike, J. H. 2005. The biology and agronomy of switchgrass for biofuels. BPTS, 24(5-6), 423-459.

Parrish, D. J., Fike, J. H., Bransby, D. I., and Samson, R. 2008. Establishing and managing switchgrass as an energy crop. Forage and Grazinglands, doi: 10.1094. FG-2008-0220-01-RV.

Prendergast, H. D. V., Hattersley, P. W., and Stone, N. E. 1987. New structural/biochemical associations in leaf blades of $\mathrm{C} 4$ grasses (Poaceae). Functional Plant Biology, 14(4), 403-420.

Pessarakli, M. (Ed.). 2007. Handbook of turfgrass management and physiology. CRC press. 211

Pfeffer, P. E., Tu, S. I., Gerasimowicz, W. V., and Cavanaugh, J. R. 1986. In vivo31P NMR studies of corn root tissue and its uptake of toxic metals. Plant Physiology, 80(1), 77-84

Rao, X., Lu, N., Li, G., Nakashima, J., Tang, Y., and Dixon, R. A. 2016. Comparative cell-specific transcriptomics reveals differentiation of $\mathrm{C} 4$ photosynthesis pathways in switchgrass and other $\mathrm{C} 4$ lineages. Journal of experimental botany, 67(6), 1649-1662.

Reuter, D. J., Cartwright, B., Judson, G. J., McFarlane, J. D., Maschmedt, D. J., and Robinson, J. B. 1988. Trace elements in South Australian agriculture. Department of Agriculture South Australia Technical Report, 139.

Sanderson, M. A., Adler, P. R., Boateng, A. A., Casler, M. D., and Sarath, G. 2006. Switchgrass as a biofuels feedstock in the USA. Canadian Journal of Plant Science, 86(5), 1315.

Sanderson, M. A., Moore, K. J., and Anderson, B. E. 2000. Cutting management of native warm-season perennial grasses: morphological and physiological responses. In Native warm-season grasses: research trends and issues. Proceedings of the Native Warm-Season Grass Conference and Expo, Des Moines, IA, USA, 12-13 September 1996. 133-146. Crop Science Society of America. 
Sharwood, R. E., Sonawane, B. V., and Ghannoum, O. 2014. Photosynthetic flexibility in maize exposed to salinity and shade. Journal of experimental botany, 65(13), 3715-3724.

Sims, R. E., Hastings, A., Schlamadinger, B., Taylor, G., and Smith, P. 2006. Energy crops: current status and future prospects. Global Change Biology, 12(11), 20542076.

Sommer, M., Bräutigam, A., and Weber, A. P. M. 2012. The dicotyledonous NAD malic enzyme C4 plant Cleome gynandra displays age dependent plasticity of C4 decarboxylation biochemistry. Plant Biology, 14(4), 621-629.

Thomason, W. E., Raun, W. R., Johnson, G. V., Taliaferro, C. M., Freeman, K. W., Wynn, K. J., and Mullen, R. W. 2005. Switchgrass response to harvest frequency and time and rate of applied nitrogen. Journal of Plant Nutrition, 27(7), 11991226.

Thomson, A. M., Izarrualde, R. C., West, T. O., Parrish, D. J., Tyler, D. D., and Williams, J. R. 2009. Simulating potential switchgrass production in the United States. Pacific Northwest National Laboratory, Richland, WA.

Vogel, K. P., Brejda, J. J., Walters, D. T., and Buxton, D. R. 2002. Switchgrass biomass production in the Midwest USA. Agronomy Journal, 94(3), 413-420.

Wang, Y., Bräutigam, A., Weber, A. P., and Zhu, X. G. 2014. Three distinct biochemical subtypes of $\mathrm{C} 4$ photosynthesis? A modelling analysis. Journal of experimental botany, 65: 3567-3578.

Wilkinson, R. E., and Ohki, K. 1988. Influence of manganese deficiency and toxicity on isoprenoid syntheses. Plant physiology, 87(4), 841-846.

Yang, X. E., Chen, W. R., and Feng, Y. 2007. Improving human micronutrient nutrition through biofortification in the soil-plant system: China as a case study. Environmental Geochemistry and Health, 29(5), 413-428. 


\section{Table and figures}

Table 2-1. Chemical composition of growth media used for experiments conducted in 2014, 2015, and 2016.

\begin{tabular}{|c|c|c|c|c|c|c|c|c|c|c|c|}
\hline \multirow{2}{*}{ Years } & \multirow{2}{*}{$\begin{array}{c}\text { System } \\
\text { materials }\end{array}$} & \multirow{2}{*}{$\mathrm{pH}$} & \multicolumn{9}{|c|}{ Nutrient concentration } \\
\hline & & & $\mathrm{P}$ & $\mathrm{K}$ & $\mathrm{Ca}$ & $\mathrm{Mg}$ & $\mathrm{Na}$ & $\mathrm{Zn}$ & $\mathrm{Fe}$ & $\mathrm{Mn}$ & $\mathrm{Cu}$ \\
\hline \multirow[b]{2}{*}{2014} & & & \multicolumn{9}{|c|}{ ppm } \\
\hline & Sand & 7.540 & 6.600 & 18.200 & 333.250 & 31.600 & 5.430 & 0.100 & 7.500 & 2.590 & 0.101 \\
\hline 2015 & Vermiculite & 7.696 & 0.190 & 14.778 & 2.038 & 4.459 & --- & 0.006 & 0.874 & 0.017 & 0.008 \\
\hline \multirow{3}{*}{2016} & Perlite & 7.575 & 0.020 & 0.725 & 1.610 & 0.229 & --- & 0.001 & 0.055 & 0.008 & 0.004 \\
\hline & Rain & 6.450 & 0.220 & 1.303 & 5.422 & 0.794 & 0.382 & 0.008 & 0.005 & 0.010 & 0.006 \\
\hline & DI water & 6.280 & 0.021 & 0.099 & 0.651 & 0.057 & 0.332 & 0.240 & 0.002 & 0.001 & 0.025 \\
\hline
\end{tabular}




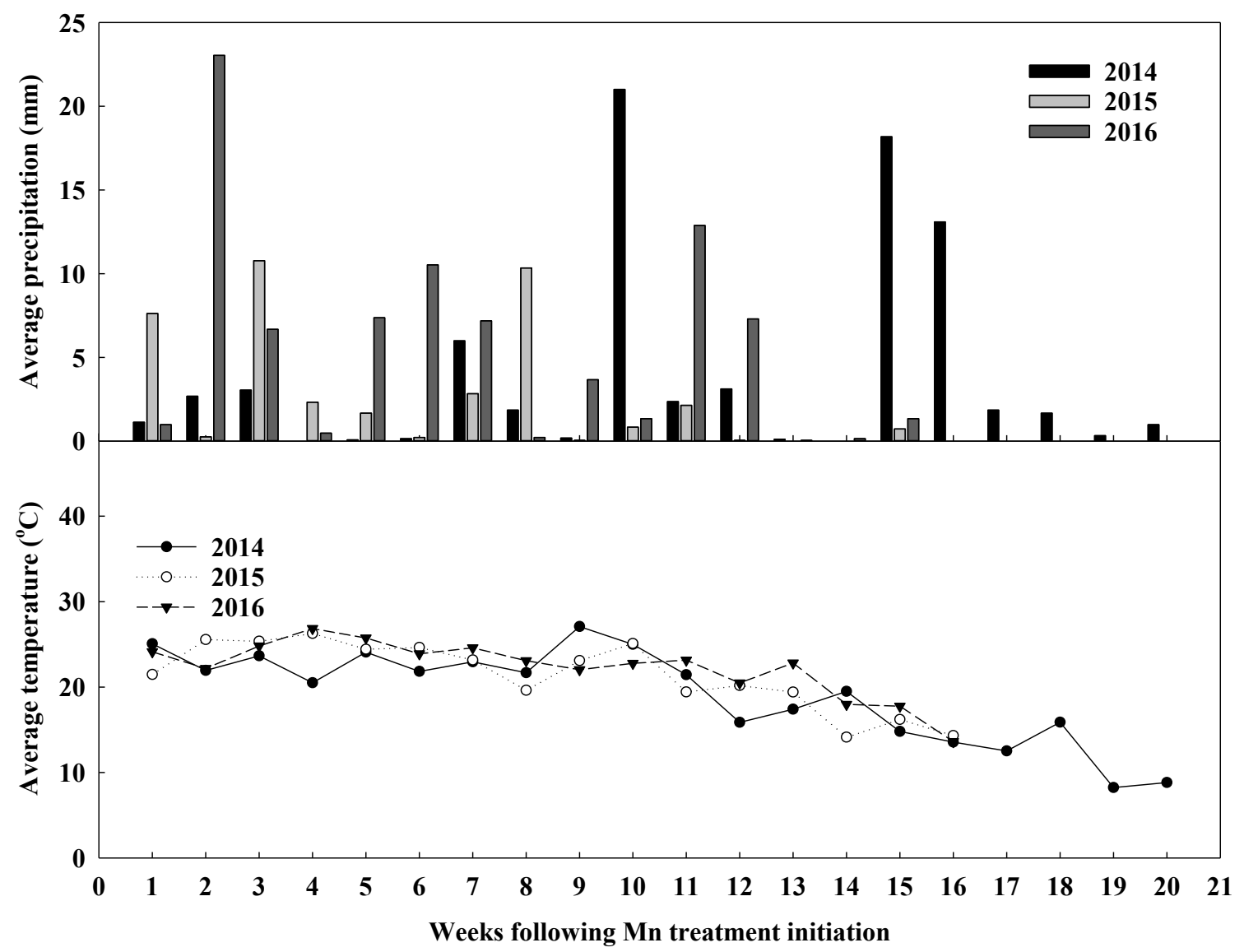

Figure 2-1. Average weekly precipitation and average weekly temperatures for 2014, 2015, and 2016 at the Bradford Research Center. 


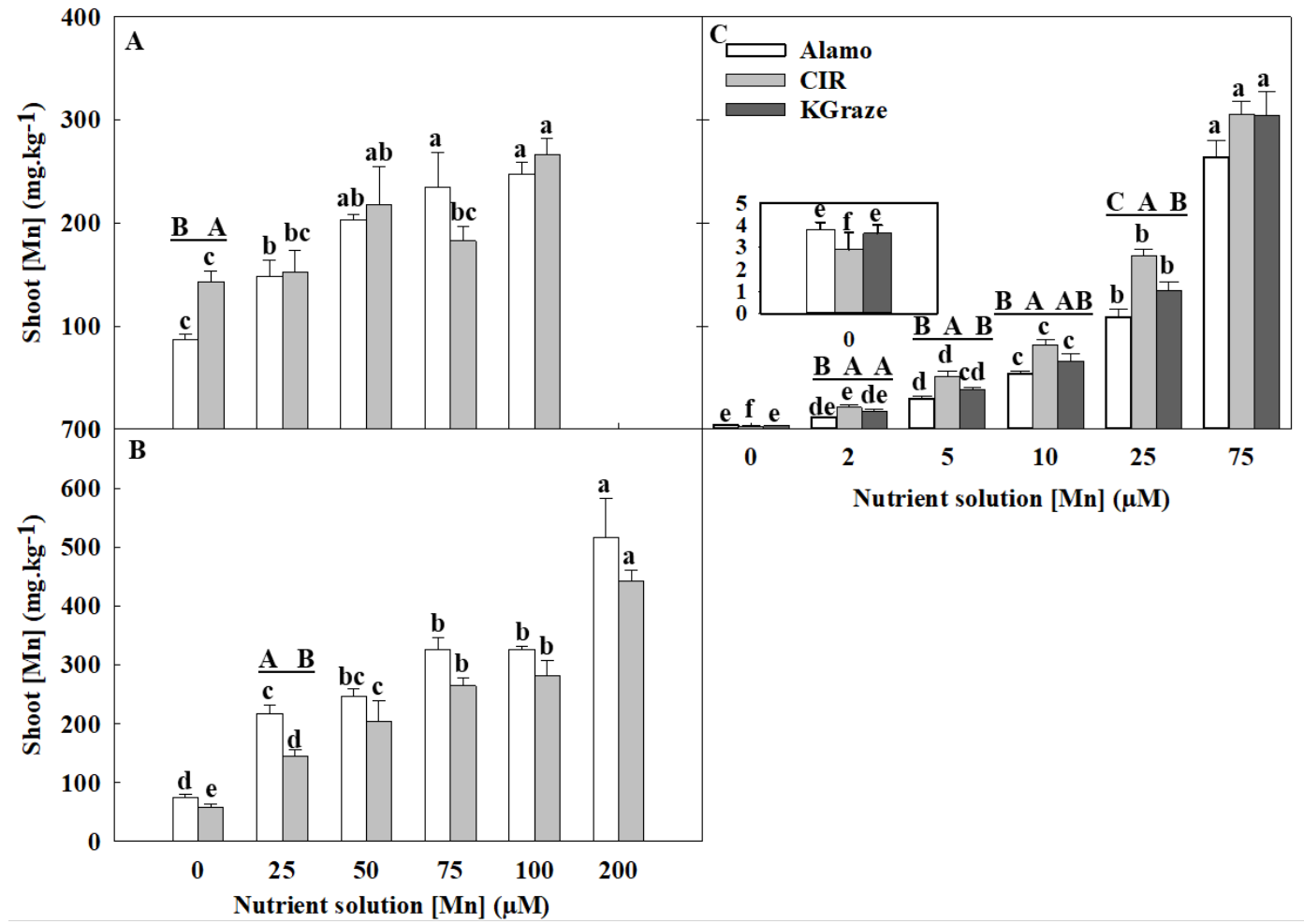

Figure 2-2. Shoot Mn concentrations of two switchgrass genotypes, Alamo and Cave-inRock (CIR), and the pearl millet genotype KGraze. The two switchgrass genotypes were grown in sand and vermiculite, in 2014 (A), 2015 (B), respectively, and in 2016 (C), all three entries were grown in perlite. The insert in panel $\mathrm{C}$ shows shoot $\mathrm{Mn}$ concentration in the treatment with no Mn addition. Values are means \pm se ( $n=5$ in 2014 and 2015; n=6 in 2016). Different lower-case letters above the columns indicate significant differences between Mn treatments within genotype, while different upper-case letters represent differences among genotypes $(\mathrm{p}<0.05)$. 


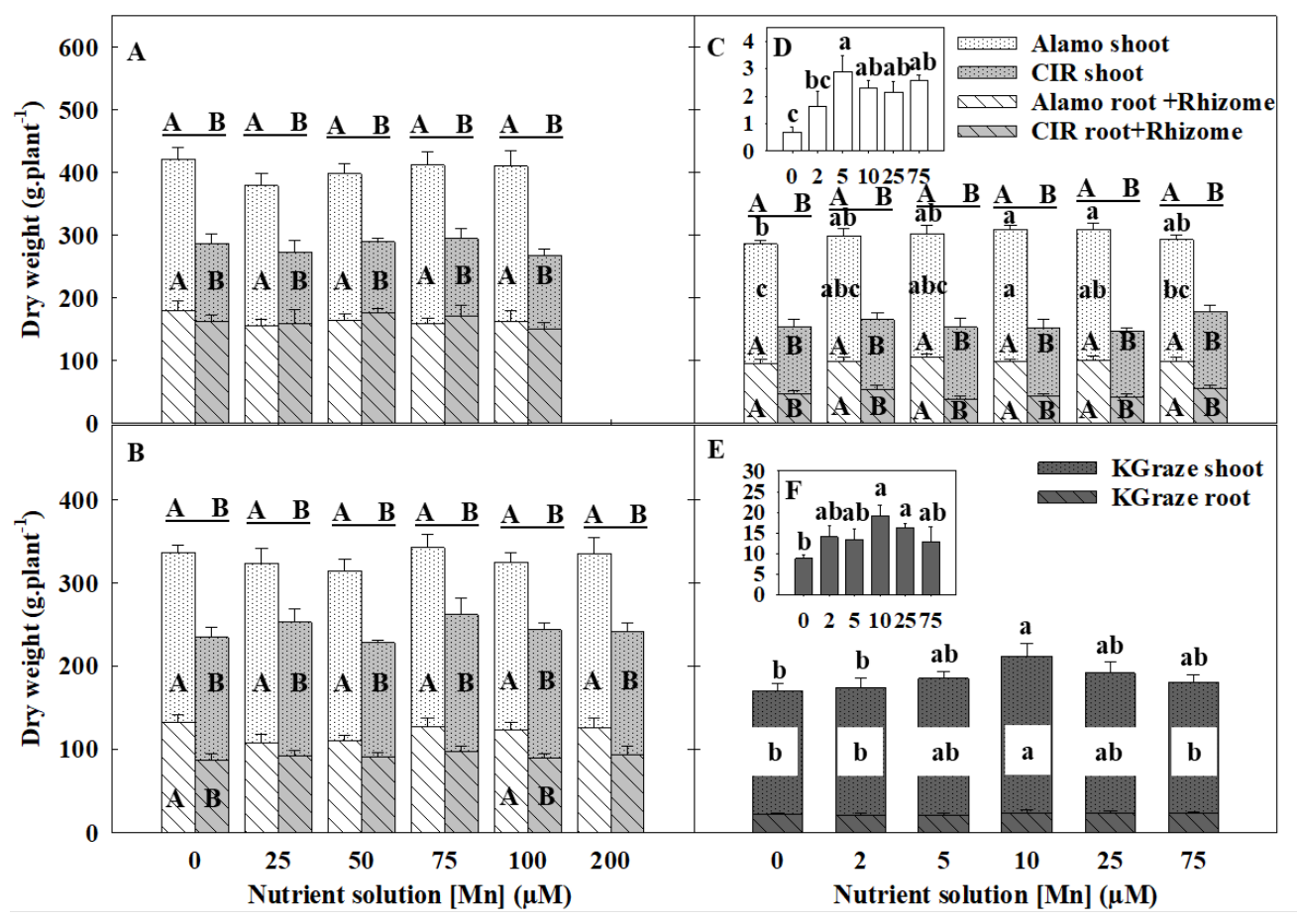

Figure 2-3. Total biomass and biomass fractions of two switchgrass genotypes, Alamo and Cave-in-Rock (CIR), and the pearl millet genotype KGraze. The two switchgrass genotypes were grown in sand and vermiculite, in 2014 (A), 2015 (B), respectively, and in 2016 (C - F), the three entries were grown in perlite. D: Rhizome dry weight of Alamo. F: Seed dry weight of KGraze. Values are means \pm se ( $n=5$ in 2014 and 2015; n=6 in 2016). Different lower-case letters above the columns indicate significant differences in total biomass (switchgrass: root + rhizome + shoot; pearl millet: root + shoot). And lower-case letters within columns indicate differences within shoot, rhizome and seed dry weights between $\mathrm{Mn}$ treatments within entry $(\mathrm{P}<0.05)$. Upper-case letters represent differences among genotypes $(\mathrm{p}<0.05)$. 


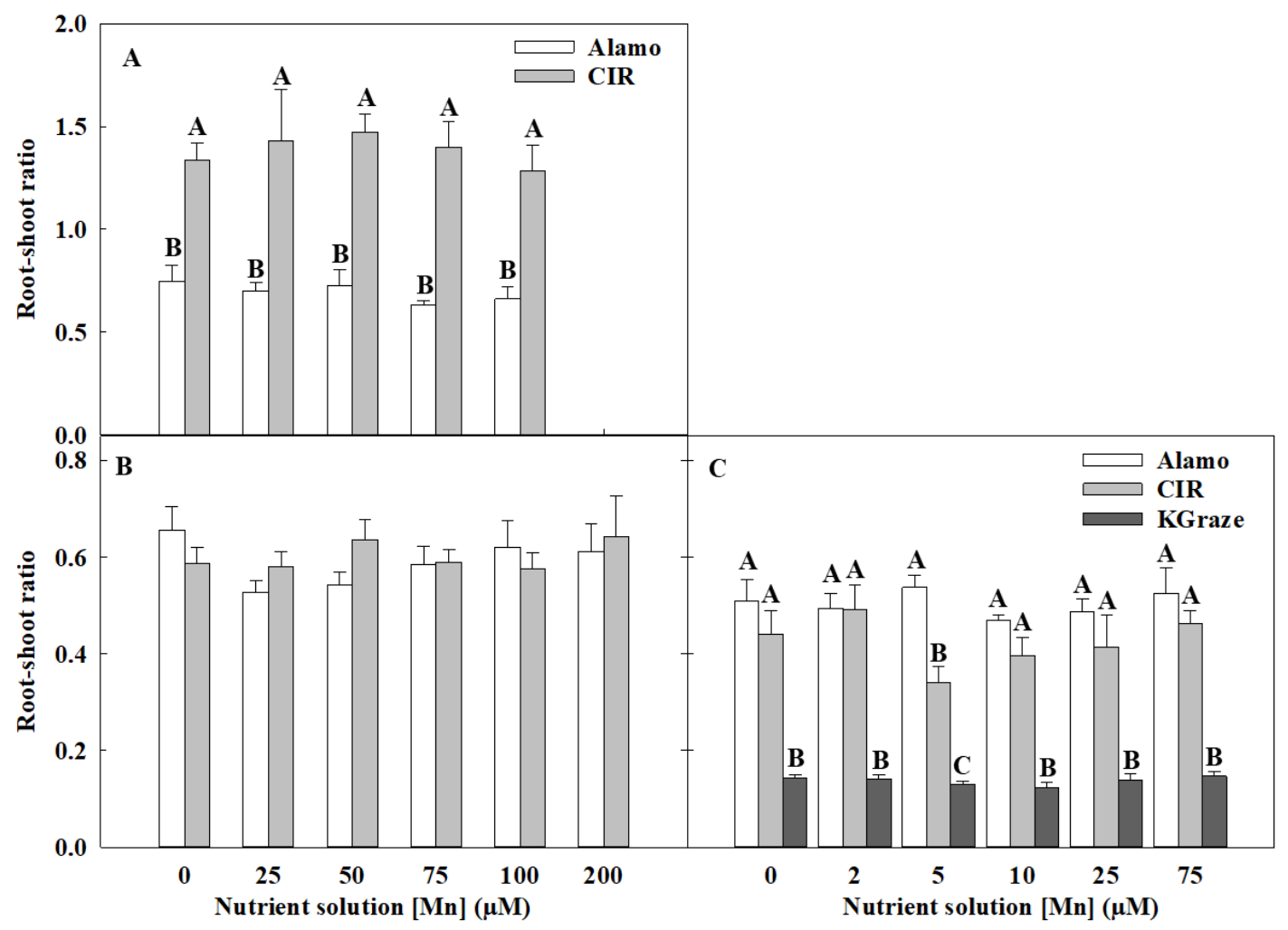

Figure 2-4. Root-shoot ratios of two switchgrass genotypes, Alamo and Cave-in-Rock (CIR), and the pearl millet genotype KGraze. The two switchgrass genotypes were grown in sand and vermiculite, in 2014 (A), 2015 (B), respectively, and in 2016 (C), all three entries were grown in perlite. Values are means \pm se $(n=5$ in 2014 and 2015; n=6 in 2016). Different upper-case letters above the columns indicate significant differences between genotypes or species $(p<0.05)$ No differences between Mn treatments within entry were found at $\mathrm{P}<0.05$. 


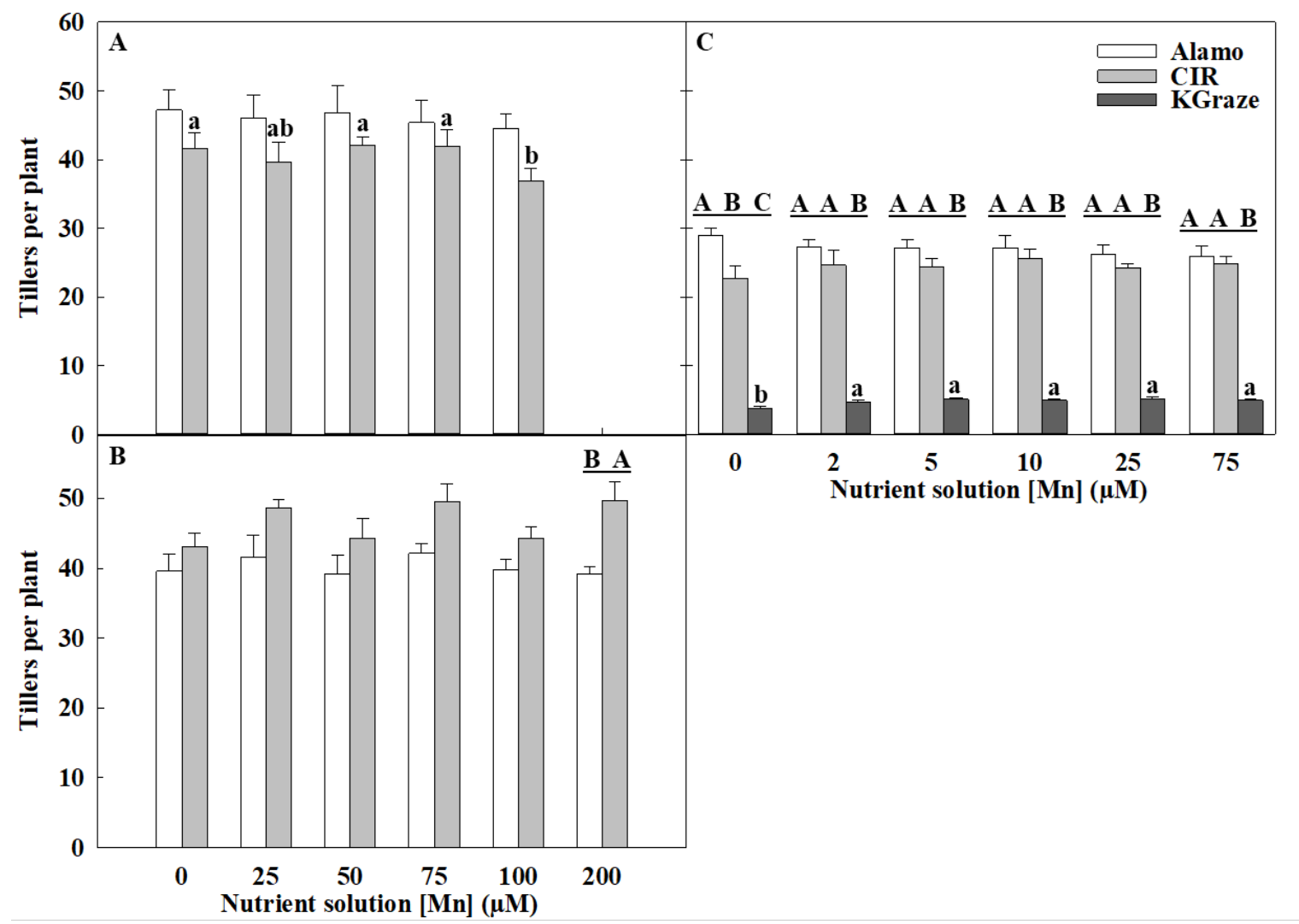

Figure 2-5. Number of tillers per plant for two switchgrass genotypes, Alamo and Cavein-Rock (CIR), and the pearl millet genotype KGraze. The two switchgrass genotypes were grown in sand and vermiculite, in 2014 (A), 2015 (B), respectively, and in 2016 (C), all three entries were grown in perlite. Values are means \pm se ( $n=5$ in 2014 and 2015; n=6 in 2016). Different lower-case letters above the columns indicate significant differences between Mn treatments within genotype, while different upper-case letters represent differences between genotypes or species $(p<0.05)$. 


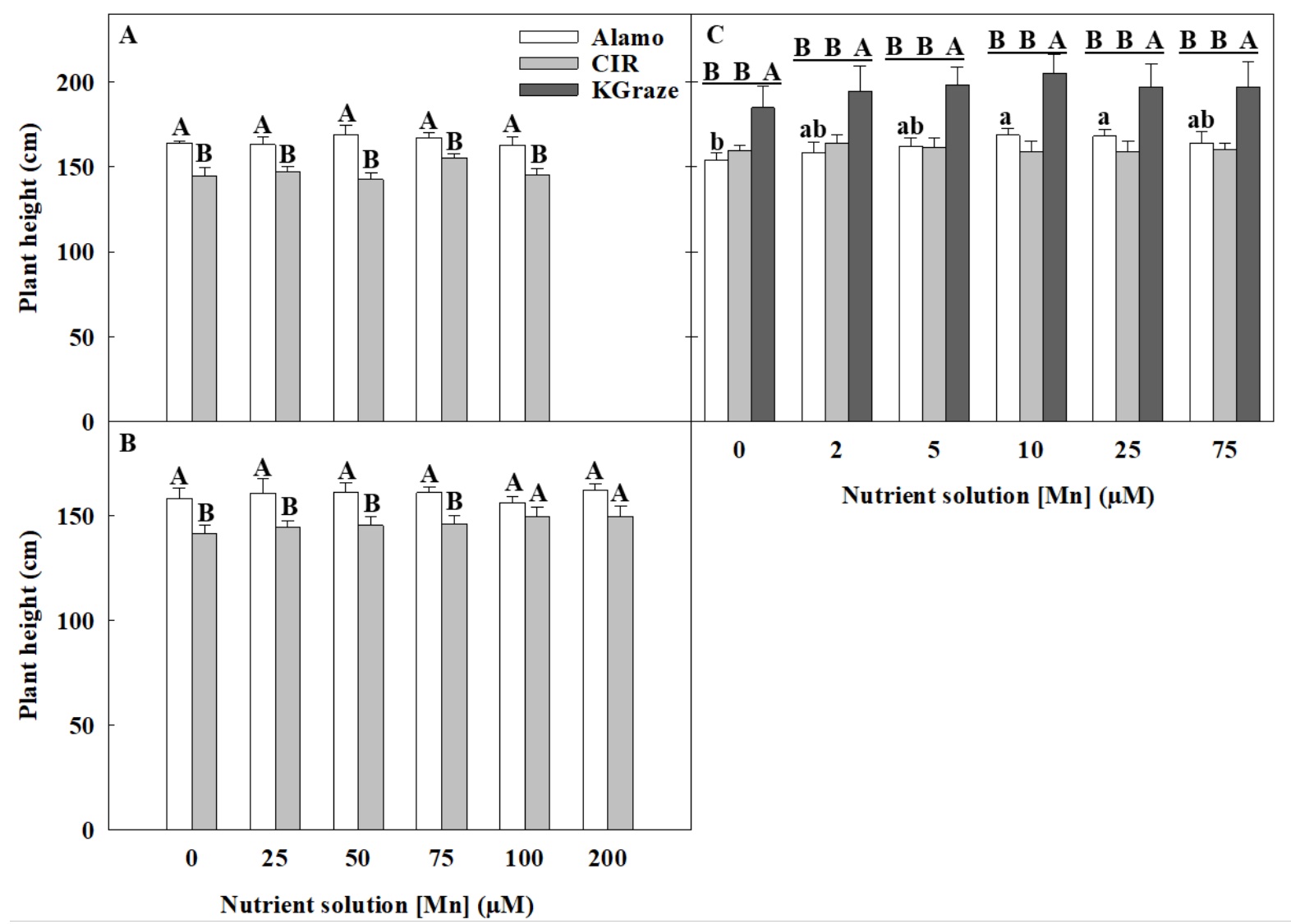

Figure 2-6. Plant height for two switchgrass genotypes, Alamo and Cave-in-Rock (CIR), and the pearl millet genotype KGraze. The two switchgrass genotypes were grown in sand and vermiculite, in 2014 (A), 2015 (B), respectively, and in 2016 (C), all three entries were grown in perlite. Values are means \pm se $(n=5$ in 2014 and 2015; n=6 in 2016). Different lower-case letters above the columns indicate significant differences between $\mathrm{Mn}$ treatments within genotype. Different upper-case letters represent differences between genotypes or species $(\mathrm{p}<0.05)$. 

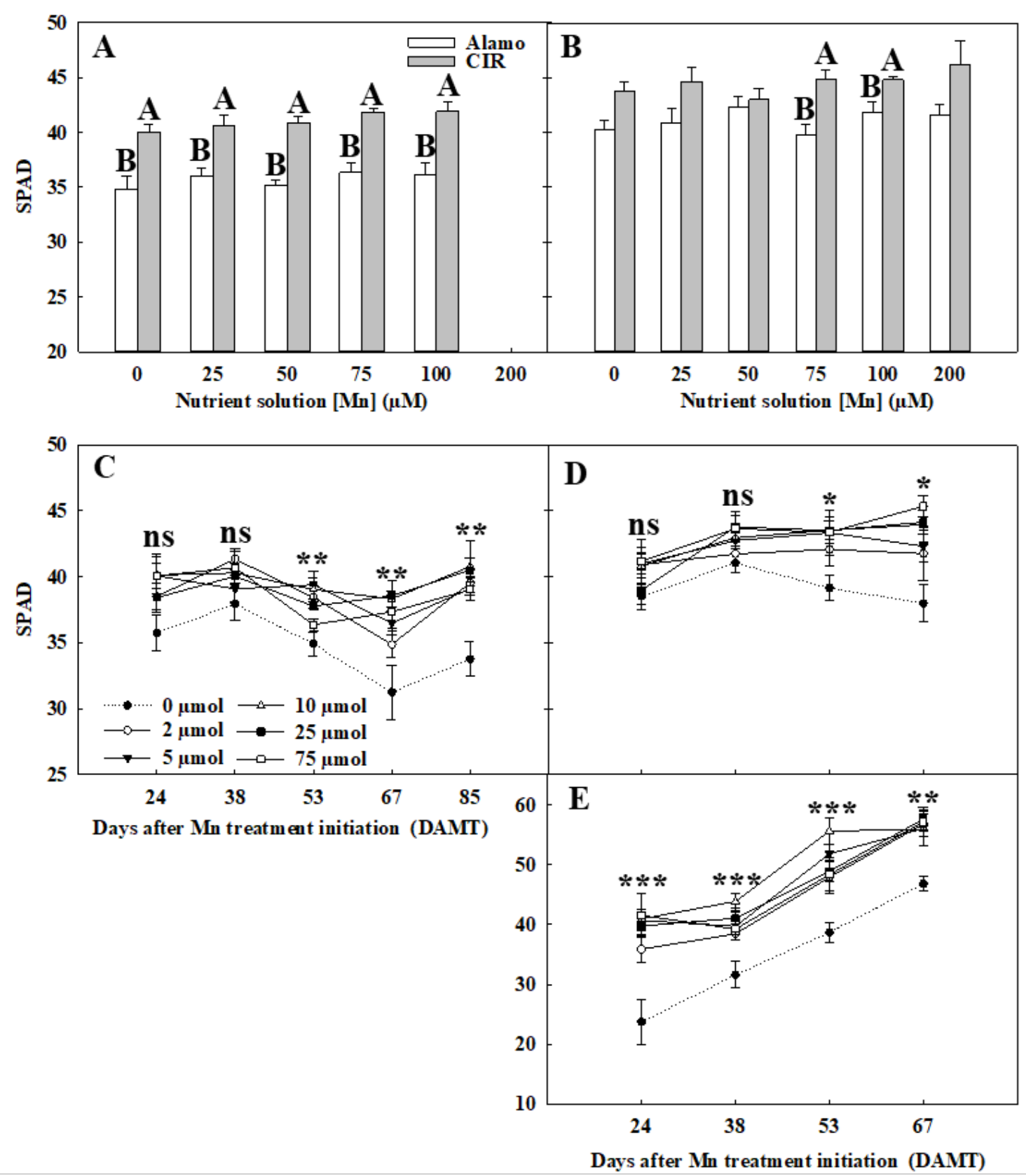

Figure 2-7. SPAD-502 chlorophyll meter reading of leaves for two switchgrass genotypes, Alamo and Cave-in-Rock (CIR), and the pearl millet genotype KGraze. The two switchgrass genotypes were grown in sand and vermiculite, in 2014 (A), 2015 (B), respectively, and in 2016 (C-E), all three entries were grown in perlite. C: Alamo, D: CIR, E: KGraze. Values are means \pm se ( $n=5$ in 2014 and 2015; $n=6$ in 2016). Different upper-case letters represent differences between genotypes at $\mathrm{p}<0.05$. ${ }^{*} \mathrm{P}<0.05 ;{ }^{* *} \mathrm{P}<$ $0.01, * * * \mathrm{P}<0.001 ;$ ns, not significant. 


\section{CHAPTER 3}

Influence of manganese availability on photosynthesis-related characteristics in switchgrass and pearl millet 


\begin{abstract}
Manganese $(\mathrm{Mn})$ plays a crucial role in NAD-ME $\mathrm{C}_{4}$ photosynthesis, including as an activator of the nicotinamide adenine dinucleotide -malic enzyme (NAD-ME), which is the primary decarboxylation enzyme in bundle sheath cells of NAD-ME C4 plants. The objective of this study were to examine photosynthetic characteristics of a lowland and an upland switchgrass (Panicum virgatum L.) ecotype and of pearl millet (Pennisetum glaucum L. R. Br.), two NAD-ME $\mathrm{C}_{4}$ species, to Mn availability. Leaf Mn concentration of all entries increased with increasing $\mathrm{Mn}$ concentration in the nutrient solution. In switchgrass, leaf Mn concentration was significantly greater early than late in the season in the absence of $\mathrm{Mn}$ in the nutrient solution; however, this was not the case for pearl millet. In switchgrass, lower photosynthetic rates and maximum PSII efficiency $\left(\mathrm{F}_{\mathrm{v}} / \mathrm{F}_{\mathrm{m}}\right)$ were observed late in the season in the absence of $\mathrm{Mn}$ in the nutrient solution. In contrast, absence of $\mathrm{Mn}$ in the nutrient solution had a more pronounced effect on pearl millet net photosynthesis and $\mathrm{F}_{\mathrm{v}} / \mathrm{F}_{\mathrm{m}}$ early in the season. Chloroplast ultrastructure in mesophyll, and bundle sheath cells only was affected by Mn availability in the lowland switchgrass ecotype 'Alamo'. Manganese availability did not influence NAD-ME, NADP-ME and PEPCK activities in switchgrass, but NAD-ME and PEPCK activities were reduced in pearl millet early in the season in the absence of $\mathrm{Mn}$ in the nutrient solution. Based on these results, the primary limitation of low Mn availability on net photosynthesis appears to be due to Mn limitation for the oxygen evolving compex of PSII. Overall, switchgrass and pearl millet exhibited distinct temporal responses to limited Mn availabillity.
\end{abstract}




\section{Introduction}

As an essential micronutrient, manganese $(\mathrm{Mn})$ is involved in diverse plant functions, including in redox processes and enzyme activation. Manganese plays critical roles in NAD-ME C4 photosynthesis including as a component of the oxygen-evolving complex (OEC) in photosystem II (PSII) and as an activator of the NAD malic enzyme (NAD-ME) that catalizes the release of $\mathrm{CO}_{2}$ from malate in mitochondria of the bundle sheath cells (BSC).

The role of Mn in PSII, in which a four Mn-cluster coordinates with the OEC to perform the water-splitting reaction (Nickelsen and Rengstl, 2013) is a priority and $\mathrm{Mn}$ is irreplaceable (Burnell, 1988). Therefore, Mn deficiency affects the OEC of PSII and in turn the entire photosynthetic light reactions. This Mn function in PSII has been exploited to diagnose Mn efficiency and deficiency by measuring the parameters of chlorophyll a (Chla) fluorescence in winter barley (Hordeum vulgare) (Hebbern et al., 2005; Husted et al., 2009; Schmidt et al., 2013). Previous studies demonstrated that Mn deficiency can significantly decrease maximum PSII efficiency $\left(\mathrm{F}_{\mathrm{v}} / \mathrm{F}_{\mathrm{m}}\right)$, which is a Chl a fluorescence associated parameter (Schmidt et al., 2013). Indeed, measurements of $F_{v} / F_{m}$ have been considered as a relatively simple and non-destructive tool to diagnose Mn deficiency in winter barley and other plants (Hebbern et al., 2005; Husted and et al., 2009; Leplat et al., 2016).

Leaves of $\mathrm{C} 4$ plants are characterized by Kranz-type anatomy, in which the vascular bundle is surrounded by organelle-rich BSC, and this tissue layer is further surrounded by radially arranged mesophyll cells (MC). This Kranz anatomy is associated with different steps in $\mathrm{C} 4$ photosynthesis that occur in $\mathrm{MC}$ and $\mathrm{BSC}$. Initially, 
phosphoenolpyruvate carboxylase (PEPC) catalyzes the addition of bicarbonate $\left(\mathrm{HCO}_{3}^{-}\right)$ to phosphoenolpyruvate (PEP) to generate the four-carbon organic acid oxaloacetate in MC. Depending on the C4 pathway, oxaloacetate is converted into malate or aspartate which then diffuses into the $\mathrm{BSC}$ via plasmodesmata. In $\mathrm{BSC}$, the $\mathrm{C} 4$ acids are decarboxylated by either NAD-ME, NADP-malic enzyme (NADP-ME) or phosphoenolpyruvate carboxykinase (PEP-CK) to release $\mathrm{CO}_{2}$ for fixation by Rubisco. Therefore, $\mathrm{C} 4$ plants are grouped into three $\mathrm{C} 4$ subtypes based on the process of decarboxylation of C4 acids: NAD-ME, NADP-ME and PEP-CK types (Hatch, 1987). NAD-ME has an absolute $\mathrm{Mn}$ requirement to catalyze the $\mathrm{CO}_{2}$ release reaction, which is the main source of $\mathrm{CO}_{2}$ for Calvin cycle reactions in chloroplast bundle sheath cells in NAD-ME C4 plants (Dever et al., 1998). Therefore, Mn availability may be particularly important for photosynthesis, growth and biomass production of NAD-ME plants.

Switchgrass (Panicum virgatum L.) is a warm season perennial NAD-ME C4 grass identified as a promising species for lignocellulosic biofuel feedstock production (McLaughlin and Kszos 2005). Switchgrass is classified into two phenotypically distinct ecotypes: lowland and upland (Lu et al., 1998). Based on gene ontology (GO) analysis of the transcriptome, lowland ecotypes have significantly higher representation for cellular components associated with the photosynthestic machinery controlling carbon fixation than upland ecotypes (Serba et al., 2016). Despite the importance of Mn in NAD-ME C4 photosynthesis type plants, very little is known about Mn nutrition of switchgrass. Previous research only focused on Mn uptake by switchgrass and switchgrass response to Mn toxicity in acid soil (Wright et al., 1988; Clark, 2002). Accordingly, given Mn functions in NAD-ME C4 photosynthesis, the promise of switchgrass for biofuel 
feedstock production, and the inadequate information available on Mn nutrition of switchgrass, studies of switchgrass responses to Mn availability are needed.

Interestingly, our assessment of the response to increasing Mn availability on biomass production only revealed a minimal response in both, a lowland and an upland switchgrass ecotype (Chapter 2), and indicated that switchgrass may be more tolerant to low Mn availability than suggested based on the performance of pearl millet (Pennisetum glaucum) and purple amaranth (Amaranthus hypochondriacus), two other NAD-ME C4 species (Kering et al., 2009). To investigate the tolerance of switchgrass and pearl millet to low manganese availability, leaf physiological, anatomical, biochemical, and molecular responses were investigated in upland and lowland switchgrass ecotypes and in a pearl millet cultivar.

\section{Materials and methods}

\subsection{Plant material and growth conditions}

Pot experiments were carried out as described in Chapter 2. Briefly, two switchgrass genotypes, 'Alamo', a lowland ecotype, and 'Cave-in-Rock', an upland ecotype, and a pearl millet cultivar 'KGraze' were grown in $19 \mathrm{~L}$ pots and fertigated with nutrient solutions containing different Mn concentrations. Switchgrass ecotypes were grown in experiments conducted in 2014, 2015, and 2016 in pots filled with washed sand, vermiculite, and perlite, respectively. KGraze was only grown in 2016 in the perlite system. Pots were placed in the field at the University of Missouri Bradford Research Center, Columbia, MO. Switchgrass seeds were germinated under controlled conditions, transplanted to the greenhouse, and later transplanted to the pots in the field, whereas KGraze seeds were sown directly into the pots in the field on the day of switchgrass 
transplanting to the pots. Except for adjustment of Mn to the concentrations needed for the different treatments, plants were fertilized with complete nutrient solution between 8:00 am - 9:00 am every day through a drip system. The nutrient solution contained 2.5 $\mathrm{mM} \mathrm{NH}_{4} \mathrm{NO}_{3}, 2.0 \mathrm{mM} \mathrm{KCl}, 2.0 \mathrm{mM} \mathrm{CaCl}_{2} \cdot 2 \mathrm{H}_{2} \mathrm{O}, 0.5 \mathrm{mM} \mathrm{MgSO}_{4} \cdot 7 \mathrm{H}_{2} \mathrm{O}, 2.0 \mathrm{mM}$ $\mathrm{KNO}_{3}, 0.08 \mathrm{mM} \mathrm{K}_{2} \mathrm{HPO}_{4}, 0.32 \mathrm{mM} \mathrm{KH} \mathrm{PO}_{4}, 0.025 \mathrm{mM}$ FeSeq330, $2.3 \mu \mathrm{M} \mathrm{H}_{3} \mathrm{BO}_{3}, 0.6$ $\mu \mathrm{M} \mathrm{ZnSO}_{4} \cdot 7 \mathrm{H}_{2} \mathrm{O}, 0.10 \mu \mathrm{M} \mathrm{NaMoO}_{4} \cdot 2 \mathrm{H}_{2} \mathrm{O}, 0.11 \mu \mathrm{M} \mathrm{NiCl}_{2} \cdot 6 \mathrm{H}_{2} \mathrm{O}, 0.15 \mu \mathrm{M} \mathrm{CuSO}_{4} \cdot$

$5 \mathrm{H}_{2} \mathrm{O}$. Manganese sulfate $\left(\mathrm{MnSO}_{4}\right)$ was used as $\mathrm{Mn}$ source to establish treatments with Mn at concentrations of $0,25,50,75$ and $100 \mu \mathrm{M} M n$ in 2014, 0, 25, 50, 75, 100 and 200 $\mu \mathrm{M} \mathrm{Mn}$ in 2015 , and $0,2,5,10,25$ and $75 \mu \mathrm{M} \mathrm{Mn}$ in 2016. The $\mathrm{pH}$ of all nutrient solutions was adjusted to 5.6. The experiments were arranged as randomized complete block design (RCBD) with five replications, and every replication contained two plants in separate pot 2014 and 2015. In 2016, every treatment included six replications and every replication contained three plants per pot.

\subsection{Chlorophyll fluorescence and gas exchange measurements}

Chlorophyll fluorescence parameters were measured between 8:30 am - 10:00 am on dark-adapted leaves using a FluorPen FP 100 (Photon System Instruments, Brno, Czech Republic). Maximum PSII efficiency $\left(\mathrm{F}_{\mathrm{v}} / \mathrm{F}_{\mathrm{m}}\right)$, minimum chlorophyll fluorescence $\left(\mathrm{F}_{0}\right)$, and maximum chlorophyll fluorescence $\left(\mathrm{F}_{\mathrm{m}}\right)$ were used for this study. $\mathrm{Fv}$ is variable fluorescence. It is calculated as $F_{v}=F_{m}-F_{0}$. In 2014 and 2015, chlorophyll fluorescence measurements were conducted 82 and 78 days after Mn treatment imposition (DAMT) on recently fully expanded leaves. Leaf clips were attached in the middle-third of one leaf per replication for a dark adaptation of $20 \mathrm{~min}$ prior to fluorescence measurements. In 
2016, the measurements were taken in the same manner at 24, 38, 53, and 67 DAMT for Cave-in-rock and KGraze, and one additional time for Alamo at 85 DAMT.

On the days of chlorophyll fluorescence measurements, photosynthetic rates and stomatal conductance were determined between 10:30 am and 2:30 pm using a LI-COR 6400 Portable Photosynthesis System (LICOR Inc., Lincoln, Nebraska, USA) with a 6400-02 LED light source cuvette. Before determining photosynthetic rates, air temperature and photosynthetic photon flux density (PPFD) were measured just above the canopy, and used to adjust the conditions in the leaf cuvette. Once adjusted, cuvette conditions were maintained throughout the measurements on a particular measurement day, with $\mathrm{CO}_{2}$ concentration of $400 \mu \mathrm{mol} \mathrm{mol}{ }^{-1}$ air.

\subsection{Leaf ultrastructure analyses}

In 2016, samples from a recently fully expanded leaf were collected at 1:30 -3:30 pm 67 DAMT for ultrastructure analyses. To this end, $2 \mathrm{~mm}$ diameter leaf disks were collected from KGraze and $3 \times 3 \mathrm{~mm}$ squares from Alamo and Cave-in-Rock from the middle of the leaf blade (half-way between the ligule and the tip of the leaf blade) and avoiding the mid-rib from one leaf in each replication of the $0 \mu \mathrm{M}$ and $10 \mu \mathrm{M} \mathrm{Mn}$ treatments. The leaf samples were immediately placed into fixative consisting of $2 \%$ paraformaldehyde and $2 \%$ glutaraldehyde in $100 \mathrm{mM}$ sodium cacodylate buffer $\mathrm{pH}=$ 7.35 (Ning et al., 2018). Specimen preparation and images were performed at the Electron Microscopy Core Facility, University of Missouri. The fixed tissues were rinsed with $100 \mathrm{mM}$ sodium cacodylate buffer, pH 7.35 containing $130 \mathrm{mM}$ sucrose. Secondary fixation was performed using $1 \%$ osmium tetroxide (Ted Pella, Inc. Redding, California) in cacodylate buffer using a Pelco Biowave (Ted Pella, Inc. Redding, California) 
operated at 100 Watts for 1 minute. Specimens were next incubated at $4{ }^{\circ} \mathrm{C}$ for 1 hour, then rinsed with cacodylate buffer and further with distilled water. En bloc staining was performed using $1 \%$ aqueous uranyl acetate and incubated at $4{ }^{\circ} \mathrm{C}$ overnight, then rinsed with distilled water. A graded dehydration series was performed using ethanol, transitioned into acetone, and dehydrated tissues were then infiltrated with a $1 / 1 \mathrm{v} / \mathrm{v}$ of Epon and Spurr resin for 24 hours at room temperature and polymerized at $60{ }^{\circ} \mathrm{C}$ overnight. Sections were cut to a thickness of $75 \mathrm{~nm}$ using an ultramicrotome (Ultracut UCT, Leica Microsystems, Germany) and a diamond knife (Diatome, Hatfield PA). Thin sections were stained using Reynold's Lead Citrate. Images were acquired with a JEOL JEM 1400 transmission electron microscope (JEOL, Peabody, MA) at $80 \mathrm{kV}$ on a Gatan Ultrascan 1000 CCD (Gatan, Inc, Pleasanton, CA). Images obtained were used for the collection of quantitative anatomical data using ImageJ software. Images from four replications were used to count and measure chloroplasts in $10 \mathrm{MC}$ and $10 \mathrm{BSC}$. Starch granule number, starch granule size, and the relative area of starch granules per chloroplast were assessed in $30 \mathrm{MC}$ chloroplasts and $20 \mathrm{BSC}$ chloroplasts per sample.

\subsection{Enzyme extraction and assay}

At 24 and 67 DAMT, leaf blades of recently fully expanded leaves were cut from 0 and $10 \mu \mathrm{M} \mathrm{Mn}$ treatments with three replications per treatment and immediately snapfrozen in liquid nitrogen, and then stored at $-80^{\circ} \mathrm{C}$ until used for enzyme activity assays, and transcript abundance analysis.

For enzyme assays, leaf blade samples from three biological replicates of the 0 and $10 \mu \mathrm{mM}$ Mn treatments were ground to a fine powder in liquid nitrogen by mortar and pestle. Aliquots of $30 \mathrm{mg}$ of leaf powder were extracted as described (Sommer et al., 
2012). The extract was divided into two equal parts, one half was used to measure enzyme activity of NAD-ME, NADP-ME and PEPCK, and the other half was used to determine the concentration of total soluble proteins by the Bradford method (Bradford, 1976).

Activities of NAD-ME, NADP-ME, and PEPCK were measured using spectrophotometric assays at $30{ }^{\circ} \mathrm{C}$ at $340 \mathrm{~nm}$ as previously described (Sonawane et al., 2018; Sharwood et al., 2008; Hatch, 1982,). Briefly, NAD-ME activity was measured using $25 \mu \mathrm{l}$ of leaf extract in an assay buffer containing $50 \mathrm{mM}$ HEPES-KOH (pH 7.2), 5 $\mathrm{mM}$ malate (malic acid), $2 \mathrm{mM} \mathrm{NAD}{ }^{+}, 0.2 \mathrm{mM}$ EDTA, $5 \mathrm{mM}$ DTT, and $2 \mathrm{mM} \mathrm{MnCl}_{2}$. NADP-ME activity was measured using $25 \mu 1$ of leaf extract in assay buffer containing 50 mM HEPES-KOH (pH 8.0), 5 mM malate (malic acid), $0.5 \mathrm{mM} \mathrm{NADP}^{+}, 0.2 \mathrm{mM}$ EDTA, $5 \mathrm{mM}$ DTT, and $2 \mathrm{mM} \mathrm{MgCl}$. PEPCK activity was measured in the carboxylation direction in assay buffer containing $50 \mathrm{mM}$ HEPES-KOH $(\mathrm{pH} \quad 7.0), 4 \% \quad \beta$ mercaptoethanol, $100 \mathrm{mM} \mathrm{KCl}, 90 \mathrm{mM} \mathrm{KHCO}_{3}, 0.5 \mathrm{mM}$ ADP, $2 \mathrm{mM} \mathrm{MnCl}_{2}, 0.2 \mathrm{mM}$ $\mathrm{NADH}, 6 \mathrm{U}$ of $\mathrm{MDH}$, and $5 \mathrm{mM}$ aspartic acid. After the addition of $10 \mathrm{mM}$ PEP to the assay buffer, $25 \mu 1$ of leaf extract was added.

NAD-ME, NADP-ME and PEPCK activity is calculated according to the equation (Bayoumi and Rosalki, 1976):

$$
\frac{\Delta \mathrm{A} \times 1.0}{6.22 \times 0.025} \times \frac{1}{[\text { Protein }]}=\operatorname{Activity}\left({\mathrm{U} . \mathrm{mg}^{-1}}^{-1} \text { protein }\right)
$$

Where $\Delta \mathrm{A}$ is the change in absorbance at $340 \mathrm{~nm}$ per min, $6.22 \times 10^{3}$ is the molar absorbance of NADH and NADPH at $340 \mathrm{~nm}, 1.0$ is final total reaction volume $(\mathrm{ml})$, 
0.025 is volume of enzyme ( $\mathrm{ml})$ in sample, [protein] is the concentration of total soluble protein $\left(\mathrm{mg} \cdot \mathrm{ml}^{-1}\right)$ in extraction solution.

\subsection{Leaf blade Mn concentration}

Leaf blade Mn concentration was determined on a subsample of the leaf blades collected and flash frozen in liquid $\mathrm{N}_{2} 24$ DAMT and 67 DAMT. Ground leaf samples were oven-dried to constant weight at $60{ }^{\circ} \mathrm{C}$. The dried samples were submitted for $\mathrm{Mn}$ determination by ICP-OES at the Agriculture Diagnostic Laboratory of University of Arkansas as described in Chapter 2. Analyses were conducted on three (24 DAMT) or four (67 DAMT) replications for each Mn treatment.

\subsection{RNA extraction}

Total RNA was extracted from the subsamples of leaf blade tissue used for enzyme assays with an RNeasy Micro Kit (Qiagen, Valencia,CA,USA) according to the manufacturer's protocol. The purity and integrity of the extracted RNA was confirmed using a NanoDrop ${ }^{\mathrm{TM}} 1000$ spectrophotometer (Thermo Fisher Scientific) and by $1 \%$ agarose gel electrophoresis. After passing RNA quality control, an aliquot of mRNA was sent to Novogene while the remaining mRNA was retained for quantitative real-time PCR.

\subsection{RNA-Seq library construction}

High quality mRNA from leaf blade tissues of Alamo from three replications from 0 and $10 \mu \mathrm{M}$ Mn treatments collected 24 and 67 DAMT were sent to Novogene for RNA-seq library construction and sequencing. Library construction and sequencing were perfomed by Novogene using standard protocols. Briefly, following RNA quality control, RNA-seq libraries were constructed using a NEBNext ${ }^{\circledR}$ Ultra $^{\mathrm{TM}}$ II RNA Library Prep Kit 
for Illumina ${ }^{\circledR}$. Processing of cDNA libraries for sequencing included a round of purification, terminal repair, A-tailing, ligation of sequencing adapters, size selection and PCR enrichment. Library concentration was quantified using a Qubit 2.0 fluorimeter (Life Technologies), and then diluted to $1 \mathrm{ng} \mu \mathrm{l}^{-1}$ and checked for insert size on an Agilent 2100 and quantifyied to greater accuracy by quantitative PCR (library activity $>2$ nM). Libraries were sequenced using an Illumina HiSeq platform PE150.

\subsection{Data analysis of transcript abundance}

For data analysis, raw reads are first filtered to remove reads containing adapters or reads of low quality, so that downstream analyses are based on clean reads. Sequence reads were then mapped to switchgrass genome Panicum virgatum v1.1 (http://phytozome.jgi.doe.gov/) using Tophat V2.0.12 software. The mismatch parameter is set to two, and other parameters are set to default. In order for the gene expression levels estimated from different genes and experiments to be comparable, the FPKM is used. In RNA-seq, FPKM, short for the expected number of Fragments Per Kilobase of transcript sequence per millions base pairs sequenced, is the most common method of estimating gene expression levels, which takes into account the effects of both sequencing depth and gene length oncounting of fragments (Trapnell et al., 2010). HTSeq software was used to analyze the gene expression levels in this experiment, using the union mode. FPKM from the normalized read counts from gene expression level were used for differential gene expression analysis, and the software DESeq 1.10.1 (Anders et al., 2010) was used for the analysis. False discovery rate (FDR) value estimation based on multiple hypothesis testing (Benjamini and Hochberg method) was adopted to adjust the final $p$ values. As the DESeq (1.10.1) already eliminates the biological variation, the 
threshold is set as: padj $<0.05$. Volcano plots were used to infer the overall distribution of differentially expressed genes. Hierarchical clustering was used to group different genes based on their expression patterns. Finally, GO enrichment analysis was conducted by GOseq (Young et al, 2010), which is based on Wallenius non-central hyper-geometric distribution. KEGG (Kyoto Encyclopedia of Genes and Genomes) analysis was applied to figure out the interactions of multiple genes involved in certain biological functions.

\subsection{Real-time quantitative reverse transcription-PCR}

Transcript abundance was quantified for the $\mathrm{CO}_{2}$ fixation enzymes: NAD-ME (Pavir.Ia01553), NADP-ME (Pavir.Eb00308), PEP-CK (Pavir.Ia03881), phosphoenolpyruate carboxylase (PEPC) (Pavir.Da00871), and light reaction center PSII (PsbP protein of OEC in PSII) (Pavir.Gb01641), and malate dehyfrogenase (MDH) (Pavir.Bb03415) that catalyzes the oxidation of malate to oxaloacetate and genes using real-time quantitative polymerase chain reaction (qPCR). One $\mu \mathrm{g}$ of isolated total RNA was reverse-transcribed into complementary DNA (cDNA) using an oligo (dT) 15 primer and Moloney murine leukemia virus (MMLV) Reverse Transcriptase (Promega, WI, USA) following the manufacturer's protocol. The resultant cDNA was diluted 10-fold and was used as a template for qPCR. Amplifications were performed in 96-well plates with a CFX Connect Real-Time PCR System (Bio-rad, CA, USA) with the following thermal cycling conditions: $95^{\circ} \mathrm{C}$ for $10 \mathrm{~min}, 40$ cycles of $95^{\circ} \mathrm{C}$ for $15 \mathrm{~s}$, and $60^{\circ} \mathrm{C}$ for 1 min and 1 cycle of $95{ }^{\circ} \mathrm{C}$ for $1 \mathrm{~min}, 60^{\circ} \mathrm{C}$ for $30 \mathrm{~s}$ and $95{ }^{\circ} \mathrm{C}$ for $30 \mathrm{~s}$. Transcript levels were normalized using $e E F-1 \alpha$ as an internal control (Gimeno et al, 2014; Zhang et al., 2018). Analyses were performed for three biological replications from each treatment, and measurements were performed at least twice with similar results. Primer sequences 
used for NAD-ME, NADP-ME, PEPCK and PEPC were from Rao et al. (2016), eEF-1 $\alpha$ from Gimeno et al. (2014), and for PSII and MDH were designed using Primer3 (http://bioinfo.ut.ee/primer3-0.4.0/), and are listed in Appendix Table 3-1.

\subsection{Statistical analyses}

Each pot experiment was a randomized complete block with five replications per Mn treatment in 2014 and 2015, six replications in 2016. The influence of effects on measured parameters were analyzed by PROC GLM procedure (SAS9.4 Institute Inc. Cary, NC.). For all measured parameters, replication was treated as a random effect, all effects significant deference between pairwise treatments were separated using PROC GLM ls means statement for gas exchange and chlorophyll fluorescence parameters while treating entries and $\mathrm{Mn}$ treatment as fixed effects, and for leaf Mn concentration growth stage and Mn treatment were treated as fixed effects, using PROC GLM. LSD analysis for enzyme activity with treated growth stage, enzyme type and Mn treatments as fixed effects, and for TEM anatomical analysis with treating Mn treatment as fixed effects, and using Student's t-test analysis for Gene expression with treating stage and Mn treatment as fixed effects. All effects were considered significant difference at $\mathrm{p}<$ 0.05 .

\section{Results}

\subsection{Photosynthetic rate and stomatal conductance}

Leaf photosynthetic rates measured 82 DAMT (2014) and 78 DAMT (2015) did not differ among Mn manganese treatments in either switchgrass ecotypes and averaged $28 \mu \mathrm{mol} \mathrm{m} \mathrm{m}^{-1}$ across years and genotypes (Fig. 3-1 A and B). In 2016, while not different among Mn treatments for much of the season, photosynthetic rate of both 
Alamo and Cave-in-Rock at 67 DAMT and later was lower in the $0 \mu \mathrm{M}$ Mn treatment compared to the other treatments, for which photosynthetic rates remained similar (Fig. 3-1C and D). In contrast, KGraze leaf photosynthetic rate was lower in the $0 \mu \mathrm{M} \mathrm{Mn}$ treatment than the other treatments at the beginning of the season addition in early growth stage $(\geq 53$ DAMT). At the last measurement (67DAMT), differences between Mn treatments had disappeared, largely because photosynthetic rates in the Mn-supplemented treatments had declined more since the last measurement than those in the $0 \mathrm{Mn}$ treatment. Across the season, the photosynthetic rate in the $0 \mathrm{Mn}$ treatment averaged 26 $\mu \mathrm{mol} \mathrm{m} \mathrm{m}^{-1}$, whereas it averaged $37 \mu \mathrm{mol} \mathrm{m} \mathrm{m}^{-2}$ for the $10 \mu \mathrm{M}$ Mn treatment which had the numerically greatest photosynthetic rate at every measurement (Fig. 3-1E).

Like photosynthetic rate, leaf stomatal conductance of both switchgrass ecotypes was not influenced by Mn treatment in 2014 and 2015 (Fig. 3-2A and B). Similarly, except for the measurement in Alamo at 85 DAMT when Mn addition increased stomatal conductance, Mn treatment did not affect stomatal conductance in 2016 (Fig. 3-2 C and D). In pearl millet, leaf stomatal conductance was only not significantly influenced by Mn treatments at whole season (Fig3-2E).

\subsection{Chlorophyll fluorescence}

Maximum PSII efficiency $\left(\mathrm{F}_{\mathrm{v}} / \mathrm{F}_{\mathrm{m}}\right)$ in switchgrass was similar among all $\mathrm{Mn}$ treatment sin 2014 in both Alamo and Cave-in-Rock (Fig. 3-3 A). In 2015, F $/ F_{\mathrm{v}}$ was similar among all Mn treatments, except for a reduction that was observed in the $100 \mu \mathrm{M}$ Mn treatment in Cave-in-Rock (Fig. 3-3 A). Temporal dynamics of $F_{v} / F_{m}$ in 2016, revealed a strong reduction in the $0 \mu \mathrm{M}$ Mn treatment at starting 67 DAMT in both switchgrass ecotypes. While for Alamo, treatments with $\geq 2 \mu \mathrm{M}$ Mn maintained of $F_{v} / F_{m}$ 
values of 0.69 and 0.66 , it dropped to 0.50 and 0.49 in the $0 \mu \mathrm{M} \mathrm{Mn}$ treatment at 67 and 85 DAMT, respectively. Similarly, at 67 DAMT, $F_{v} / F_{m}$ of Cave-in-Rock plants that received $\mathrm{Mn}$ averaged 0.69 whereas it was only 0.52 in the $0 \mu \mathrm{M} \mathrm{Mn}$ treatment. In contrast, in KGraze, $\mathrm{F}_{\mathrm{v}} / \mathrm{F}_{\mathrm{m}}$ in the $0 \mu \mathrm{M}$ Mn treatment was dramatically lower $(0.15)$ than in all other treatments (average: 0.67) at 24 DAMT (Fig. 3-3 E). Although $F_{v} / F_{m}$ in the 0 $\mu \mathrm{M}$ Mn treatment recovered to 0.74 by 38 DAMT, it was not significant difference compared with all other treatments (average: 0.80 ), and remained slightly lower for the remainder of the season. Since $F_{v}$ is difference between minimum chlorophyll fluorescence $\left(\mathrm{F}_{0}\right)$ and Maximum chlorophyll fluorescence $\left(\mathrm{F}_{\mathrm{m}}\right)$, the question remains whether the observed differences in $\mathrm{F}_{\mathrm{v}} / \mathrm{F}_{\mathrm{m}}$ were due to impacts on $\mathrm{F}_{0}, \mathrm{~F}_{\mathrm{m}}$, or both.

In the two switchgrass genotypes, $\mathrm{F}_{\mathrm{m}}$ was not affected by $\mathrm{Mn}$ treatment at any time (Fig. 3-5, but $\mathrm{F}_{0}$ was increased in Alamo at 67 and 85 DAMT and in Cave-in-Rock at 67 DAMT in the $0 \mu \mathrm{M} M n$ treatment. Thus, the reduced $F_{v} / F_{m}$ observed in that treatment at those measurement dates, was due to an increase in $F_{0}$ rather than a decrease in $\mathrm{F}_{\mathrm{m}}$. Interestingly, in pearl millet, $\mathrm{F}_{0}$ was greater and $\mathrm{F}_{\mathrm{m}}$ smaller in the $0 \mu \mathrm{M} \mathrm{Mn}$ treatment than $\geq 2 \mu \mathrm{M}$ Mn treatments at 24 DAMT. This general pattern persisted through 38 and 53 DAMT measurements, but only $\mathrm{F}_{0}$ was different from in the 0 than the $\geq 2 \mu \mathrm{M}$ Mn treatments at 67 DAMT (Fig. 3-5).

\section{3. Leaf Mn concentration}

As expected, leaf blade Mn concentrations strongly increased with additional Mn in the nutrient solution in both switchgrass ecotypes as well as in pearl millet (Fig. 3-6AC). For plants grown in the $0 \mu \mathrm{M} \mathrm{Mn}$ treatment, the response in $\mathrm{Mn}$ concentration in leaves collected at different developmental stages varied between species. In both 
switchgrass genotypes, leaf blade Mn concentration was significantly greater in samples collected early (24DAMT) than in those collected late (67DAMT), but, no significant difference in leaf blade Mn concentration was observed in KGraze between early and late sampled leaves (Fig. 3-6 D-F). Manganese concentrations in leaf blades sampled at 24 DAMT averaged 8.7, 7.2, and $9.8 \mathrm{mg} \mathrm{kg}^{-1}$ whereas those collected at 67 DAMT averaged 16.3, 11.1, and $10.4 \mathrm{mg} \mathrm{kg}^{-1}$ for Alamo, Cave-in-Rock, and KGraze, respectively. These leaf blade Mn concentrations were higher compared to the whole shoot sample Mn concentrations reported in Chapter 2.

\subsection{TEM analysis of leaf anatomy}

Based on photosynthesis and chlorophyll fluorescence measurements, Mn availability appeared to be adequate in the $10 \mu \mathrm{M} \mathrm{Mn}$ treatment for both switchgrass and pearl millet. Therefore, samples from 0 (Mn deficiency) and $10 \mu \mathrm{M} \mathrm{Mn}$ (Mn sufficient) treatments were selected to assess effects of Mn availability on selected leaf anatomical characteristics. Representative TEM micrographs of MC and BSC from leaf blades of 0 and $10 \mu \mathrm{M} \mathrm{Mn}$ treatment plants are shown in Figure 3-7.

No statistically significant differences were observed in Cave-in-Rock and KGraze for any of the chloroplast and starch granule characteristics assessed in MC and BSC cells. However, in Alamo MC, fewer chloroplasts were observed in the 0 than $10 \mu \mathrm{M}$ Mn treatment, but no differences were observed in BSC chloroplast numbers (Fig. 3-7, Fig. 3-8). Average area per chloroplast was smaller in both MC and BSC in Alamo leaves from 0 as compared to $10 \mu \mathrm{M}$ Mn treatments (Fig. 3-8B and G). Starch granules were observed in the stroma of chloroplasts of MC and BSC. The relative area of starch granules per chloroplast was significantly greater in $0(2.3 \%)$ than in $10 \mu \mathrm{M} \mathrm{Mn}(0.37 \%)$ 
treatments in Alamo MC cells, and a trend, although not significant, was also apparent in Cave-in-Rock and KGraze (Fig. 3-8). However relative area of starch granules per BSC chloroplast did not differ between Mn treatments in any of the three genotypes. Mn deficiency reduced starch granule size and increased starch granule numbers per MC chloroplast in Alamo (Fig. 3-8D and E). In BSC, the starch granule size was reduced in the $0 \mu \mathrm{M}$ Mn treatment of Alamo, but, unlike in $\mathrm{MC}$, starch granule number per chloroplast was not increased compared to the $10 \mu \mathrm{M}$ Mn treatment.

\subsection{Validation of expression of selected genes by $\mathrm{qPCR}$}

RNA-seq was performed on Alamo leaf blade tissue to survey the response in gene expression to Mn availability, using the 0 and $10 \mu \mathrm{M}$ Mn treatments and samples collected early (24 DAMT) and late (67 DAMT) in the season. See the Appendix part after this chapter for more details on RNA-seq data analysis.

Because of their critical roles in photosynthetic processes and the importance of Mn for some of them, NAD-ME, NADP-ME, PEPCK, PEPC, PSII, and MDH were selected for verification of gene expression in Alamo by qRT-PCR. In addition, transcript abundance of these genes was also examined in leaf blade tissues of Cave-in-Rock that was sampled in the 0 and $10 \mu \mathrm{M}$ Mn treatments at 24 and 67 DAMT, as for Alamo. Generally speaking, qPCR results for Alamo were consistent with those from RNA-seq (Fig 3-9 A, B). For instance, PSII transcript abundance was greater at $10 \mu \mathrm{M}$ Mn level at 24 DAMT for both RNA-seq and qPCR results, and, although not significantly different, the same trend was found for the samples collected late in the season (67 DAMT). While $M D H$ transcripts were most abundant in the early samples from $10 \mu \mathrm{M}$ treatment, they were only significantly different from the late samples from the same Mn treatment. 
Interestingly, transcript abundance between $\mathrm{Mn}$ treatments within the same sampling time did not differ for NADP-ME, NAD-ME, PEPCK, or PEPC. Although the pattern in transcript abundance of the different genes appeared somewhat different in Cave-in-Rock than in Alamo, the outcome of transcript abundance comparisons between $\mathrm{Mn}$ treatments within the same sampling time produced the same outcome - no differences in transcript abundance of $N A D P-M E, N A D-M E, P E P C K$, or PEPC.

\subsection{Activity of the $\mathrm{C} 4$ decarboxylating enzymes}

To test whether Mn availability influenced decarboxylation enzyme activities, in vitro activities of NAD-ME, NADP-ME and PEPCK were assayed in leaf blade samples collected at 24 DAMT and 67 DAMT from Alamo, Cave-in-Rock, and KGraze grown in 0 and $10 \mu \mathrm{M}$ Mn treatments. However, Mn addition did not influence the activity of any of the three enzymes in switchgrass leaves at either sampling time (Fig. 3-10). In Alamo, the activity of PEPCK was similar to that of NAD-ME activity, and activities of both were about 16-fold greater (average across samplings and Mn treatments than the NADPME activity in Alamo (Fig.3-10A-D).Just like in Alamo, NADP-ME activity was much lower than NAD-ME and PEPCK activities in Cave-in-rock. However, in leaves from $10 \mu \mathrm{M}$ Mn treatments, PEPCK activity was greater at 24 DAMT than at 67 DAMT.

NADP-ME activity in pearl millet was much greater than in switchgrass and was similar (67 DAMT) or greater (24 DAMT) than activities of NAD-ME and PEPCK in both Mn treatments (Fig. 3-10 E and F). Unlike in switchgrass, NAD-ME and PEPCK activities were significantly lower in the $0 \mu \mathrm{M}$ than in the $10 \mu \mathrm{M} \mathrm{Mn}$ treatment in KGraze leaves sampled at 24 DAMT. However, by 67 DAMT activities of all three enzymes were the same in both treatments. In addition, NADP-ME and PEPCK activities 
differed between early- and late-collected KGraze leaf samples. The early stage leaves sampled at 24 DAMT had greater NADP-ME activity than those sampled at 67 DAMT in both 0 and $10 \mu \mathrm{M} \mathrm{Mn}$ treatments. PEPCK activity was lower at the early sampling than the late sampling in the $0 \mu \mathrm{M}$ Mn treatment, but did not differ between sampling times in the $10 \mu \mathrm{M} \mathrm{Mn}$ treatment.

\section{Discussion}

The critical deficiency level of Mn for most plant species is in the range of 10-20 $\mathrm{mg} \mathrm{Mn} \mathrm{kg}{ }^{-1}$ dry matter in mature leaves (Broadley et al., 2012). In this study, Mn concentration in switchgrass and pearl millet leaf blades increased significantly with increasing $\mathrm{Mn}$ concentration in the nutrient solution (Fig. 3-6). In the 0 to $75 \mu \mathrm{M} \mathrm{Mn}$ treatments in the perlite system, Mn concentrations in leaf blades sampled at 24 DAMT ranged from $16.29-209.00,11.05-161.67$, and $10.36-357.67 \mathrm{mg} \mathrm{kg}^{-1}$ whereas those collected at harvest time ranged from $8.66-232.32,7.22-266.05$, and $9.80-486.75 \mathrm{mg} \mathrm{kg}^{-}$

1 for Alamo, Cave-in-Rock, and KGraze, respectively. These leaf blade Mn concentrations were greater in the $0 \mu \mathrm{M}$ Mn treatment for two species and less for switchgrass, higher for KGraze in $75 \mu \mathrm{M}$ Mn treatment, compared to the whole shoot sample Mn concentrations reported in Chapter 2. Thus, in all three entries, early-sampled leaf blades were within, and those of late-sampled leaf blades were below that $10-20$ $\mathrm{mg} \mathrm{kg}^{-1}$ range reported to be deficient for most plants by Broadley et al. (2012). Interestingly, compared with late stage leaf blade Mn concentrations, those in earlysampled leaf blades were significantly higher in both switchgrass ecotypes, but were not different from each other in pearl millet. These leaf blade Mn concentrations were associated with severe chlorosis at early growth stages in pearl millet grown in the $0 \mu \mathrm{M}$ 
Mn treatment. However, as the season progressed, chlorotic symptoms disappeared. In contrast to pearl millet, no visible symptoms were observed in switchgrass throughout most of the growing season, only at late stages (67DAMT), did limited chlorosis appear.

Photosynthetic rates measured were consistent with the observations of chlorosis in the two species. That is, no effect of Mn treatment was found in the sand- and vermiculite-systems, and photosynthetic rates in Alamo and Cave-in-Rock were similar for most of the season among all $\mathrm{Mn}$ treatments, but were lower in the $0 \mu \mathrm{M} \mathrm{Mn}$ treatment at late stages (Fig. 3-1). In pearl millet where severe chlorosis was observed in the early stages in the $0 \mu \mathrm{M}$ Mn treatment, photosynthesis was lower than at $10 \mu \mathrm{M} \mathrm{Mn}$, but later in the season, differences were not significant anymore. The differences observed in net photosynthesis were associated with the impact of Mn availability on photosynthetic light reactions that were revealed by chlorophyll fluorescence measurements (Figs. 3-3 through 3-5). These measurements revealed significant decreases in $F_{v} / F_{m}$ early in the season in pearl millet whereas the decreases in $F_{v} / F_{m}$ in switchgrass were observed at late stages when the plants were grown in the $0 \mu \mathrm{M} \mathrm{Mn}$ treatment in perlite. The decrease in $F_{v} / F_{m}$ in pearl millet was due to both, an increase in $F_{0}$ as well as a decrease in $F_{m}$, but in switchgrass, it was due to an increase in $F_{0}$ while $F_{m}$ was not affected. These impacts on chlorophyll fluorescence are consistent with the role of Mn in the OEC of PSII, and that Mn is irreplaceable for OEC function (Burnell, 1988).

While leaf blade Mn concentrations at low Mn concentrations nutrient solution were quite similar between switchgrass and pearl millet, these results are consistent with these two species having different critical leaf blade Mn deficiency levels, and different responses to Mn availability over the course of growth and development. 
In addition to its role in the $\mathrm{OEC}, \mathrm{Mn}$ is required for NAD-ME in $\mathrm{C} 4$ photosynthesis. While $\mathrm{C} 4$ plants traditionally are divided into three subtypes (NAD-ME type, NADP-ME type and PEPCK type) based on the primary enzyme decarboxylation enzyme in BSC, coexistence of the three subtypes is well known, and some degree of flexibility with respect to the activity of the three enzymes has been reported (Sommer et al., 2012; Wang et al., 2014; Sharwood et al., 2014). NAD-ME and NADP-ME subtypes can exist independently and both can coexist with PEPCK cycle as the supplementary pathway (Furbank, 2011; Wang et al., 2014; Liu and Osborne, 2014; Sharwood et al., 2014; Rao et al., 2016). Since environmental and developmental conditions can impact the flexibility or coexist between these three subtypes (Sommer et al., 2012; Wang et al., 2014; Sharwood et al., 2014), we hypothesized that, because of its Mn requirement, low Mn availability may reduce NAD-ME activity and that this could cause a shift to greater NADP-ME and/or PEPCK activity. However, neither NAD-ME transcript abundance nor NAD-ME activity differed in switchgrass leaves collected at early and late stages from 0 and $10 \mu \mathrm{M}$ Mn treatments. Similarly, no differences in transcript abundance and activities of NADP-ME and PEPCK were found in response to Mn treatment. Overall, in both switchgrass ecotypes, NAD-ME and PEPCK activities were similar whereas NADPME activities were much lower, regardless of Mn treatment and sampling time. These results were consistent with those reported by Rao et al. ( 2016), who also found young switchgrass has lower NADP-ME activity, and NAD-ME and PEPCK activity were similar.

Interestingly, transcripts of NADP-ME (Pavir.Eb00308) were abundant in switchgrass leaves of 0 and $10 \mu \mathrm{M}$ Mn treatments, particularly at 24 DAMT. A high 
expression level of the NADP-ME gene in switchgrass leaves has been reported in several previous studies(Zhang et al., 2013; Meyer et al., 2014; Palmer et al., 2015; Rao et al., 2016) and it was strongly confirmed by q-PCR analysis (Fig. 3-12B). Previous research also pointed out that this highly expressed swicthgrass NADP-ME gene clustered with the C4 NADP-ME of $S$. viridis, and shares identity with the nonphotosynthetic plastidic NADP-ME in maize (Saigo et al.,2004). Despite the abundance of NADP-ME transcripts, NADP-ME activity was low in switchgrass leaves (Fig 3-10AD), which is consistent with observations reported by Rao et al (2016). Rao et al. (2016) point outed that it is posssible for switchgrass that strong post-transcriptional or translational control of NADP-ME may cause the activity in BSC, or that this gene encodes a low activity NADP-ME isoform (Rao et al., 2016). By identifing the syntenic orthologs of NADP-ME isoforms, Rao et al (2016) also found non-C4 and C4 NADP-ME group genes were syntenic in switchgrass, S.viridis, maize and sorghum. Thus, it is possible that photosynthetic and non-photosynthetic isoforms found in $\mathrm{C} 4$ plants were present at some level within the most recent common ancestor (Washburn et al., 2015), and these isoforms may or may not be active in $\mathrm{C} 4$ photosynthesis under different selective pressures.

In contrast to switchgrass, the NAD-ME and PEPCK activities in pearl millet leaf blades sampled at 24 DAMT were lower ( $13 \%$ and $28 \%$, respectively) in the 0 than the $10 \mu \mathrm{M}$ Mn treatment, and NADP-ME activities were similar between these two treatments, and greater than the NAD-ME and PEPCK activities. However, at the late season sampling (67 DAMT), no Mn treatment differences were found in any of the three decarboxylation enzymes. 
Overall, combined chlorophyll fluorescence and enzyme activity measurements indicated that the decrease in photosynthetic rate under Mn deficiency which occurred early in the season in pearl millet and late in the season in switchgrass, were mainly attribuTable to the impact of reduced Mn availability on OEC activity and thus photosynthetic light reactions. However, as an activator of enzymes, $\mathrm{Mn}^{2+}$ ions can sometimes be replaced by other metals and vice versa (Burnell, 1988), as $\mathrm{Mn}^{2+}(0.75 \AA$ ) and $\mathrm{Mg}^{2+}$ radi $\left(0.65 \AA\right.$ ) are relatively similar (Bock et al., 1999). For instance, $\mathrm{Mn}^{2+}$ can replace $\mathrm{Mg}^{2+}$ to alter the oxygenase activity of RUBP- carboxylase/oxygenase, and $\mathrm{Mn}^{2+}$ can replace $\mathrm{Mg}^{2+}$ to activate PEPC (Wildner and Henkel, 1978; Christeller, and Laing, 1979). Thus, even though there was little NAD-ME activity in most species when $\mathrm{Mg}^{2+}$ replaced $\mathrm{Mn}^{2+}$ (Hatch and Kagawa, 1974), it may be of interest to revisite whether $\mathrm{Mg}^{2+}$ (or other metals) can replace $\mathrm{Mn}^{2+}$ as NAD-ME activator in some species or conditions that result in low tissue Mn concentrations.

Kranz-type leaf anatomy includes a single ring of BSC surrounding the vascular bundle followed by a concentric ring of specialized MC, and chloroplasts are distributed in both MC and BSC. In general, distribution of chloroplasts in BSC is centrifugal in NADP-ME and PEPCK subtypes, and is centripetal in NAD-ME subtype (Gutierrez et al., 1974). However, no centripetal distribution of BSC chloroplasts was observed in either switchgrass ecotype or pearl millet in this study. In general, MC chloroplasts include both PSI and PSII but do not accumulate much starch while BSC chloroplasts lack PSII but are accumulate large amounts of starch by the end of the photoperiod (Wise, 2007). Given the differences in MC and BSC functions in C4 photosynthesis and the known roles of Mn associated with some photosynthetic processes, differences in 
chloroplast and starch characteristics in these cell types may be expected. Indeed, some effects of Mn availability on chloroplast and starch traits were found in the lowland ecotype (Alamo), but no differences were observed in the upland ecotype (Cave-in-Rock) and pearl millet. In Alamo, Mn deficiency reduced MC chloroplast and starch granule size, and decreased the number of chloroplasts per MC and, but increased starch granule number per MC chloroplast and the relative starch area per chloroplast at 67 DAMT. In BSC of Alamo, only the chloroplast size and starch granule size were affected by the Mn treatment, both were reduced in the 0 compared to the $10 \mu \mathrm{M}$ Mn treatment. Similarly, previous studies also found that Mn deficiency could reduce chloroplast number in MC of soybean leaf (Lavres Junior et al., 2009) and increased starch grains percentage in MC chloroplast of orange leaf (Papadakis et al., 2007). To our knowledge, this is the first report on Mn effect on MC and BSC chloroplast and starch morphology in NAD-ME C4 plants.

\section{Conclusions}

Manganese deficiency reduced net photosynthesis in switchgrass toward the end of the season, but had a bigger impact early in the season in pearl millet. Based on reduced maximum PSII efficiencies $\left(\mathrm{F}_{\mathrm{v}} / \mathrm{F}_{\mathrm{m}}\right)$ and no effect of Mn deficiencies on NADME, NADP-ME, and PEPCK activities in switchgrass, the primary limitation to net photosynthesis appeared to be Mn limitation on the OEC activity. In pearl millet, Mn deficiency early in the season resulted in strong chlorosis, reduced net photosynthesis,

and lower $F_{v} / F_{m}$, but these effects disappeared or became less pronounced as the season progressed. Thus, despite small reductions in NAD-ME and PEPCK activities early in the season, the light reactions were likely the main limitation for photosynthesis under $\mathrm{Mn}$ 
deficient condtions. Although both species are classified as NAD-ME C4 types, NADPME activity was greater than those of NAD-ME and PEPCK in leaves of pearl millet early in the season. Additional research is needed to elucidate the mechanisms underlying the different responses of switchgrass and pearl millet to Mn availability.

\section{References}

Anders, S., and Huber, W. 2010. Differential expression analysis for sequence count data. Genome biology, 11(10), R106.

Bayoumi, R. A., and Rosalki, S. B. 1976. Evaluation of methods of coenzyme activation of erythrocyte enzymes for detection of deficiency of vitamins B1, B2, and B6. Clinical chemistry, 22(3), 327-335.

Bock, C. W., Katz, A. K., Markham, G. D., and Glusker, J. P. 1999. Manganese as a replacement for magnesium and zinc: functional comparison of the divalent ions. Journal of the American Chemical Society, 121(32), 7360-7372.

Bradford, M. M. 1976. A rapid and sensitive method for the quantitation of microgram quantities of protein utilizing the principle of protein-dye binding. Analytical biochemistry, 72(1-2), 248-254.

Broadley, M., Brown, P., Cakmak, I., Ma, J. F., Rengel, Z., and Zhao, F. 2012. Beneficial elements. In Marschner's mineral nutrition of higher plants (pp. 191-248). Academic Press.

Bunce, J. A. 2004. Carbon dioxide effects on stomatal responses to the environment and water use by crops under field conditions. Oecologia, 140(1), 1-10.

Burnell, J. N. 1988. The biochemistry of manganese in plants. In Manganese in soils and plants (pp. 125-137). Springer Netherlands.

Cassida, K. A., Muir, J. P., Hussey, M. A., Read, J. C., Venuto, B. C., and Ocumpaugh, W. R. 2005. Biomass yield and stand characteristics of switchgrass in south central US environments. Crop Science, 45(2), 673-681.

Christeller, J. T., and Laing, W. A. 1979. Effects of manganese ions and magnesium ions on the activity of soya-bean ribulose bisphosphate carboxylase/oxygenase. Biochemical Journal, 183(3), 747-750.

Clark, R. B. 2002. Differences among mycorrhizal fungi for mineral uptake per root length of switchgrass grown in acidic soil. Journal of Plant Nutrition, 25(8), 17531772 . 
Dever, L. V., Pearson, M., Ireland, R. J., Leegood, R. C., and Lea, P. J. 1998. The isolation and characterisation of a mutant of the $\mathrm{C} 4$ plant Amaranthus edulis deficient in NAD-malic enzyme activity. Planta, 206(4), 649-656.

Ehleringer JR, Monson RK 1993 Evolutionary and ecological aspects of photosynthetic pathway variation. Annu Rev Ecol Syst 24:411-439

Furbank, R. T. 2011. Evolution of the C4 photosynthetic mechanism: are there really three C4 acid decarboxylation types? Journal of experimental botany, 62(9), 3103-3108.

Gimeno, J., Eattock, N., Van Deynze, A., and Blumwald, E. 2014. Selection and validation of reference genes for gene expression analysis in switchgrass (Panicum virgatum) using quantitative real-time RT-PCR. PloS one, 9(3), e91474.

Guretzky, J. A., Biermacher, J. T., Cook, B. J., Kering, M. K., and Mosali, J. 2011. Switchgrass for forage and bioenergy: harvest and nitrogen rate effects on biomass yields and nutrient composition. Plant and Soil, 339(1-2), 69-81.

Gutierrez, M., Gracen, V. E., and Edwards, G. E. 1974. Biochemical and cytological relationships in C4 plants. Planta, 119(4), 279-300.

Hatch, M. D. 1987. C4 photosynthesis: a unique blend of modified biochemistry, anatomy and ultrastructure. Biochimica et Biophysica Acta (BBA)-Reviews on Bioenergetics, 895(2), 81-106.

Hatch, M. D., and Kagawa, T. 1974. Activity, location and role of NAD malic enzyme in leaves with C4-pathway photosynthesis. Functional Plant Biology, 1(3), 357-369.

Hebbern, C. A., Pedas, P., Schjoerring, J. K., Knudsen, L., and Husted, S. 2005. Genotypic differences in manganese efficiency: field experiments with winter barley (Hordeum vulgare L.). Plant and Soil, 272(1-2), 233-244.

Husted, S., Laursen, K. H., Hebbern, C. A., Schmidt, S. B., Pedas, P., Haldrup, A., and Jensen, P. E. 2009. Manganese deficiency leads to genotype-specific changes in fluorescence induction kinetics and state transitions. Plant Physiology, 150(2), 825-833.

Kering, M. K., Lukaszewska, K., and Blevins, D. G. 2009. Manganese requirement for optimum photosynthesis and growth in NAD-malic enzyme C-4 species. Plant and Soil, 316(1-2), 217-226.

Leplat, F., Pedas, P. R., Rasmussen, S. K., and Husted, S. 2016. Identification of manganese efficiency candidate genes in winter barley (Hordeum vulgare) using genome wide association mapping. BMC genomics, 17(1), 775.

Liu, H., and Osborne, C. P. 2014. Water relations traits of C4 grasses depend on phylogenetic lineage, photosynthetic pathway, and habitat water availability. Journal of experimental botany, 66(3), 761-773. 
Lu, K., Kaeppler, S. M., Vogel, K. P., Arumuganathan, K., and Lee, D. J. 1998. Nuclear DNA content and chromosome numbers in switchgrass. Great Plains Research, 269-280.

Mariana, S., bologna Federico, P., maurino Verónica, G., Enrique, D., andreo Carlos, S., and drincovich María, F. 2004. Maize recombinant non-C 4 NADP-malic enzyme: a novel dimeric malic enzyme with high specific activity. Plant molecular biology, 55(1), 97-107.

McLaughlin, S. B., and Kszos, L. A. 2005. Development of switchgrass (Panicum virgatum) as a bioenergy feedstock in the United States. Biomass and Bioenergy, 28(6), 515-535.

Meyer, E., Aspinwall, M. J., Lowry, D. B., Palacio-Mejía, J. D., Logan, T. L., Fay, P. A., and Juenger, T. E. 2014. Integrating transcriptional, metabolomic, and physiological responses to drought stress and recovery in switchgrass (Panicum virgatum L.). BMC genomics, 15(1), 527.

Muir, J. P., Sanderson, M. A., Ocumpaugh, W. R., Jones, R. M., and Reed, R. L. 2001. Biomass production of 'Alamo'switchgrass in response to nitrogen, phosphorus, and row spacing. Agronomy Journal, 93(4), 896-901.

Nickelsen, J., and Rengstl, B. 2013. Photosystem II assembly: from cyanobacteria to plants. Annual review of plant biology, 64, 609-635.

Ning, P., Yang, L., Li, C., and Fritschi, F. B. 2018. Post-silking carbon partitioning under nitrogen deficiency revealed sink limitation of grain yield in maize. Journal of experimental botany, 69(7), 1707-1719.

Palmer, N. A., Donze-Reiner, T., Horvath, D., Heng-Moss, T., Waters, B., Tobias, C., and Sarath, G. 2015. Switchgrass (Panicum virgatum L) flag leaf transcriptomes reveal molecular signatures of leaf development, senescence, and mineral dynamics. Functional and integrative genomics, 15(1), 1-16.

Papadakis, I. E., Bosabalidis, A. M., Sotiropoulos, T. E., and Therios, I. N. 2007. Leaf anatomy and chloroplast ultrastructure of Mn-deficient orange plants. Acta Physiologiae Plantarum, 29(4), 297-301.

Parrish D.J., Fike J.H., Bransby D.I., Samson R 2008 Establishing and managing switchgrass as an energy crop. Forage and Grazinglands. doi:10.1094/FG-20080220-01-RV

Rao, X., Lu, N., Li, G., Nakashima, J., Tang, Y., and Dixon, R. A. 2016. Comparative cell-specific transcriptomics reveals differentiation of $\mathrm{C} 4$ photosynthesis pathways in switchgrass and other $\mathrm{C} 4$ lineages. Journal of experimental botany, 67(6), 1649-1662.

Saigo M., Bologna F.P., Maurino V.G., Detarsio E., Andreo C.S., Drincovich M.F. 2004. Maize recombinant non-C4 NADP-malic enzyme:a novel dimeric malic enzyme with high specific activity. Plant Molecular Biology 55, 97-107. 
Sanderson, M. A., Read, J. C., and Reed, R. L. 1999. Harvest management of switchgrass for biomass feedstock and forage production. Agronomy Journal, 91(1), 5-10.

Schmidt, S. B., Pedas, P., Laursen, K. H., Schjoerring, J. K., and Husted, S. 2013. Latent manganese deficiency in barley can be diagnosed and remediated on the basis of chlorophyll a fluorescence measurements. Plant and Soil, 372(1-2), 417-429.

Serba, D. D., Uppalapati, S. R., Krom, N., Mukherjee, S., Tang, Y., Mysore, K. S., and Saha, M. C. 2016. Transcriptome analysis in switchgrass discloses ecotype difference in photosynthetic efficiency. BMC genomics, 17(1), 1040.

Sharwood, R. E., Sonawane, B. V., and Ghannoum, O. 2014. Photosynthetic flexibility in maize exposed to salinity and shade. Journal of experimental botany, 65(13), 3715-3724.

Sommer, M., Bräutigam, A., and Weber, A. P. 2012. The dicotyledonous NAD malic enzyme C4 plant Cleome gynandra displays age dependent plasticity of $\mathrm{C} 4$ decarboxylation biochemistry. Plant Biology, 14(4), 621-629.

Sonawane, Balasaheb V., Robert E. 2018. Sharwood, Spencer Whitney, and Oula Ghannoum. "Shade compromises the photosynthetic efficiency of NADP-ME less than that of PEP-CK and NAD-ME C4 grasses." Journal of experimental botany 69, no. 12: 3053-3068.

Trapnell, C., Williams, B. A., Pertea, G., Mortazavi, A., Kwan, G., Van Baren, M. J., and Pachter, L. 2010. Transcript assembly and quantification by RNA-Seq reveals unannotated transcripts and isoform switching during cell differentiation. Nature biotechnology, 28(5), 511-515.

Vogel, K. P., Brejda, J. J., Walters, D. T., and Buxton, D. R. 2002. Switchgrass biomass production in the Midwest USA. Agronomy Journal, 94(3), 413-420.

Wang, Y., Bräutigam, A., Weber, A. P., and Zhu, X. G. 2014. Three distinct biochemical subtypes of $\mathrm{C} 4$ photosynthesis? A modelling analysis. Journal of experimental botany, 65: 3567-3578.

Washburn, J. D., Schnable, J. C., Davidse, G., and Pires, J. C. 2015. Phylogeny and photosynthesis of the grass tribe Paniceae. American Journal of Botany, 102(9), 1493-1505.

Wildner, G. F., and Henkel, J. 1978. Differential reactivation of ribulose 1, 5bisphosphate oxygenase with low carboxylase activity by Mn2+. FEBS Letters, 91(1), 99-103.

Wise, R. R. 2007. The diversity of plastid form and function. In The structure and function of plastids (pp. 3-26). Springer, Dordrecht.

Wright, R. J., Baligar, V. C., and Wright, S. F. 1988. Estimation of plant available manganese in acidic subsoil horizons. Communications in soil science and plant analysis, 19(6), 643-662. 
Young, M. D., Wakefield, M. J., Smyth, G. K., and Oshlack, A. 2010. Gene ontology analysis for RNA-seq: accounting for selection bias. Genome biology, 11(2), R14.

Zhang, C., Peng, X., Guo, X., Tang, G., Sun, F., Liu, S., and Xi, Y. 2018. Transcriptional and physiological data reveal the dehydration memory behavior in switchgrass (Panicum virgatum L.). Biotechnology for biofuels, 11(1), 91. 


\section{Figures}
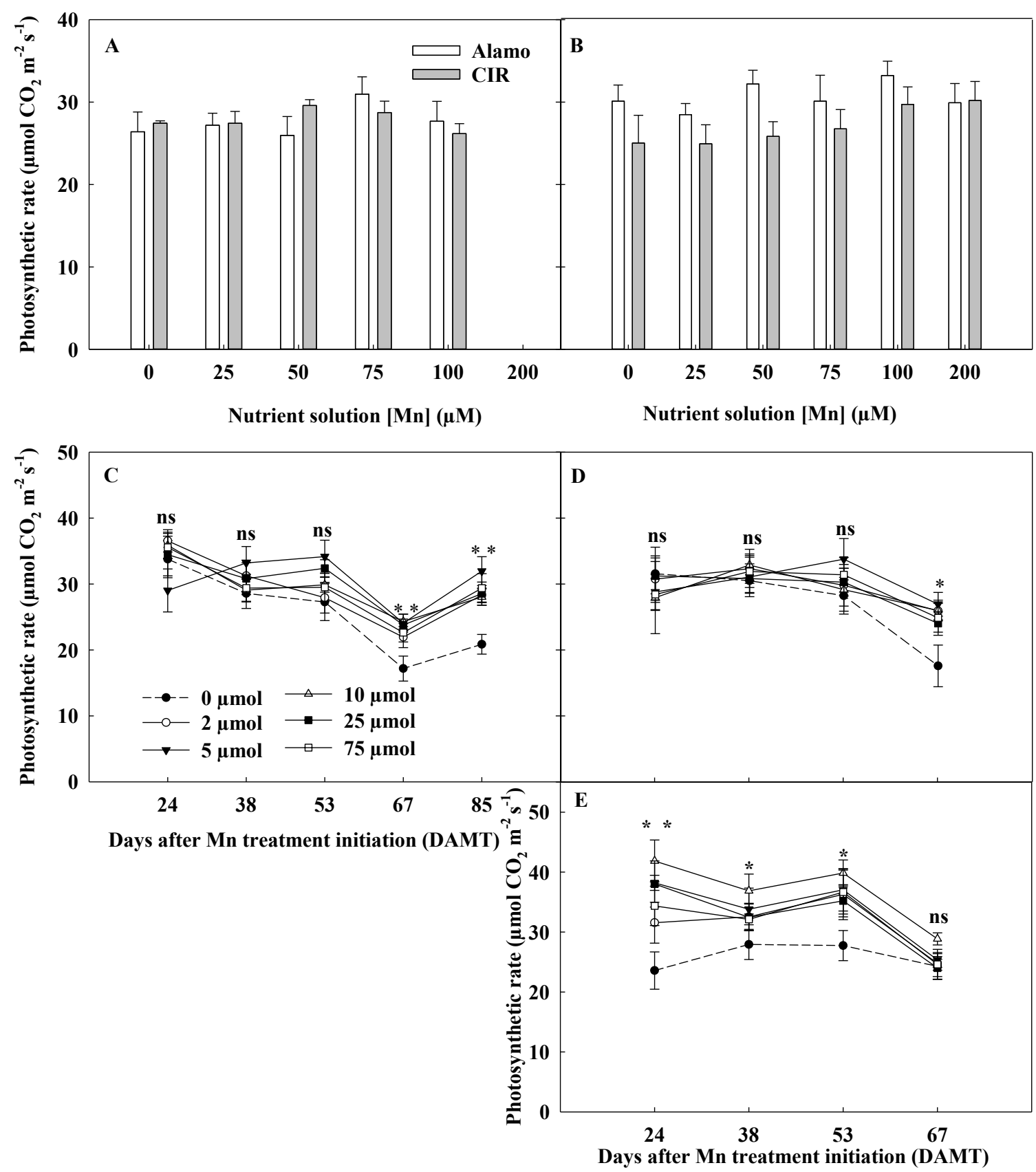

Figure 3-1. Leaf photosynthetic rate of two switchgrass genotypes, Alamo and Cave-inrock (CIR), and the pearl millet genotype KGraze. The two switchgrass genotypes were grown in sand and vermiculite, in 2014 (A), 2015 (B), respectively, and in 2016 (C: Alamo, D: CIR, and E: KGraze), all three entries were grown in perlite. Values are means \pm se ( $n=5$ in 2014 and 2015; $n=6$ in 2016). *, ** represent differences between Mn treatments within genotypes $(p<0.05), 0.01$; ns, not significant. No letters above bar means no significant difference between Mn treatments within genotypes $(p<0.05)$. 

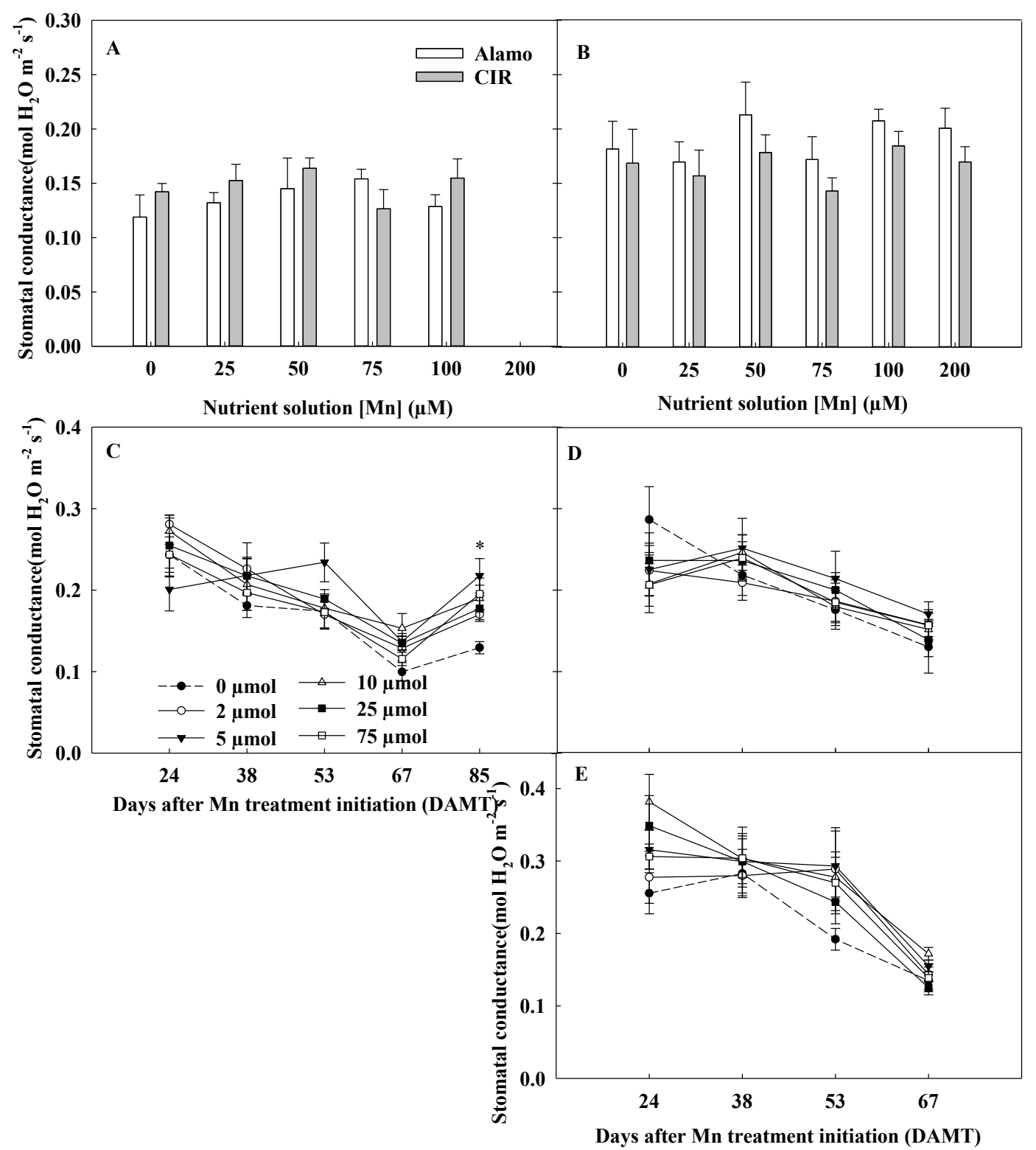

Figure 3-2. Stomatal conductance of two switchgrass genotypes, Alamo and Cave-in-rock (CIR), and the pearl millet genotype KGraze. The two switchgrass genotypes were grown in sand and vermiculite, in 2014 (A), 2015 (B), respectively, and in 2016(C: Alamo, D: $\mathrm{CIR}$, and E: KGraze), all three entries were grown in perlite. Values are means $\pm \mathrm{se}(\mathrm{n}=5$ in 2014 and 2015; $\mathrm{n}=6$ in 2016). ${ }^{*}$, represent differences between Mn treatments within genotypes $(p<0.05)$; ns, not significant. No letters above bar means no significant difference between $\mathrm{Mn}$ treatments within genotypes $(\mathrm{p}<0.05)$. 

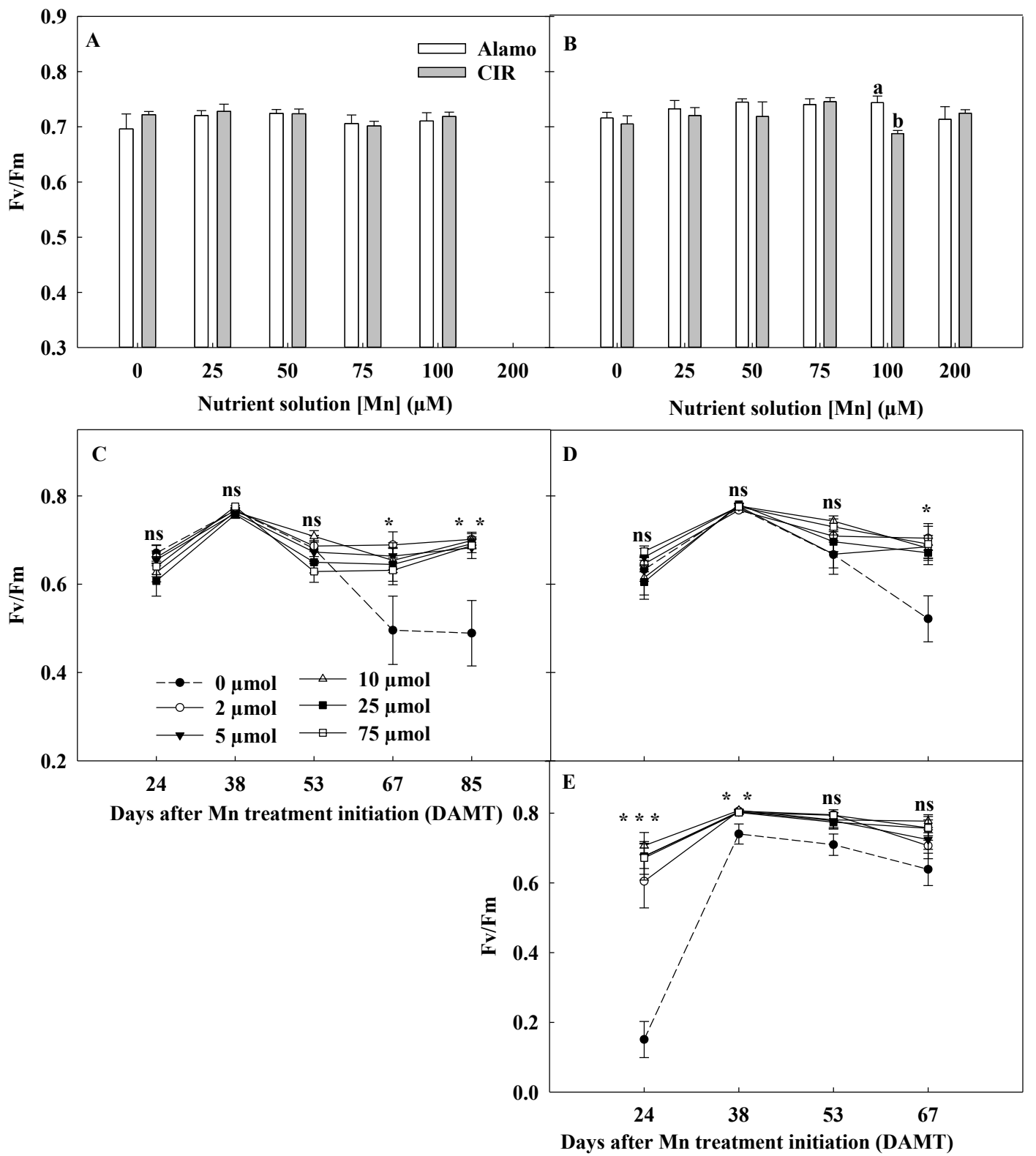

Figure 3-3. Fv/Fm ratios of two switchgrass genotypes, Alamo and Cave-in-rock (CIR), and the pearl millet genotype KGraze. The two switchgrass genotypes were grown in sand and vermiculite, in 2014 (A), 2015 (B), respectively, and in 2016(C: Alamo, D: $\mathrm{CIR}$, and E: KGraze), all three entries were grown in perlite. Values are means \pm se ( $\mathrm{n}=5$ in 2014 and 2015; $\mathrm{n}=6$ in 2016). Different letter indicate statistically significant difference among genotypes $(\mathrm{p}<0.05) ; *, * *, * * *$ represent differences between $\mathrm{Mn}$ treatments $(\mathrm{p}<0.05,0.01$ and 0.001$)$; ns, not significant. 

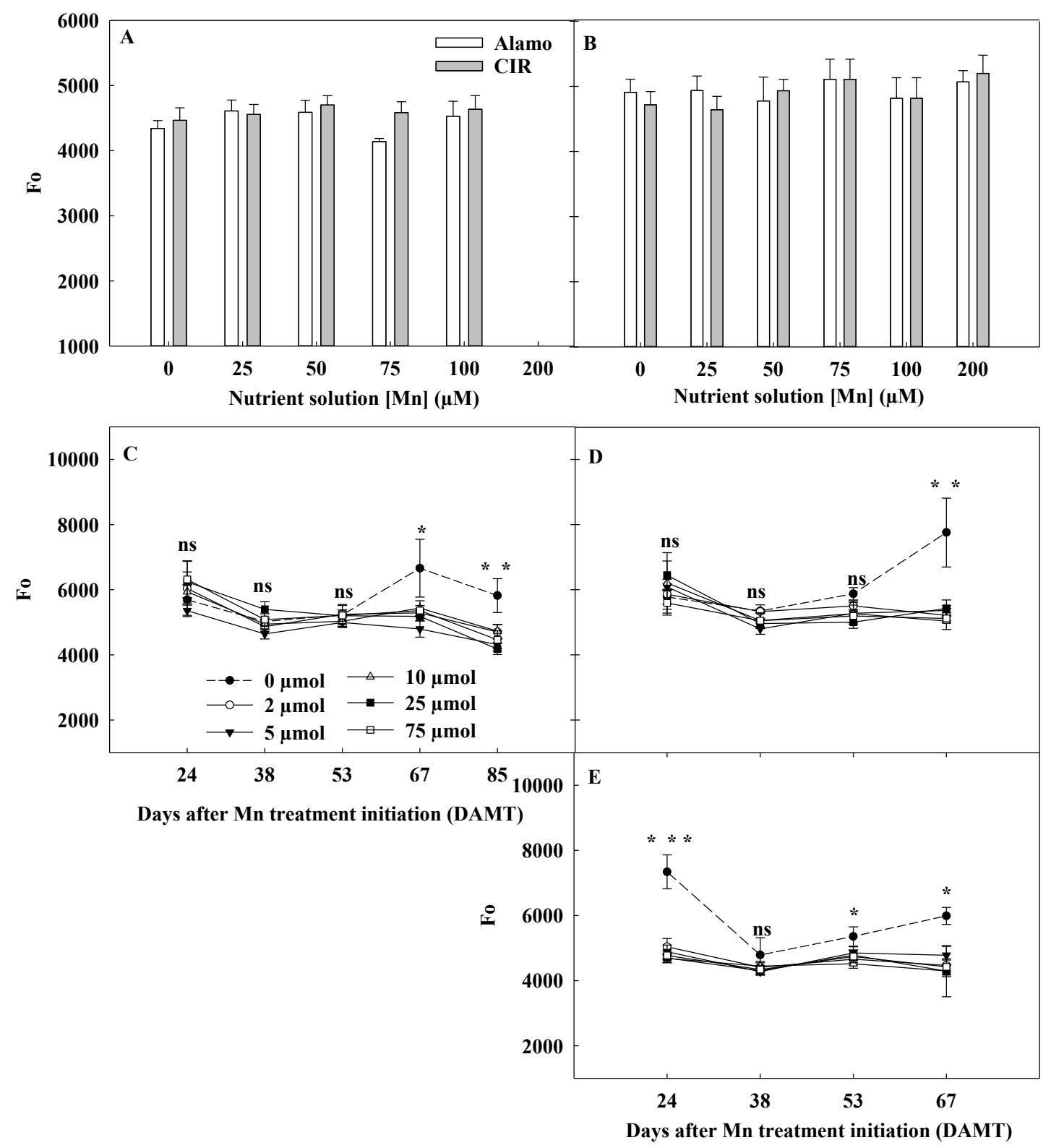

Figure 3-4. Minimal chlorophyll fluorescence (Fo) of two switchgrass genotypes, Alamo and Cave-in-rock (CIR), and the pearl millet genotype KGraze. The two switchgrass genotypes were grown in sand and vermiculite, in 2014 (A), 2015 (B), respectively, and in 2016(C: Alamo, D: CIR, and E: KGraze), all three entries were grown in perlite. Values are means \pm se ( $n=5$ in 2014 and 2015; $n=6$ in 2016). No letter above the bar indicates no significant statistically difference between Mn treatments $(\mathrm{p}<0.05) ;{ }^{*}, * *$, *** represent differences between Mn treatments ( $\mathrm{p}<0.05,0.01$ and 0.001$)$; ns, not significant. 

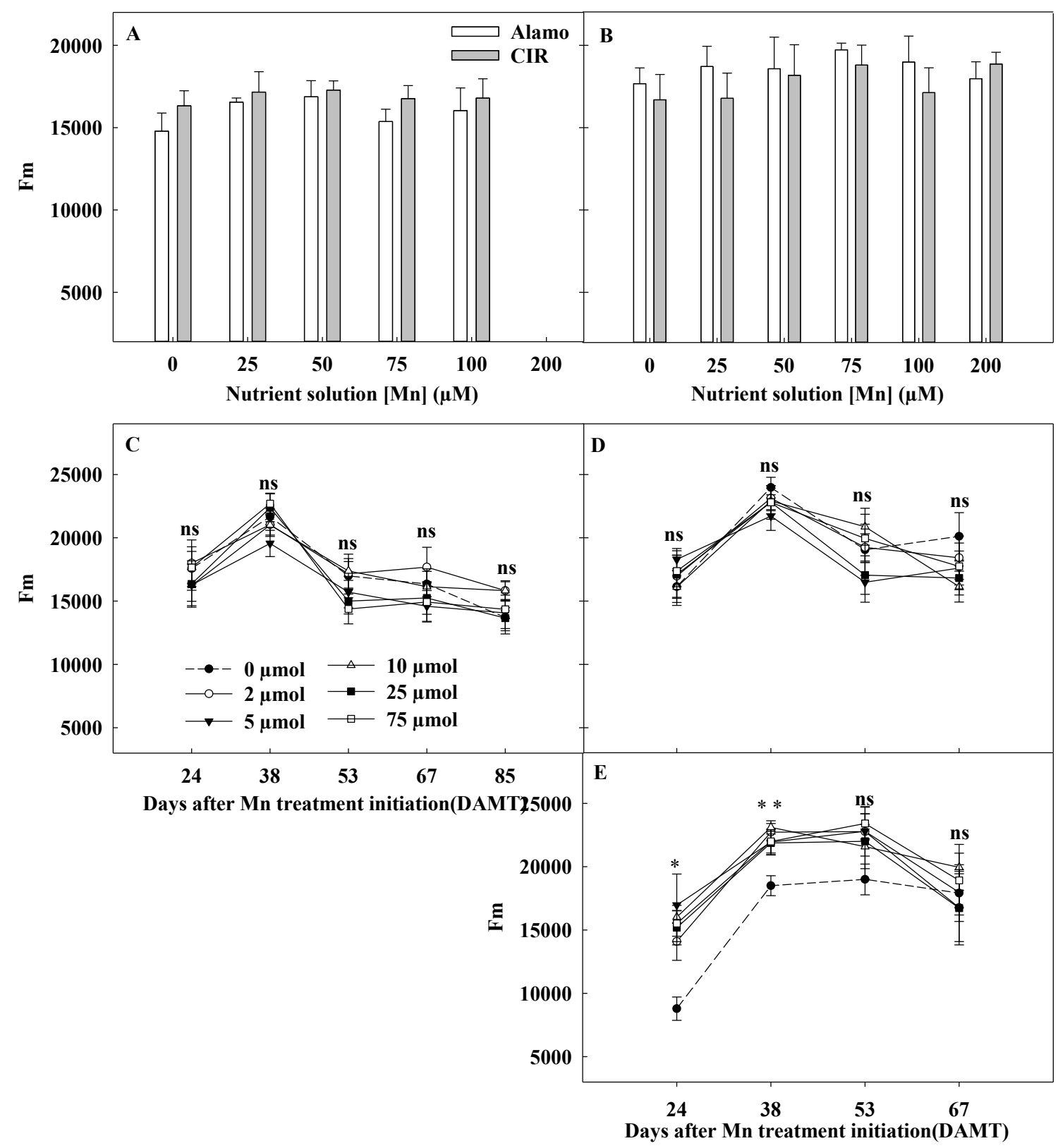

Figure 3-5. Maximum chlorophyll fluorescence (Fm) of two switchgrass genotypes, Alamo and Cave-in-rock (CIR), and the pearl millet genotype KGraze. The two switchgrass genotypes were grown in sand and vermiculite, in 2014 (A), 2015 (B), respectively, and in 2016 (C: Alamo, D: CIR, and E: KGraze), all three entries were grown in perlite. Values are means \pm se ( $n=5$ in 2014 and 2015; $n=6$ in 2016). No letter above the bar indicates no significant statistically difference between Mn treatments $(\mathrm{p}<$ $0.05) ; * * *, * * *$ represent differences between Mn treatments $(\mathrm{p}<0.05,0.01$ and 0.001$)$; ns, not significant. 


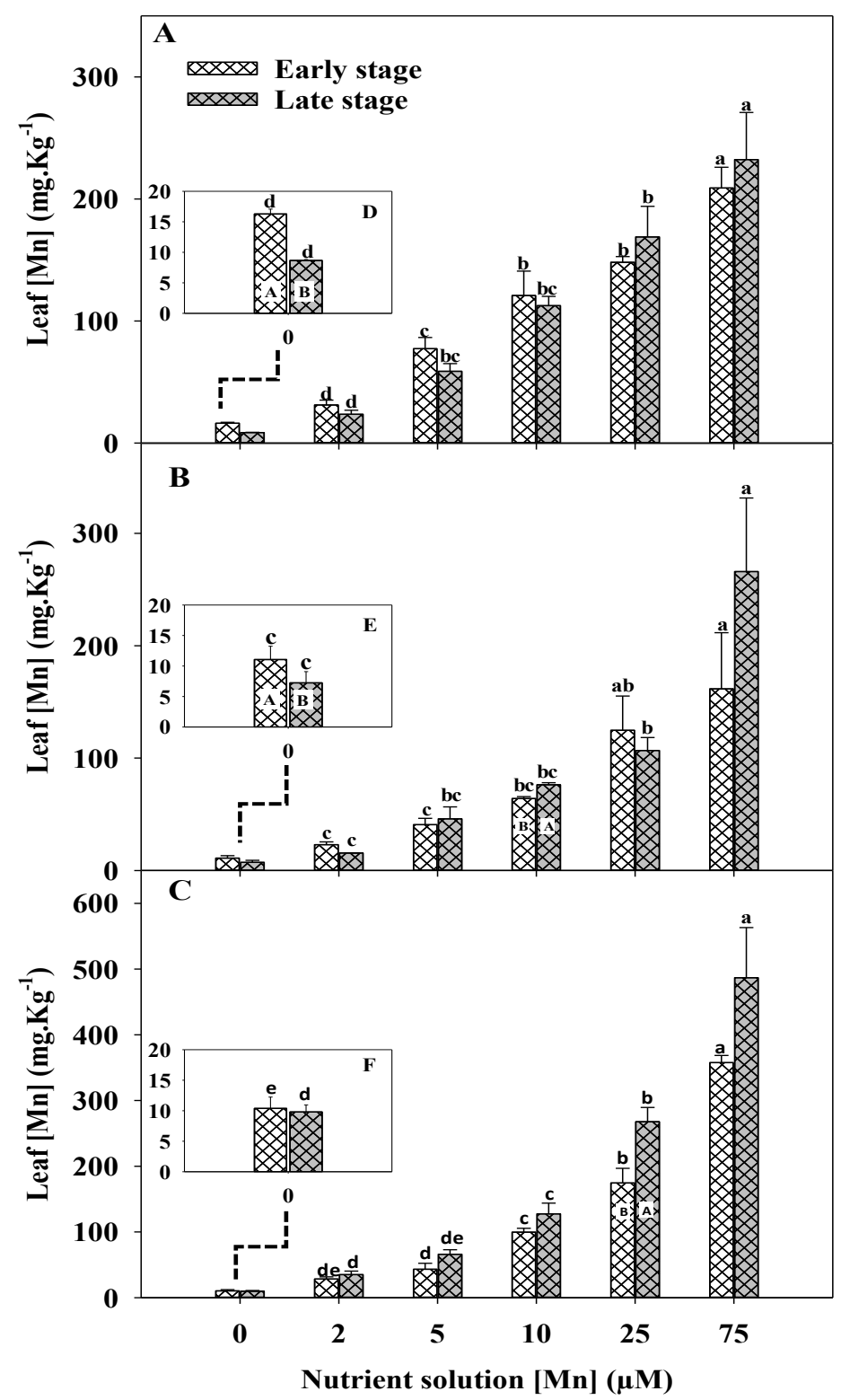

Figure 3-6. Leaf Mn concentrations of two switchgrass genotypes, Alamo and Cave-inrock (CIR), and the pearl millet genotype KGraze in 2016. All three entries were grown in perlite. Leaf Mn concentrations of Alamo (A), CIR(B), and KGraze (C) collected at early (24DAMT) and late stage (67DAMT). The insert in figure shows leaf $\mathrm{Mn}$ concentrations of Alamo (D), CIR(E), and KGraze (F) in treatment with no Mn addition.Values are means $\pm \mathrm{se}(\mathrm{n}=3$, early stage; $\mathrm{N}=4$ late stage). Different lower-case letters above the columns indicate statistically significant differences among $\mathrm{Mn}$ treatments, while different upper-case letters represent differences between stages $(p<$ $0.05)$. 


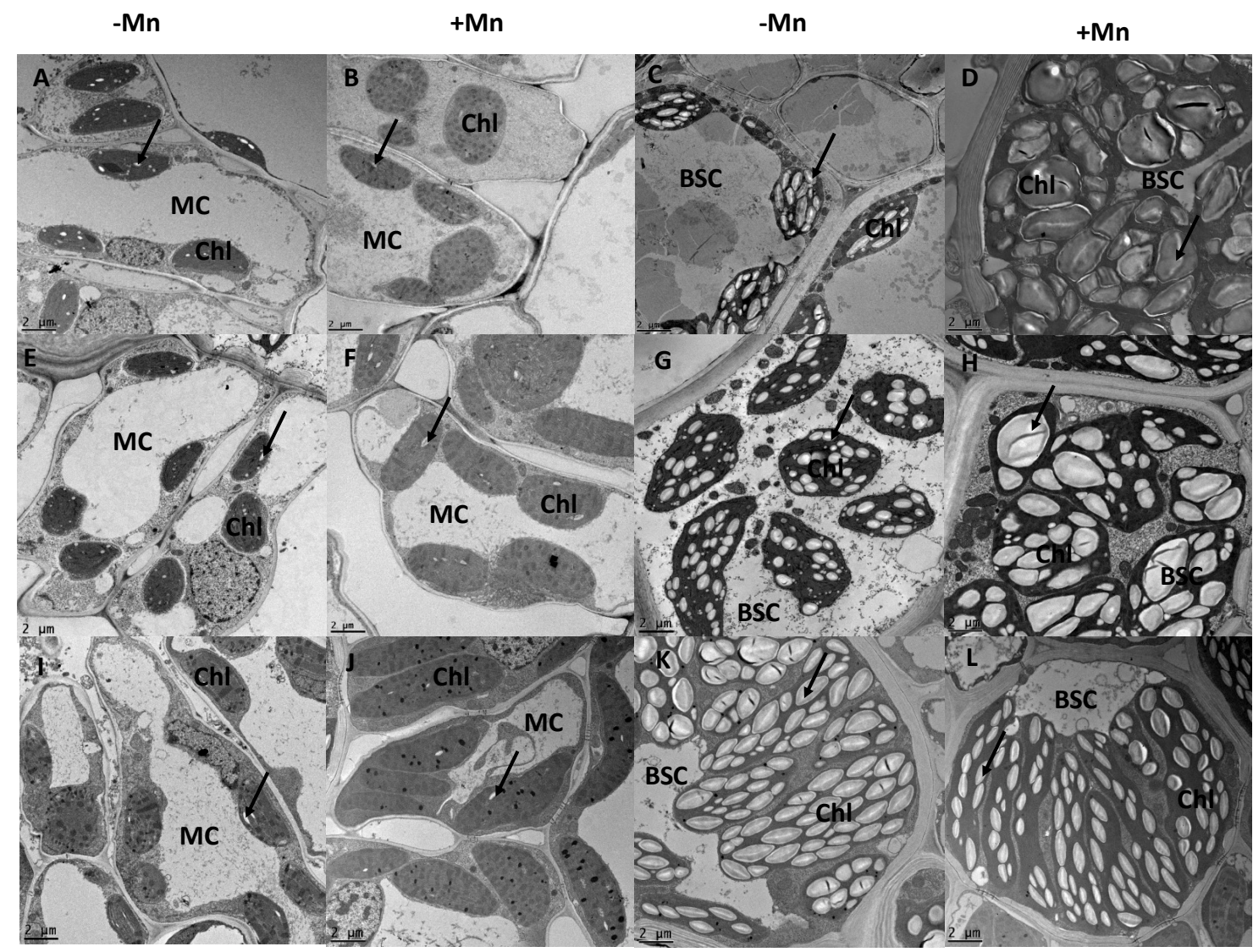

Figure3-7. Transmission electron micrographs of chloroplasts with starch granules in leaves of two switchgrass genotypes Alamo, Cave-in-rock and the pearl millet genotype KGraze in 2016. A-D, E-H and I-L show leaf ultrastructure images of Alamo, Cave-inrock and KGraze at 67DAMT, reapectively. Arrows indicate the starch granules. BSC, bundle sheath cell; Chl, chloroplast; MC, mesophyll cell. Scale bars: $2 \mu \mathrm{m}$. 

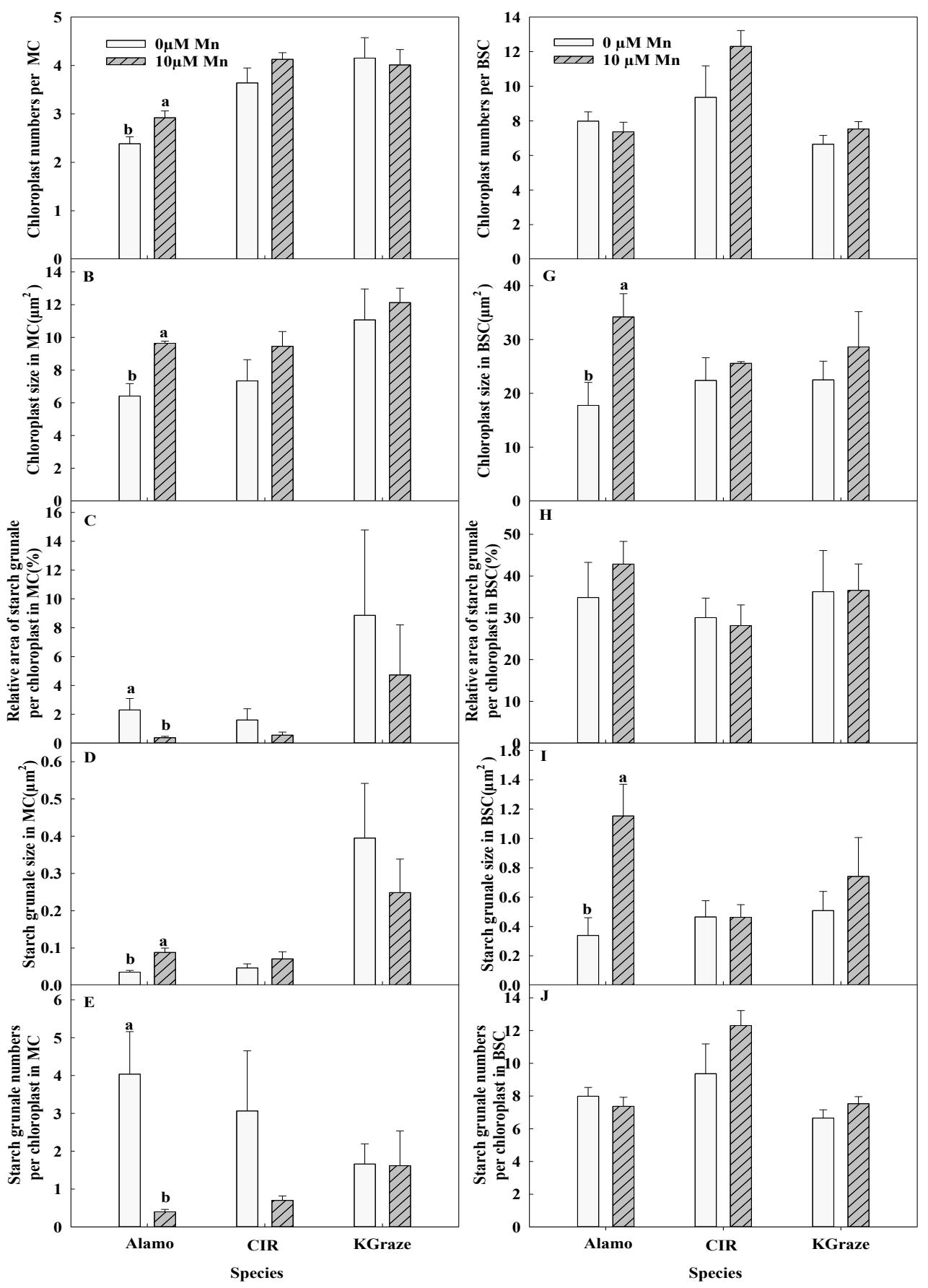

Figure3-8. Anatomical changes of chloroplasts in mesophyll cells (MC) and bundle sheath cell (BSC) of two switchgrass genotypes, Alamo and Cave-in-rock (CIR), and the pearl millet genotype KGraze in 2016. Different letters above the columns indicate significant statistically difference between Mn treatments $(\mathrm{p}<0.05)$. Values are means \pm se $(\mathrm{n}=4)$. No letters above bar means no significant deferences between Mn treatments $(\mathrm{p}<0.05)$. 


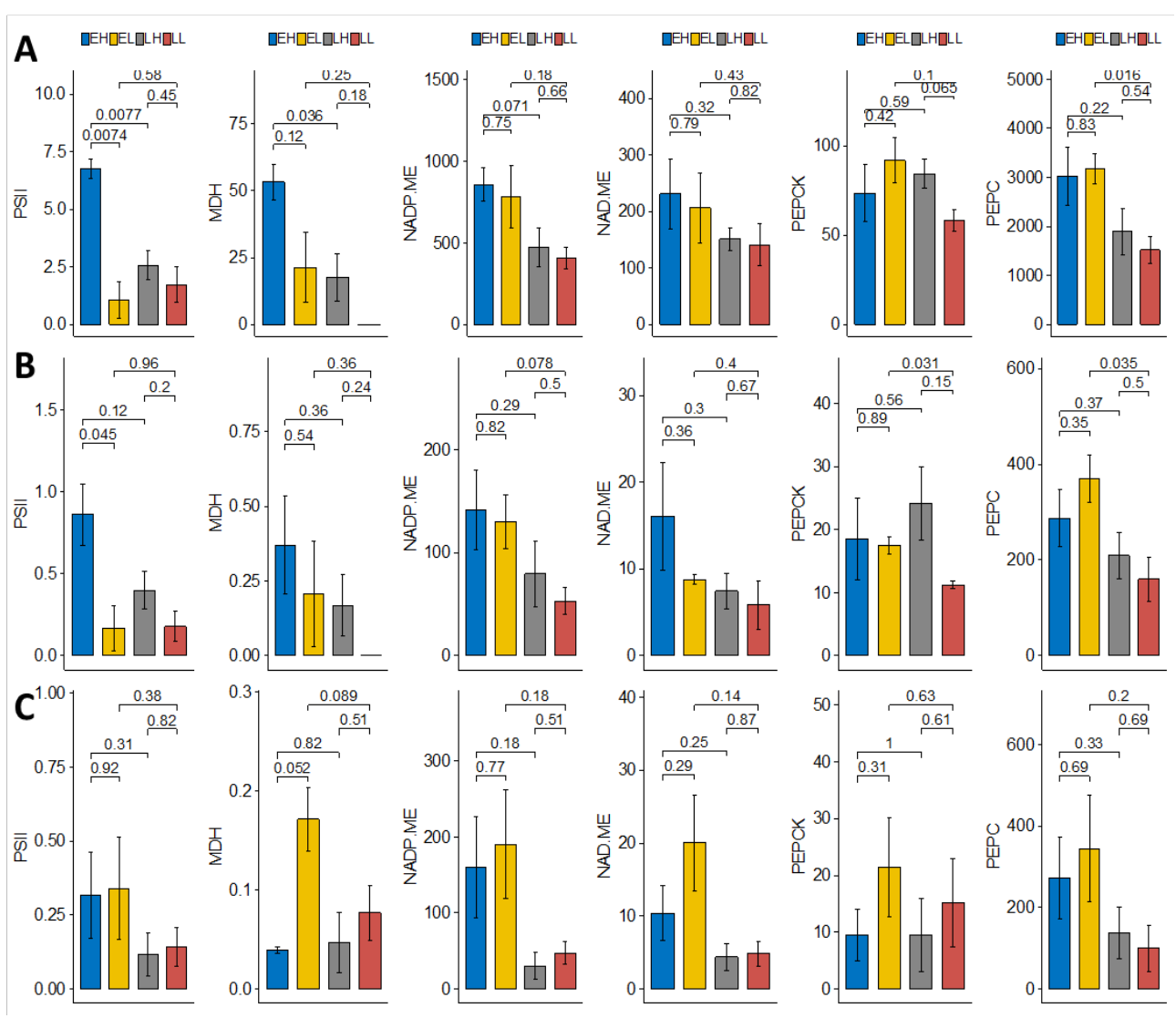

Figure 3-9. Gene expression levels of PSII, MDH, NADP-ME, NAD-ME, PEPCK and PEPC in two switchgrass genotypes leaves, Alamo and Cave-in-rock in 2016. A: Gene expression levels (FPKM) in Alamo by RNA -seq analysis, B: Gene relative expression levels in Alamo by qPCR analysis. C: Gene relative expression levels in Cave-in-rock by qPCR analysis. Data value is P value. EH: early (24DAMT) stage with $10 \mu \mathrm{M} \mathrm{Mn;} \mathrm{EL:}$ early (24DAMT) stage with $0 \mu \mathrm{M}$ Mn. LH: late (67 DAMT) stage with $10 \mu \mathrm{M} \mathrm{Mn,} \mathrm{LL:}$ late (67 DAMT) stage with $0 \mu \mathrm{M} M n,(n=3)$. 


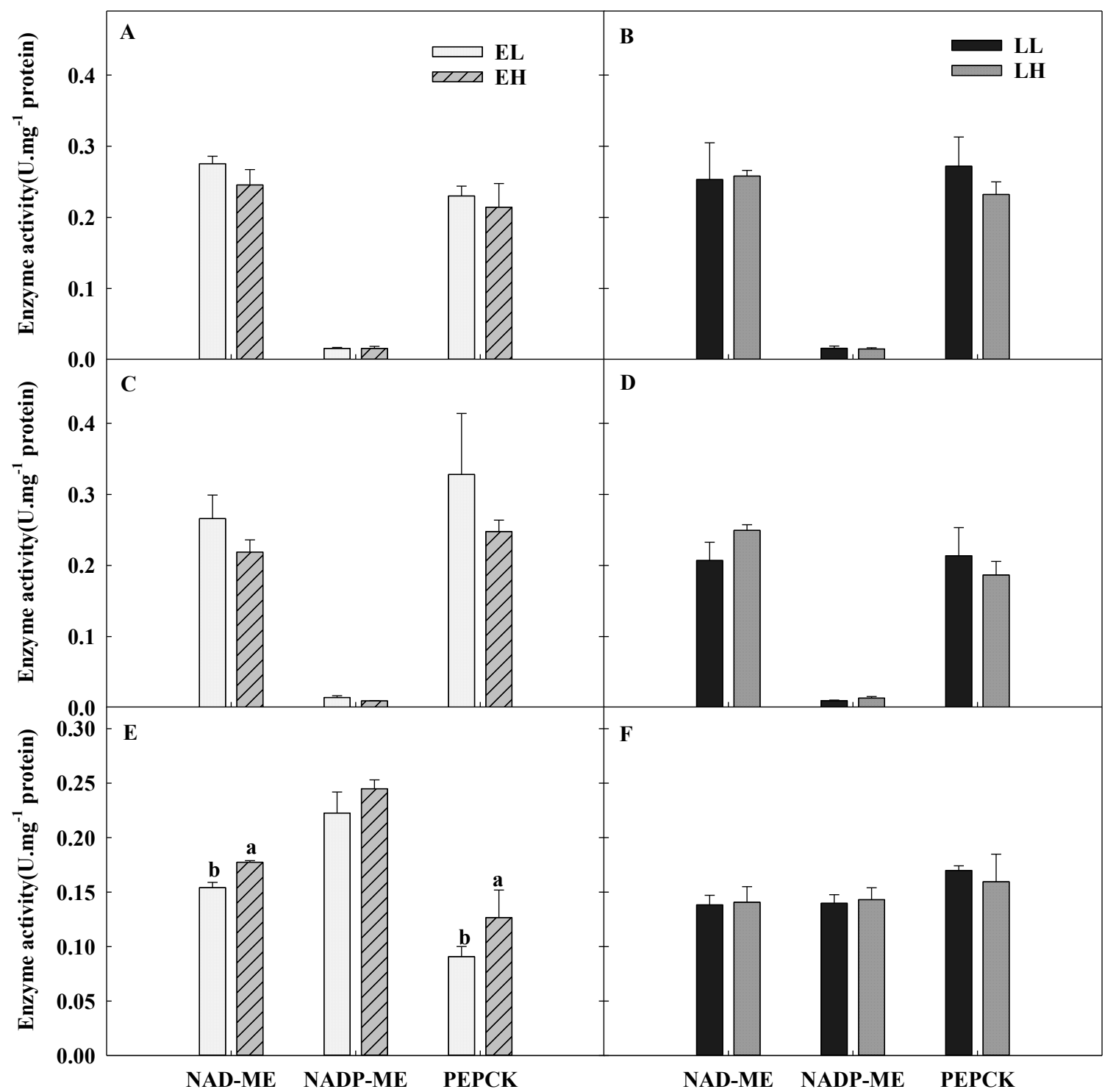

Figure 3-10. Enzyme activity in leaves of two switchgrass genotypes, Alamo and Cavein-rock (CIR), and the pearl millet genotype KGraze in 2016. A-B, C-D and E-F show enzyme activity in leaves of Alamo, Cave-in-rock and KGraze, respectively. Values are means \pm se $(\mathrm{n}=3)$. EH: early (24DAMT) stage with $10 \mu \mathrm{M} \mathrm{Mn}$; EL: early (24DAMT) stage with $0 \mu \mathrm{M}$ Mn. LH: late (67 DAMT) stage with $10 \mu \mathrm{M}$ Mn, LL: late (67 DAMT) stage with $0 \mu \mathrm{M} \mathrm{Mn}$. Different letters above the columns indicate statistically significant difference between $\mathrm{Mn}$ treatments $(\mathrm{p}<0.05)$. No letters above bar means no statistically significant difference between Mn treatments $(p<0.05)$. 


\section{CHAPTER 4}

\section{Conclusions}

All plants require $\mathrm{Mn}$ for growth, but since NAD-ME is thought to have an absolute requirement for $\mathrm{Mn}$, NAD-ME type $\mathrm{C} 4$ plants may require more Mn for growth and reproduction than non-NAD-ME plants. Therefore, as an NAD-ME C4 plant, switchgrass photosynthesis and growth may be responsive to higher Mn availability. However, only limited information is available on the Mn responses to Mn availability. The objective of this study was to develop a better understanding of switchgrass responses in biomass production and photosynthetic characteristics to Mn availability.

The results revealed that shoot $\mathrm{Mn}$ concentration was highly responsive to increasing Mn concentration in the nutrient solution in all experiments and for all entries. In switchgrass, leaf Mn concentration was significantly greater early than late in the season in the absence of $\mathrm{Mn}$ in the nutrient solution; however, this was not the case for pearl millet. When grown in washed sand and vermiculite, no Mn treatment effects on biomass production were found for either switchgrass ecotype. In perlite, a significant decrease in biomass production was found in $0 \mu \mathrm{M}$ Mn treatment compared to 10-25 $\mu \mathrm{M}$ Mn treatments for Alamo and KGraze, but not for Cave-in-Rock. Late in the season, relative chlorophyll contents of both switchgrass ecotypes were significantly lower in the $0 \mu \mathrm{M}$ Mn treatment than other treatments, but, in KGraze, relative chlorophyll content was low early in the season, increased throughout the season, resulting in less pronounced, but still significant differences, at late stages. 
In switchgrass, the absence of $\mathrm{Mn}$ in the nutrient solution significantly decreased photosynthetic rates and maximum PSII efficiency $\left(\mathrm{F}_{\mathrm{v}} / \mathrm{F}_{\mathrm{m}}\right)$ late in the season. In contrast, more pronounced effects on pearl millet net photosynthesis and $\mathrm{F}_{\mathrm{v}} / \mathrm{F}_{\mathrm{m}}$ to absence of $\mathrm{Mn}$ in the nutrient solution were observed early in the season. Chloroplast ultrastructure in mesophyll and bundle sheath cells were only affected by Mn availability in the lowland switchgrass ecotype 'Alamo'. In contrast, Mn availability did not influence NAD-ME, NADP-ME and PEPCK activities in switchgrass, but NAD-ME and PEPCK activities were reduced in pearl millet early in the season in the absence of $\mathrm{Mn}$ in the nutrient solution.

Over all, the results indicated that switchgrass and pearl millet biomass production responses to increasing levels of Mn availability in the nutrient solution were minimal. Even small amounts of $\mathrm{Mn}$ in the nutrient solution were sufficient to maximize biomass production. Absence of $\mathrm{Mn}$ in the nutrient solution reduced net photosynthesis in switchgrass toward the end of the season, but had a bigger impact early in the season in pearl millet. Based on reduced maximum PSII efficiencies $\left(\mathrm{F}_{\mathrm{v}} / \mathrm{F}_{\mathrm{m}}\right)$ and no effect of $\mathrm{Mn}$ deficiencies on NAD-ME, NADP-ME, and PEPCK activities in switchgrass, the primary limitation to net photosynthesis appears to be due to limited Mn for the OEC complex. In pearl millet, Mn deficiency early in the season resulted in strong chlorosis, reduced net photosynthesis, and lower $\mathrm{F}_{\mathrm{v}} / \mathrm{F}_{\mathrm{m}}$, but these effects disappeared or became less pronounced as the season progressed. Thus, despite small reductions in NAD-ME and PEPCK activities early in the season, the light reactions were likely the main limitation for photosynthesis under Mn deficient condtions. Although both species are classified as NAD-ME C4 types, NADP-ME activity was greater than NAD-ME and PEPCK in leaves 
of pearl millet early in the season. Additional research is needed to elucidate the mechanisms underlying the different responses of switchgrass and pearl millet to $\mathrm{Mn}$ availability. 


\section{Appendix. Global transcript abundance analysis in switchgrass and pearl millet leaves}

C4 plants have traditionally been grouped into NAD-ME, NADP-ME, and PEPCK subtypes, interestingly, it is now clear that the different $\mathrm{C} 4$ photosynthetic pathways can coexist (Wang et al., 2014; Liu and Osborne, 2014; Sharwood et al., 2014; Rao et al., 2016). It should be noted, the flexibility among the three subtypes might be controlled by environmental and developmental conditions (Sommer et al., 2012; Wang et al., 2014; Sharwood et al., 2014). Additionally, several C4 plants have been shown to conduct $\mathrm{C} 3$ photosynthesis along the leaf blade and at different leaf ages and positions and during seedling stage (Dai et al., 1995; Ghannoum et al., 1998).

While categorized as an NAD-ME C4 plant, PEPCK activity has been observed in young switchgrass leaves (Rao et al., 2016), and NAD-ME, NADP-ME and PEPCK activities have been reported in switchgrass at different developmental stages (Prendergast et al., 1987; Rao et al., 2016). Thus, it is possible that switchgrass and pearl millet may be able to shift the emphasis among C4 pathways away from the Mn-requiring NAD-ME pathway when Mn availability is limited, and thus minimize impact on growth. In addition to its role in photosynthesis as part of the OEC and for NAD-ME, Mn plays other critical roles in plants, including as an activator of a wide variety of enzymes (Marshner, 1995). Given the many important roles of Mn in plants, an analysis of Mn availability on global gene expression pattern in leaf tissues is of interest. Therefore, transcript abundance was examined based on RNA-seq analysis on leaf tissues collected from plants grown in pearlite with 0 and $10 \mu \mathrm{M} \mathrm{Mn}$ in the nutrient solution. 
High quality mRNA from leaf blade samples from 0 and $10 \mu \mathrm{M}$ Mn treatments were collected at 24 and 67 DAMT and were sent to Novogene for RNA-seq library construction and sequencing and preliminary analysis.

\section{Preliminary results}

Raw reads per sample ranged from 41.3 to 55.8 million which, following processing for quality reads, produced $>7.03 \mathrm{G}$ clean bases per sample. Among the total bases, $\sim 54.11 \%$ were G and C (Appendix Table.S3-2). Approximately $95.8 \%$ of the reads were mapped to the exon regions in the switchgrass genome (Appendix Fig 3-2), while the remaining reads were mapped either to intron or intergenic regions.

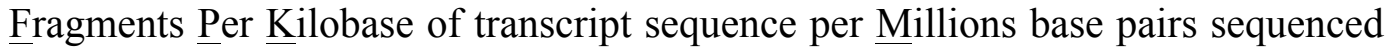
(FPKM) values were used to estimate gene expression levels, and overall FPKM distribution patterns among the different treatments were similar (Appendix Fig 3-3). Pearson correlation analysis between results from all biological replicates and treatments was performed, and revealed that all $\mathrm{R}^{2}$ between different biological replications of the same treatment were larger than 0.84 (Appendix Fig 3-4).

Read counts were used as the input data for differential gene expression analysis which revealed 59 genes that were differentially expressed between 0 and $10 \mu \mathrm{M} \mathrm{Mn}$ treatments in leaf blades sampled early (24 DAMT), 70 genes that were differentially expressed between 0 and $10 \mu \mathrm{M}$ Mn treatments in leaf blades sampled late (24 DAMT), 110 genes that were differentially expressed between leaf blades sampled early vs late from $10 \mu \mathrm{M}$ Mn treatments, and 437 genes that were differentially expressed between leaf blades sampled early vs late from $0 \mu \mathrm{M}$ Mn treatments (Appendix Fig 3-5). For each comparison, both up- and down-regulated genes were identified. Of primary interest for 
this study are the comparisons between Mn treatments within sampling date. Among these, 39 genes were down-regulated while 20 were up-regulated in 10 compared to $0 \mu \mathrm{M}$ Mn treatments of early-sampled leaf blades, and 40 genes were down-regulated while 30 were up-regulated in 10 compared to $0 \mu \mathrm{M}$ Mn treatments of late-sampled leaf blades (Appendix Fig. 3-5) Examination of the Venn diagram in Appendix Figure 3-6, reveals that 40 out of 59 were uniquely expressed genes that responded to Mn treatment at 24 DAMT, while the number is reduced from 49 out of 70 were uniquely differentially expressed at 67 DAMT. Of particular interest among all the genes that specifically responded to Mn treatment, only one gene, Pavir.J10128, was differentially expressed at both sampling time points. Unfortunately, there is no functional annotation associated with this gene at present, but its transcript abundance was. It made the gene as one of top favorite candidates for following studies, the gene functional study in particular.

Cluster analysis (Appendix Fig 3-7 A) is used to find genes with similar expression patterns under various experimental conditions. Among the genes of particular interest for this study are PSII and malate dehydrogenase (MDH) and thus, genes with very similar expression pattern may also be of importance. The expression pattern of seven genes were very similar to that $M D H$ (Appendix Fig. 3-7B), and five genes displayed an expression pattern that was very similar to PSII (Appendix Fig. 3-7C). Based on their expression pattern alone, these genes may be of interest with respect to switchgrass response to low Mn availability and deserve closer examination.

Another widely used way to describe cellular component, molecular function and biological process of genes is by the gene ontology (GO) terms analysis. A GO enrichment bar chart is generally used to illustrate the differentially expressed genes 
enriched GO terms and the counts of genes for each GO terms. However, one caveat of GO term analysis is the quality of the gene annotations of the reference genome. A better annotation of reference genome could definitely provide one more reliable results. An example here is from the DEG by comparing high (EH) and low Mn (EL) levels at early stage (Appendix Fig S3-8B). Among the most enriched GO terms biological process, there are heterocycle catabolic process, organic cyclic compound catabolic, cellular nitrogen compound catbolic, DNA mediated transformation, aromatic compound catabolic, sensory perception of taste, light-harvesting complex protein, et al. But one interesting biological process is photosynthesis (Appendix Fig 3-8A). From the bar plot, there is one gene from down-regulated gene list and another one from up-regulated gene list were reported to be involved in the photosynthesis. Especially, when looking at the expression levels of PSII gene under these two treatments, the FPKM levels are significantly different (Appendix Fig S3-8C). It may suggest the two genes involved in the photosynthesis may work together, or interact, with PSII gene in the biological process.

Instead of looking at a single gene, KEGG (Kyoto Encyclopedia of Genes and Genomes) is a way to mine the interactions of multiple genes that may be involved in certain biological functions. In Fig S3-6, enrichment degree of KEGG can be measured through Rich factor, Qvalue and genes counts enriched to this pathway. Rich factor is the ratio of DEGs counts to this pathway in the annotated genes counts. The more the Rich factor is, the higher is the degree of enrichment. Qvalue is the adjusted p-value after multiple hypothesis testing, and its range is $[0,1]$. The more the qvalue is close to zero, the more significant is the enrichment. Top 20 most significant enriched pathways are 
chosen in KEGG scatter plot. Cysteine and methionine metabolism, Circadian rhythm plant, Carotenoid biosynthesis, Carbon metabolism, Carbon fixation in photosynthetic organisms, Biosynthesis of amino acids, et al., are among the top list of DEG that identified at the same $\mathrm{Mn}^{2+}$ level but two different growth stages. Genes for biomass and amino acid production that are necessity for plant growth seem quite different between different stages and it totally makes sense. The top four most significant enrichment pathways were listed here in the supplementary Appendix Table 3-3. It is worthy to point out that the gene $M D H$ is heavily involved in those four pathways which indicates the important role of this gene in development of switchgrass under low $\mathrm{Mn}^{2+}$ stress. Because these pathways and $M D H$ gene were not identified in any other conditions/treatment 


\section{APPENDIX TABLES AND FIGURES}

Appendix Table 2-1. Shoot Mn concentration of switchgrass (Alamo and Cave-in-rock) and pearl millet (KGraze) grown with nutrient solutions containing different $\mathrm{Mn}$ concentrations. Different lower-case letters represent significant differences between ecotypes and species. Different upper-case letters indicate significant differences between years within genotype and $\mathrm{Mn}$ treatment $(\mathrm{p}<0.05)$.

\begin{tabular}{|c|c|c|c|c|c|c|c|}
\hline \multirow{2}{*}[\mathrm{Mn}]{} & \multicolumn{2}{|c|}{2014} & \multicolumn{2}{|c|}{2015} & \multicolumn{3}{|c|}{2016} \\
\hline & Alamo & Cave-in-rock & Alamo & Cave-in-rock & Alamo & Cave-in-rock & KGraze \\
\hline$(\mu \mathrm{M})$ & & & & Shoot Mn & & & \\
\hline \multicolumn{8}{|c|}{ concentration $\left(\mathrm{mg} \mathrm{kg}^{-1}\right)$} \\
\hline 0 & $87.14 \mathrm{bA}$ & $143.33 \mathrm{aA}$ & $75.15 \mathrm{aB}$ & $57.83 \mathrm{aB}$ & $3.8 \mathrm{aC}$ & $2.89 \mathrm{aC}$ & $3.64 \mathrm{a}$ \\
\hline 2 & ----- & ----- & ----- & ----- & $11.23 b$ & $21.35 \mathrm{a}$ & $17.66 \mathrm{a}$ \\
\hline 5 & ----- & ----- & ----- & ----- & $29.78 b$ & $51.39 \mathrm{a}$ & $38.17 b$ \\
\hline 10 & ----- & ----- & ----- & ----- & $54.17 b$ & $81.71 \mathrm{a}$ & $66.04 \mathrm{ab}$ \\
\hline 25 & $148.02 \mathrm{aB}$ & $152.87 \mathrm{aA}$ & $217.03 \mathrm{aA}$ & $145.01 \mathrm{bA}$ & $108.82 \mathrm{cB}$ & $168.61 \mathrm{aA}$ & $134.56 b$ \\
\hline 50 & $203.49 a$ & $217.42 \mathrm{a}$ & $246.70 \mathrm{a}$ & $203.74 a$ & ----- & ----- & ----- \\
\hline 75 & $234.78 \mathrm{aB}$ & $182.52 \mathrm{aB}$ & $325.52 \mathrm{aA}$ & $264.18 \mathrm{aA}$ & $263.85 \mathrm{aB}$ & $305.7 \mathrm{aA}$ & $304.17 \mathrm{a}$ \\
\hline 100 & $247.74 a$ & $265.95 \mathrm{a}$ & $326.24 a$ & $281.91 \mathrm{a}$ & ----- & ----- & ----- \\
\hline 200 & ----- & ----- & $515.94 a$ & $441.76 \mathrm{a}$ & ----- & ----- & ----- \\
\hline
\end{tabular}


Appendix Table 2-2. Total biomass, shoot biomass, and root + rhizome biomass of two switchgrass cultivars grown with nutrient solutions containing different Mn concentrations. Different letters represented significant statistically difference between ecotypes $(\mathrm{p}<0.05)$.

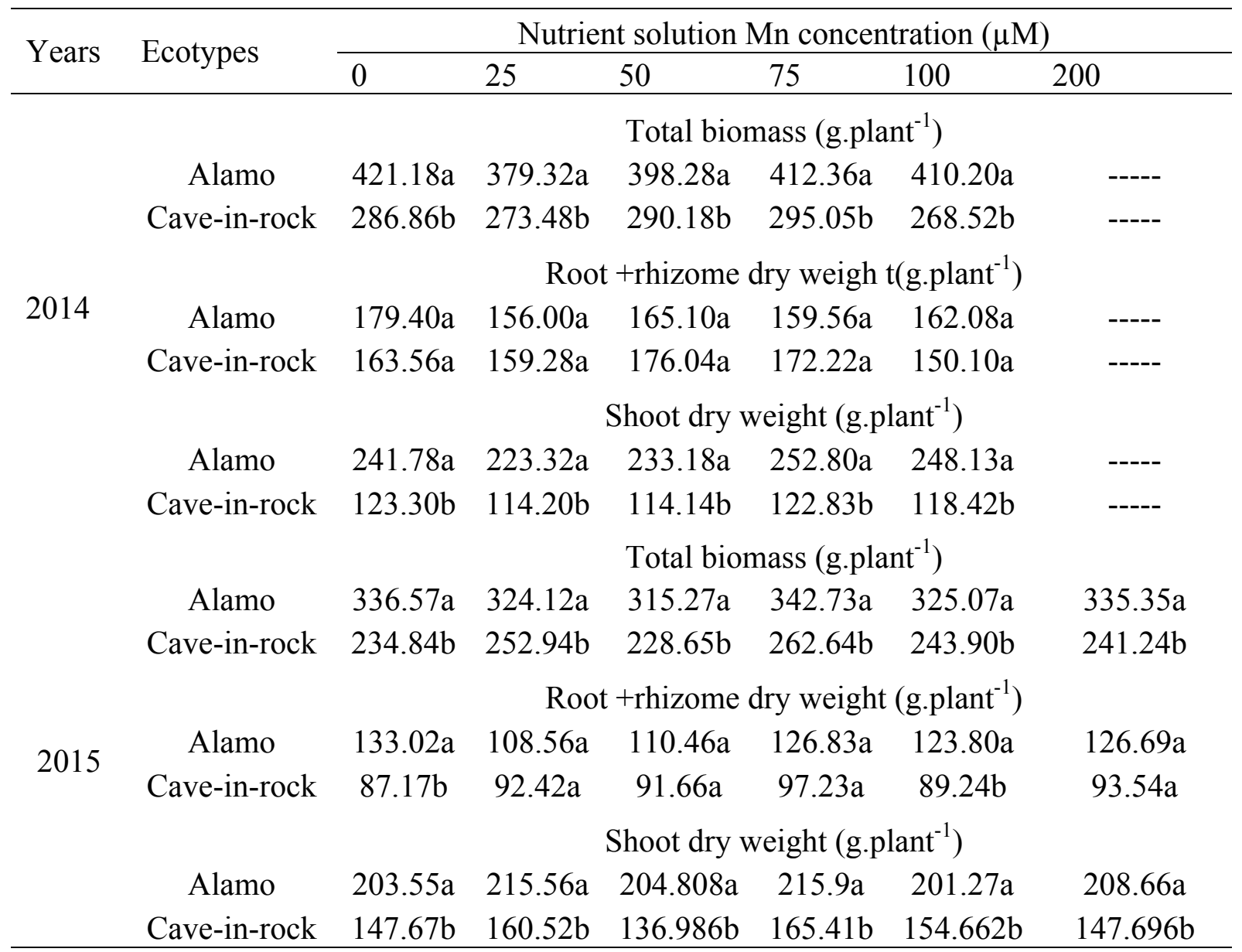


Appendix Table 2-3. Total biomass, shoot biomass, and root biomass (including rhizomes for switchgrass), of two switchgrass cultivars and the pearl millet KGraze grown with nutrient solutions containing different Mn concentrations in 2016. Different letters represented significant differences between entries $(\mathrm{p}<0.05)$.

\begin{tabular}{ccccccc}
\hline \multirow{2}{*}{ Entry } & \multicolumn{6}{c}{ Nutrient solution Mn concentration $(\mu \mathrm{M})$} \\
\cline { 2 - 7 } & 0 & 2 & 5 & 10 & 25 & 75 \\
\hline \multicolumn{7}{c}{ Total biomass $\left(\right.$ g.plant $\left.{ }^{-1}\right)$} \\
Alamo & $286.29 \mathrm{a}$ & $299.18 \mathrm{a}$ & $303.17 \mathrm{a}$ & $309.76 \mathrm{a}$ & $309.63 \mathrm{a}$ & $293.16 \mathrm{a}$ \\
Cave-in-rock & $154.52 \mathrm{~b}$ & $165.74 \mathrm{~b}$ & $154.05 \mathrm{~b}$ & $153.29 \mathrm{c}$ & $147.45 \mathrm{c}$ & $179.15 \mathrm{~b}$ \\
KGraze & $170.40 \mathrm{~b}$ & $174.53 \mathrm{~b}$ & $185.30 \mathrm{~b}$ & $212.20 \mathrm{~b}$ & $192.03 \mathrm{~b}$ & $180.51 \mathrm{~b}$ \\
& \multicolumn{7}{c}{ Root dry weight $\left(\mathrm{g} \cdot\right.$ plant $\left.^{-1}\right)$} \\
Alamo & $96.01 \mathrm{a}$ & $99.11 \mathrm{a}$ & $105.50 \mathrm{a}$ & $98.87 \mathrm{a}$ & $101.50 \mathrm{a}$ & $99.67 \mathrm{a}$ \\
Cave-in-rock & $46.96 \mathrm{~b}$ & $54.97 \mathrm{~b}$ & $39.14 \mathrm{~b}$ & $43.38 \mathrm{~b}$ & $42.34 \mathrm{~b}$ & $56.54 \mathrm{~b}$ \\
KGraze & $21.59 \mathrm{c}$ & $21.54 \mathrm{c}$ & $21.30 \mathrm{c}$ & $23.73 \mathrm{c}$ & $23.48 \mathrm{c}$ & $22.97 \mathrm{c}$ \\
& \multicolumn{7}{c}{ Shoot dry weight $\left(\mathrm{g} \cdot \mathrm{plant}{ }^{-1}\right)$} \\
Alamo & $190.2 \mathrm{a}$ & $200.08 \mathrm{a}$ & $197.67 \mathrm{a}$ & $210.89 \mathrm{a}$ & $208.13 \mathrm{a}$ & $193.49 \mathrm{a}$ \\
Cave-in-rock & $107.56 \mathrm{c}$ & $110.77 \mathrm{c}$ & $114.91 \mathrm{c}$ & $109.92 \mathrm{~b}$ & $105.11 \mathrm{c}$ & $122.61 \mathrm{c}$ \\
KGraze & $148.80 \mathrm{~b}$ & $152.99 \mathrm{~b}$ & $164.00 \mathrm{~b}$ & $188.47 \mathrm{a}$ & $168.55 \mathrm{~b}$ & $157.55 \mathrm{~b}$ \\
\hline
\end{tabular}


Appendix Table 2-4. Root-shoot ratio of two two switchgrass cultivars and the pearl millet KGraze grown with nutrient solutions containing different Mn concentrations. Different letters represented significant statistically difference between entries $(\mathrm{p}<0.05)$

\begin{tabular}{|c|c|c|c|c|c|c|c|}
\hline \multirow{2}{*}{$\operatorname{Mn}(\mu \mathrm{M})$} & \multicolumn{2}{|r|}{2014} & \multicolumn{2}{|r|}{2015} & \multicolumn{3}{|c|}{2016} \\
\hline & Alamo & Cave-in-rock & Alamo & Cave-in-rock & Alamo & Cave-in-rock & KGraze \\
\hline \multicolumn{8}{|c|}{ Root-shoot ratios } \\
\hline 0 & $0.75 b$ & $1.34 \mathrm{a}$ & $0.67 \mathrm{a}$ & $0.59 \mathrm{a}$ & $0.51 \mathrm{a}$ & $0.44 \mathrm{a}$ & $0.14 b$ \\
\hline 2 & ----- & ----- & ----- & ----- & $0.49 \mathrm{a}$ & $0.49 \mathrm{a}$ & $0.14 b$ \\
\hline 5 & ----- & ----- & ----- & ----- & $0.54 \mathrm{a}$ & $0.34 b$ & $0.13 c$ \\
\hline 10 & ----- & ----- & ----- & ----- & $0.47 \mathrm{a}$ & $0.40 \mathrm{a}$ & $0.12 b$ \\
\hline 25 & $0.70 b$ & $1.43 \mathrm{a}$ & $0.53 \mathrm{a}$ & $0.58 \mathrm{a}$ & $0.49 \mathrm{a}$ & $0.41 \mathrm{a}$ & $0.14 b$ \\
\hline 50 & $0.73 b$ & $1.47 \mathrm{a}$ & $0.54 \mathrm{a}$ & $0.64 \mathrm{a}$ & ----- & ----- & ----- \\
\hline 75 & $0.63 b$ & $1.40 \mathrm{a}$ & $0.59 \mathrm{a}$ & $0.59 \mathrm{a}$ & $0.53 \mathrm{a}$ & $0.46 \mathrm{a}$ & $0.15 b$ \\
\hline 100 & $0.66 b$ & $1.28 \mathrm{a}$ & $0.62 \mathrm{a}$ & $0.58 \mathrm{a}$ & ----- & ----- & ----- \\
\hline 200 & ----- & ----- & $0.61 \mathrm{a}$ & $0.64 \mathrm{a}$ & ----- & ----- & ----- \\
\hline
\end{tabular}


Appendix Table 2-5. Tiller numbers of two switchgrass cultivars and the pearl millet KGraze grown with nutrient solutions containing different $\mathrm{Mn}$ concentrations. Different letters represented significant statistically difference between entries $(\mathrm{p}<$ 0.05).

\begin{tabular}{|c|c|c|c|c|c|c|c|}
\hline \multirow{2}{*}{$\begin{array}{c}\mathrm{Mn} \\
(\mu \mathrm{M})\end{array}$} & \multicolumn{2}{|c|}{2014} & \multicolumn{2}{|r|}{2015} & \multicolumn{3}{|c|}{2016} \\
\hline & Alamo & Cave-in-rock & Alamo & Cave-in-rock & Alamo & Cave-in-rock & KGraze \\
\hline & \multicolumn{7}{|c|}{ Tillers per plant } \\
\hline 0 & $47.2 \mathrm{a}$ & $41.6 \mathrm{a}$ & $39.6 \mathrm{a}$ & $43.1 \mathrm{a}$ & $28.9 \mathrm{a}$ & $22.7 b$ & $3.8 \mathrm{c}$ \\
\hline 2 & ----- & ----- & ----- & ----- & $27.3 \mathrm{a}$ & $24.6 \mathrm{a}$ & $4.7 b$ \\
\hline 5 & ----- & ----- & ----- & ----- & $27.1 \mathrm{a}$ & $24.4 \mathrm{a}$ & $5.1 \mathrm{~b}$ \\
\hline 10 & ----- & ----- & ----- & ----- & $27.1 \mathrm{a}$ & $25.7 \mathrm{a}$ & $4.9 b$ \\
\hline 25 & $46.0 \mathrm{a}$ & $39.6 \mathrm{a}$ & $41.5 \mathrm{a}$ & $48.6 \mathrm{a}$ & $26.3 \mathrm{a}$ & $24.2 \mathrm{a}$ & $5.2 b$ \\
\hline 50 & $46.8 \mathrm{a}$ & $42.1 \mathrm{a}$ & $39.2 \mathrm{a}$ & $44.3 \mathrm{a}$ & ----- & ----- & ----- \\
\hline 75 & $45.4 \mathrm{a}$ & $41.9 \mathrm{a}$ & $42.1 \mathrm{a}$ & $49.5 \mathrm{a}$ & $25.9 \mathrm{a}$ & $24.8 \mathrm{a}$ & $4.9 b$ \\
\hline 100 & $44.5 \mathrm{a}$ & $36.9 a$ & $39.8 \mathrm{a}$ & $44.3 \mathrm{a}$ & ----- & ----- & ----- \\
\hline 200 & ----- & ----- & $39.1 \mathrm{~b}$ & $49.6 \mathrm{a}$ & ----- & ----- & ----- \\
\hline
\end{tabular}


Appendix Table 2-6. Plant height of two switchgrass cultivars and the pearl millet KGraze grown with nutrient solutions containing different Mn concentrations. Different letters represented significant statistically difference between entries $(\mathrm{p}<$ $0.05)$.

\begin{tabular}{|c|c|c|c|c|c|c|c|}
\hline \multirow{2}{*}{$\begin{array}{c}\mathrm{Mn} \\
(\mu \mathrm{M})\end{array}$} & \multicolumn{2}{|r|}{2014} & \multicolumn{2}{|r|}{2015} & \multicolumn{3}{|c|}{2016} \\
\hline & Alamo & Cave-in-rock & Alamo & Cave-in-rock & Alamo & Cave-in-rock & KGraze \\
\hline & \multicolumn{7}{|c|}{ Plant height $(\mathrm{cm})$} \\
\hline 0 & $164.1 \mathrm{a}$ & $144.6 \mathrm{~b}$ & $158.3 \mathrm{a}$ & $141.6 b$ & $154.1 \mathrm{~b}$ & $159.9 \mathrm{ab}$ & $184.8 \mathrm{a}$ \\
\hline 2 & ----- & ----- & ----- & ----- & $158.7 \mathrm{~b}$ & $163.7 \mathrm{~b}$ & $194.6 \mathrm{a}$ \\
\hline 5 & ----- & ----- & ----- & ----- & $162.2 b$ & $161.2 b$ & $198.5 \mathrm{a}$ \\
\hline 10 & ----- & ----- & ----- & ----- & $168.9 \mathrm{~b}$ & $158.9 \mathrm{~b}$ & $205.2 \mathrm{a}$ \\
\hline 25 & $163.1 \mathrm{a}$ & $147.1 \mathrm{~b}$ & $161 \mathrm{a}$ & $144.6 \mathrm{~b}$ & $168.1 \mathrm{ab}$ & $159.0 \mathrm{~b}$ & $196.9 a$ \\
\hline 50 & $168.9 \mathrm{a}$ & $142.5 b$ & $161.2 \mathrm{a}$ & $145.5 b$ & ----- & ----- & ----- \\
\hline 75 & $167.3 \mathrm{a}$ & $155.5 b$ & $161.2 \mathrm{a}$ & $146.4 \mathrm{~b}$ & $164.2 b$ & $160.3 b$ & $197.1 \mathrm{a}$ \\
\hline 100 & $162.9 \mathrm{a}$ & $145 b$ & $156.4 \mathrm{a}$ & $149.7 \mathrm{a}$ & ----- & ----- & ----- \\
\hline 200 & ----- & ----- & $162.6 \mathrm{a}$ & $149.6 \mathrm{a}$ & ----- & ----- & ----- \\
\hline
\end{tabular}


Appendix Table 2-7. SPAD-502 chlorophyll meter reading of two switchgrass cultivars grown with nutrient solutions containing different Mn concentrations. Different letters represented significant statistically difference between ecotypes ( $p<$ $0.05)$.

\begin{tabular}{cccccc}
\hline \multirow{2}{*}{$\begin{array}{c}\mathrm{Mn} \\
(\mu \mathrm{M})\end{array}$} & \multicolumn{2}{c}{2014} & & \multicolumn{2}{c}{2015} \\
\cline { 2 - 3 } \cline { 5 - 6 } \cline { 5 - 6 } & Alamo & Cave-in-rock & & Alamo & Cave-in-rock \\
\hline 0 & $34.86 \mathrm{~b}$ & $40.01 \mathrm{a}$ & & $40.27 \mathrm{a}$ & $43.72 \mathrm{a}$ \\
25 & $35.99 \mathrm{~b}$ & $40.56 \mathrm{a}$ & & $40.89 \mathrm{a}$ & $44.61 \mathrm{a}$ \\
50 & $35.21 \mathrm{~b}$ & $40.85 \mathrm{a}$ & & $42.24 \mathrm{a}$ & $42.97 \mathrm{a}$ \\
75 & $36.34 \mathrm{~b}$ & $41.83 \mathrm{a}$ & & $39.75 \mathrm{~b}$ & $44.83 \mathrm{a}$ \\
100 & $36.19 \mathrm{~b}$ & $41.92 \mathrm{a}$ & & $41.87 \mathrm{~b}$ & $44.80 \mathrm{a}$ \\
200 & ----- & ---- & & $41.57 \mathrm{a}$ & $46.16 \mathrm{a}$ \\
\hline
\end{tabular}


Appendix Table 2-8. SPAD-502 chlorophyll meter reading of two switchgrass cultivars and the pearl millet KGraze grown with nutrient solutions containing different $\mathrm{Mn}$ concentrations in 2016. Different letters represented significant statistically difference between entries $(\mathrm{p}<0.05)$.

\begin{tabular}{|c|c|c|c|c|c|c|c|}
\hline \multirow{2}{*}{ DAMT } & \multirow{2}{*}{ Species } & \multicolumn{6}{|c|}{$\operatorname{Mn}(\mu \mathrm{M})$} \\
\hline & & 0 & 2 & 5 & 10 & 25 & 75 \\
\hline \multirow{4}{*}{24} & \multicolumn{7}{|c|}{ SPAD-502 meter reading } \\
\hline & Alamo & $35.73 a$ & $38.5 \mathrm{a}$ & $40.07 \mathrm{a}$ & $40.12 \mathrm{a}$ & $38.42 \mathrm{a}$ & $40.07 \mathrm{a}$ \\
\hline & Cave-in-rock & $37.23 \mathrm{a}$ & $40.92 \mathrm{a}$ & $40.98 \mathrm{a}$ & $40.82 \mathrm{a}$ & $38.95 \mathrm{a}$ & $41.17 \mathrm{a}$ \\
\hline & Kgraze & $23.7 b$ & $35.85 \mathrm{a}$ & $40.67 \mathrm{a}$ & $40.92 \mathrm{a}$ & $39.73 a$ & $41.52 \mathrm{a}$ \\
\hline \multirow{3}{*}{38} & Alamo & $37.93 \mathrm{a}$ & $41.33 \mathrm{a}$ & $39.08 \mathrm{a}$ & $40.28 b$ & $40.03 \mathrm{a}$ & $40.68 \mathrm{ab}$ \\
\hline & Cave-in-rock & $41.03 \mathrm{a}$ & $41.73 \mathrm{a}$ & $42.75 \mathrm{a}$ & $42.95 \mathrm{ab}$ & $43.78 \mathrm{a}$ & $43.65 a$ \\
\hline & Kgraze & $31.58 b$ & $38.45 b$ & $39.7 \mathrm{a}$ & $43.83 \mathrm{a}$ & $41.02 \mathrm{a}$ & $39.23 b$ \\
\hline \multirow{3}{*}{53} & Alamo & $34.9 \mathrm{~b}$ & $38.42 b$ & $39.38 b$ & $39.03 c$ & $37.77 \mathrm{c}$ & $36.35 b$ \\
\hline & Cave-in-rock & $39.15 \mathrm{a}$ & $42.07 \mathrm{~b}$ & $43.33 b$ & $43.53 b$ & $43.52 b$ & $43.38 \mathrm{a}$ \\
\hline & Kgraze & $38.67 \mathrm{a}$ & $47.88 \mathrm{a}$ & $51.78 \mathrm{a}$ & $55.6 \mathrm{a}$ & $48.87 \mathrm{a}$ & $48.3 \mathrm{a}$ \\
\hline \multirow{3}{*}{67} & Alamo & $31.23 \mathrm{c}$ & $34.85 \mathrm{c}$ & $36.47 \mathrm{c}$ & $38.32 \mathrm{c}$ & $38.55 \mathrm{c}$ & $37.33 \mathrm{c}$ \\
\hline & Cave-in-rock & $37.97 \mathrm{~b}$ & $41.75 b$ & $42.317 b$ & $43.95 b$ & $44.15 b$ & $45.35 b$ \\
\hline & Kgraze & $46.78 \mathrm{a}$ & $56.78 \mathrm{a}$ & $56.02 \mathrm{a}$ & $55.86 \mathrm{a}$ & $57.6 \mathrm{a}$ & $57.12 \mathrm{a}$ \\
\hline
\end{tabular}


Appendix. Table 3-1. Primer sequences of selected genes for RT-PCR

\begin{tabular}{|c|c|c|c|}
\hline Genes & ID & Sequence & Reference and design \\
\hline \multirow[t]{2}{*}{ NADP-ME } & Pv.EB00308-F & GTTCCGCCGGATGTGTATG & \multirow{8}{*}{ (Rao et al, 2016) } \\
\hline & Pv.EB00308-R & CCCAGCAGCACCAGCAA & \\
\hline \multirow[t]{2}{*}{ NAD-ME } & Pv.la01553-F & GGCCACAAGAGAAGGTTGAT & \\
\hline & Pv.la01553-R & ACACCAAGGTCACCTAAGCC & \\
\hline \multirow[t]{2}{*}{ PEPCK } & Pv.la03881-F & GTGTGGGCAAGAGGATCAG & \\
\hline & Pv.la03881-R & TTCTTGTAGTTGGCGGTGAG & \\
\hline \multirow[t]{2}{*}{ PEPC } & Pv.Da00871-F & CTCTTTCCAGGGAGATCCAA & \\
\hline & Pv.Da00871-R & GTAACGCATTTCGTCCTGTG & \\
\hline \multirow[t]{2}{*}{ Actin12 } & actin12-F & CAGCCATCCATGATCGGTATG & \multirow{4}{*}{ (Gimeno et al, 2014) } \\
\hline & $\operatorname{actin} 12-\mathrm{R}$ & TGCCGTACAGGTCCTTTCTGA & \\
\hline \multirow[t]{2}{*}{ eEF-1 $1 \alpha$} & Eef-1 $1 \alpha-F$ & CGGTTGGTCGTGTGGAGACT & \\
\hline & Eef-1 $1 \alpha-R$ & TGGTGCATCTCAACAGACTTCAC & \\
\hline \multirow[t]{2}{*}{$\mathrm{MDH}$} & $\begin{array}{l}\text { Pavir.Bb03415- } \\
\text { F }\end{array}$ & GCGGACGTGGTGGTTATC & \multirow{4}{*}{ Designed by Primer3 } \\
\hline & $\begin{array}{l}\text { Pavir.Bb03415- } \\
\text { R }\end{array}$ & GGTACGTGATGATGTGGATCAG & \\
\hline \multirow[t]{2}{*}{ PSII-psbp } & $\begin{array}{l}\text { Pavir.Gb01641- } \\
\text { F }\end{array}$ & AGGCAGAGAAGAAGAAGGAAAG & \\
\hline & $\begin{array}{l}\text { Pavir.Gb01641- } \\
\text { R }\end{array}$ & GCTATCCAGAGCGTACTCAATC & \\
\hline
\end{tabular}


Appendix. Table 3-2. Data production.

\begin{tabular}{cccccccc}
\hline Sample name & Raw reads & Clean reads & Clean bases & Error rate(\%) & Q20(\%) & Q30(\%) & GC content(\%) \\
\hline LLMLeaf1 & 53582152 & 51956146 & $7.8 G$ & 0.01 & 97.51 & 93.40 \\
LLMLeaf2 & 48048280 & 46672968 & $7 G$ & 0.01 & 97.59 & 93.57 \\
LLMLeaf3 & 54000360 & 51928802 & $7.8 G$ & 0.01 & 97.62 & 93.59 \\
LHMLeaf1 & 54339222 & 52486528 & $7.9 G$ & 0.01 & 97.37 & 93.10 \\
LHMLeaf2 & 52131060 & 50546682 & $7.6 G$ & 0.01 & 97.56 & 93.51 \\
LHMLeaf3 & 44585022 & 43044540 & $6.5 G$ & 0.01 & 98.05 & 94.47 \\
ELMLeaf1 & 41351530 & 39860496 & $6 G$ & 0.01 & 98.38 & 95.28 \\
ELMLeaf2 & 42680818 & 41114974 & $6.2 G$ & 0.01 & 97.38 & 92.97 \\
ELMLeaf3 & 44977914 & 43392758 & $6.5 G$ & 0.01 & 98.32 & 95.14 \\
EHMLeaf1 & 44345436 & 42788082 & $6.4 G$ & 0.01 & 98.19 & 94.85 \\
EHMLeaf2 & 46273746 & 44494052 & $6.7 G$ & 0.01 & 97.53 & 93.35 \\
EHMLeaf3 & 55767572 & 53292802 & $8 G$ & 0.01 & 97.01 & 54.63 \\
\hline
\end{tabular}

Detail statistics of sequencing dat

(1) Sample name: the names of samples

(2) Raw Reads: the original sequencing reads counts

(3) Clean Reads: number of reads after filtering

(4) Clean Bases: clean reads number multiply read length, saved in G unit

(5) Error Rate: average sequencing error rate, which is calculated by Qphred=-10log 10(e)

(6) Q20: percentages of bases whose correct base recognition rates are greater than $99 \%$ in total bases

(7) Q30:percentages of bases whose correct base recognition rates are greater than $99.9 \%$ in total bases

(8) GC content: percentages of $\mathrm{G}$ and $\mathrm{C}$ in total bases 
Appendix. Table 3-3. $M D H$ gene is involved in the top 4 most significant enrichment pathways

\begin{tabular}{|c|c|c|c|c|c|c|c|}
\hline Term & $\begin{array}{l}\text { Sample } \\
\text { number }\end{array}$ & $\begin{array}{l}\text { Background } \\
\text { number }\end{array}$ & P-value & $\begin{array}{l}\text { Corrected } \\
\text { P-value }\end{array}$ & UniGenes & KO & Entrez ID \\
\hline$\frac{\text { Circadian rhythm }}{\text { - plant }}$ & 6 & 53 & 0.000199739172789 & 0.00454491676826 & $\begin{array}{l}\text { Pavir.Eb00237 Pavir.J24672 } \\
\text { Pavir.Ea00223 } \\
\text { Pavir.Ab00856 } \\
\text { Pavir.Aa02966 Pavir.J31609 }\end{array}$ & $\begin{array}{l}\text { zma: } 100127527 \\
\text { zma: } 100286123 \\
\text { zma: } 100127523 \\
\text { zma: } 100286123 \\
\text { zma: } 100286123 \\
\text { zma: } 100127518\end{array}$ & $\begin{array}{l}100127527 \\
100286123 \\
100127523 \\
100286123 \\
100286123 \\
100127518\end{array}$ \\
\hline$\frac{\text { Carbon fixation in }}{\frac{\text { photosynthetic }}{\text { organisms }}}$ & 7 & 81 & 0.000276397115669 & 0.00454491676826 & $\begin{array}{l}\text { Pavir.la04487 Pavir.J31928 } \\
\text { Pavir.Bb03415 } \\
\text { Pavir.Da00569 } \\
\text { Pavir.Ba00357 Pavir.Ib00442 } \\
\text { Pavir.J23272 }\end{array}$ & $\begin{array}{c}\text { zma: } 542368 \text { zma: } 542368 \\
\text { zma: } 100193663 \\
\text { zma: } 100283676 \\
\text { zma: } 100193663 \\
\text { zma:100282201 zma:542368 }\end{array}$ & $\begin{array}{c}542368542368 \\
100193663 \\
100283676 \\
100193663 \\
100282201542368\end{array}$ \\
\hline$\frac{\text { Cysteine and }}{\text { methionine }}$ & 7 & 82 & 0.000296407615321 & 0.00454491676826 & $\begin{array}{c}\text { Pavir.J33604 Pavir.Ga02401 } \\
\text { Pavir.Ib00643 Pavir.Bb03415 } \\
\text { Pavir.Ha00152 Pavir.la01779 } \\
\text { Pavir.Ba00357 }\end{array}$ & $\begin{array}{c}\text { zma:542438 zma: } 100216722 \\
\text { zma:541959 zma: } 100193663 \\
\text { zma: } 100191816 \\
\text { zma: } 100285340 \\
\text { zma:100193663 }\end{array}$ & $\begin{array}{c}542438100216722 \\
541959100193663 \\
100191816 \\
100285340 \\
100193663\end{array}$ \\
\hline$\underline{\text { Carbon }}$ & 11 & 247 & 0.0012969882057 & 0.0149153643656 & $\begin{array}{l}\text { Pavir.J33604 Pavir.la04487 } \\
\text { Pavir.Ga02401 Pavir.Ib00643 } \\
\text { Pavir.Eb03550 Pavir.J31928 } \\
\text { Pavir.Bb03415 } \\
\text { Pavir.Da00569 } \\
\text { Pavir.Ba00357 Pavir.Ib00442 } \\
\text { Pavir.J23272 }\end{array}$ & $\begin{array}{c}\text { zma:542438 zma:542368 } \\
\text { zma:100216722 zma:541959 } \\
\text { zma:542578 zma:542368 } \\
\text { zma: } 100193663 \\
\text { zma:100283676 } \\
\text { zma:100193663 } \\
\text { zma:100282201 zma:542368 }\end{array}$ & $\begin{array}{c}542438542368 \\
100216722541959 \\
542578542368 \\
100193663 \\
100283676 \\
100193663 \\
100282201542368\end{array}$ \\
\hline
\end{tabular}




\section{Classification of Raw Reads (EHMLeaf1)}

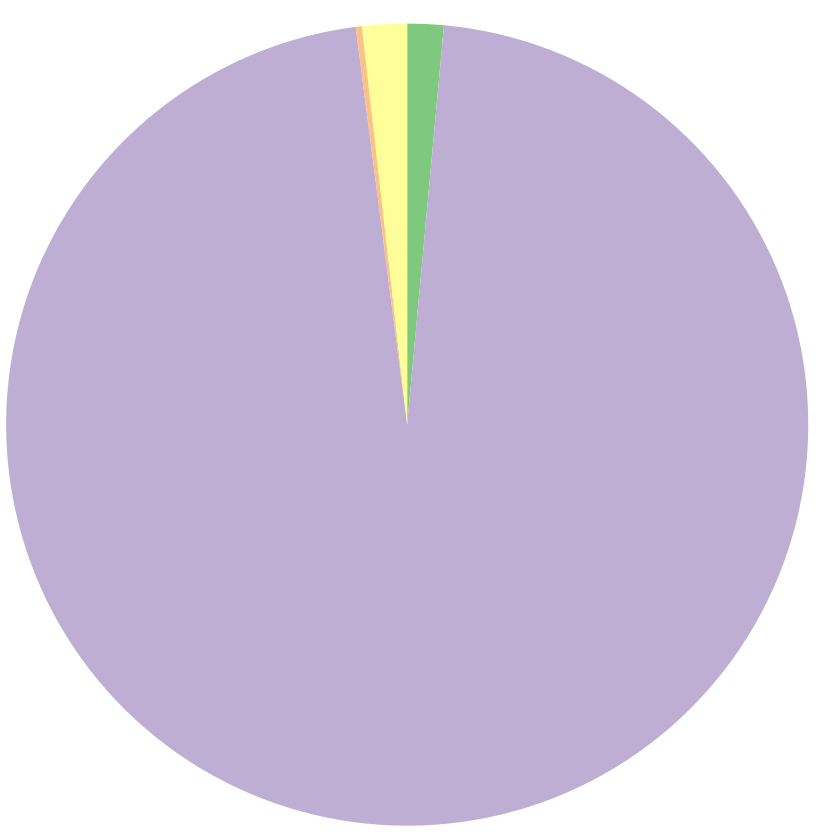

Clean Reads $(21394041,96.49 \%)$
Containing N $(399776,1.80 \%)$
Low Quality $(54723,0.25 \%)$
Adapter Related $(324178,1.46 \%)$

Appendix. Figure 3-1. Classification of Raw Reads. 


\section{Percent of reads mapped to genome regions (EHMLeaf1)}
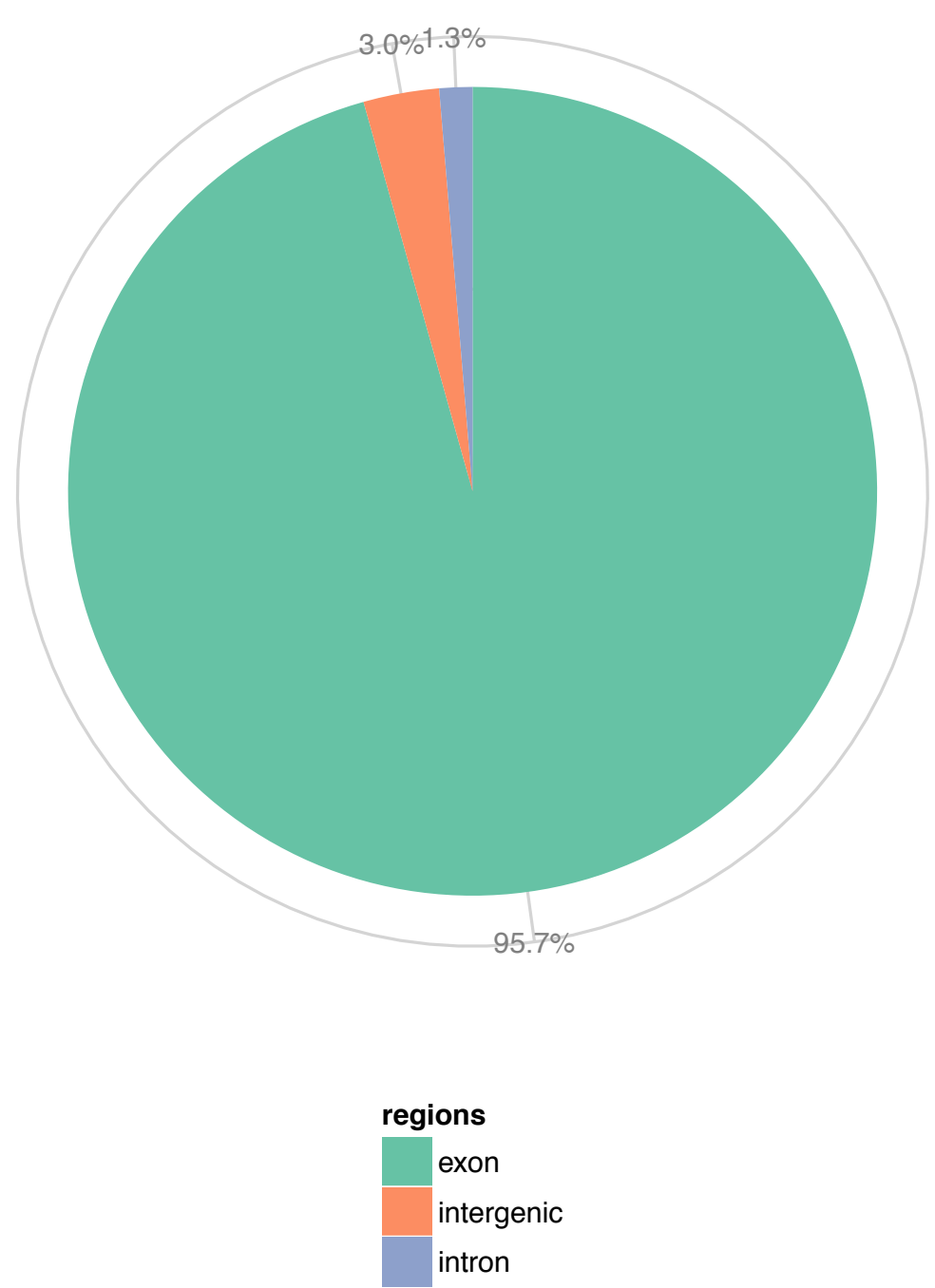

Appendix. Figure 3-2. Percent of reads mapped to genome regions (EHMLeaf1). 




Appendix. Figure 3-3. Overall gene expression levels. 


\section{Pearson correlation between samples}

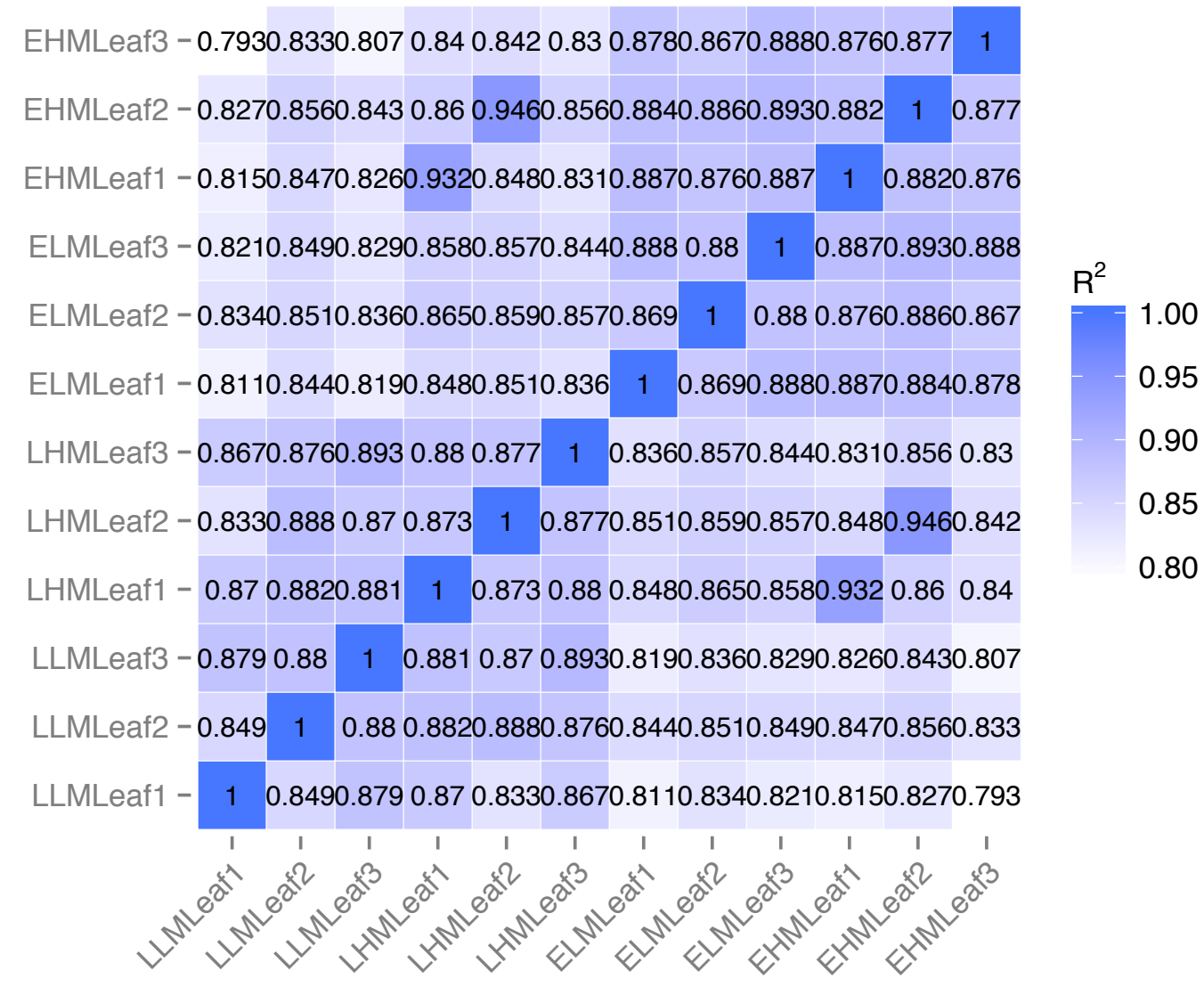

Appendix. Figure 3-4. Pearson correlation between samples. 

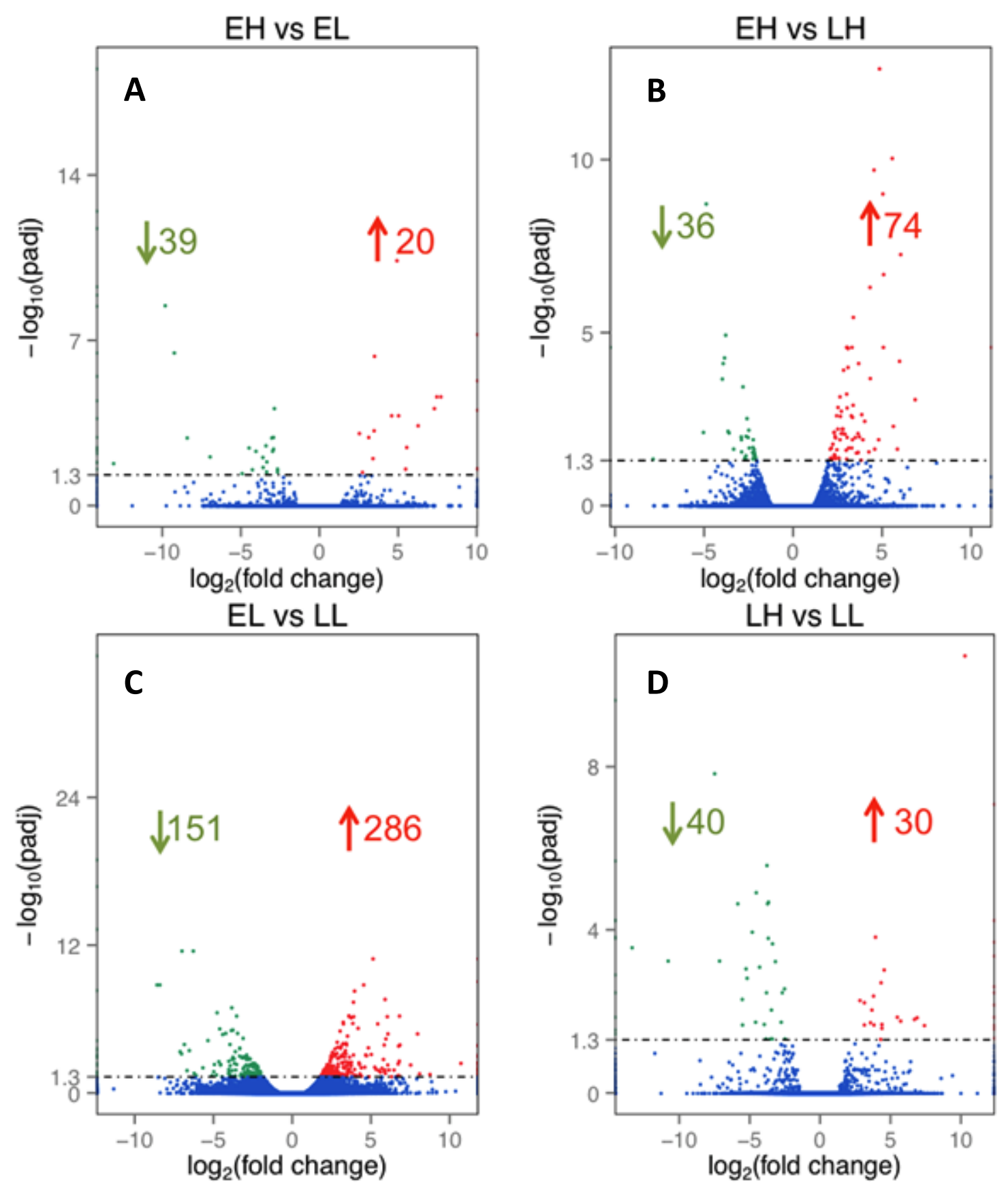

Appendix. Figure 3-5. Volcano plot of the overall distribution of different expression genes. For the experiment without biological replicates, the threshold is normally set as: $\mid \log 2$ (FoldChange) $\mid>1$ and qvalue $<0.005$. For the experiment with biological replicates, as the DESeq has already eliminate the biological variations, our threshold is normally set as: padj $<0.05$. 


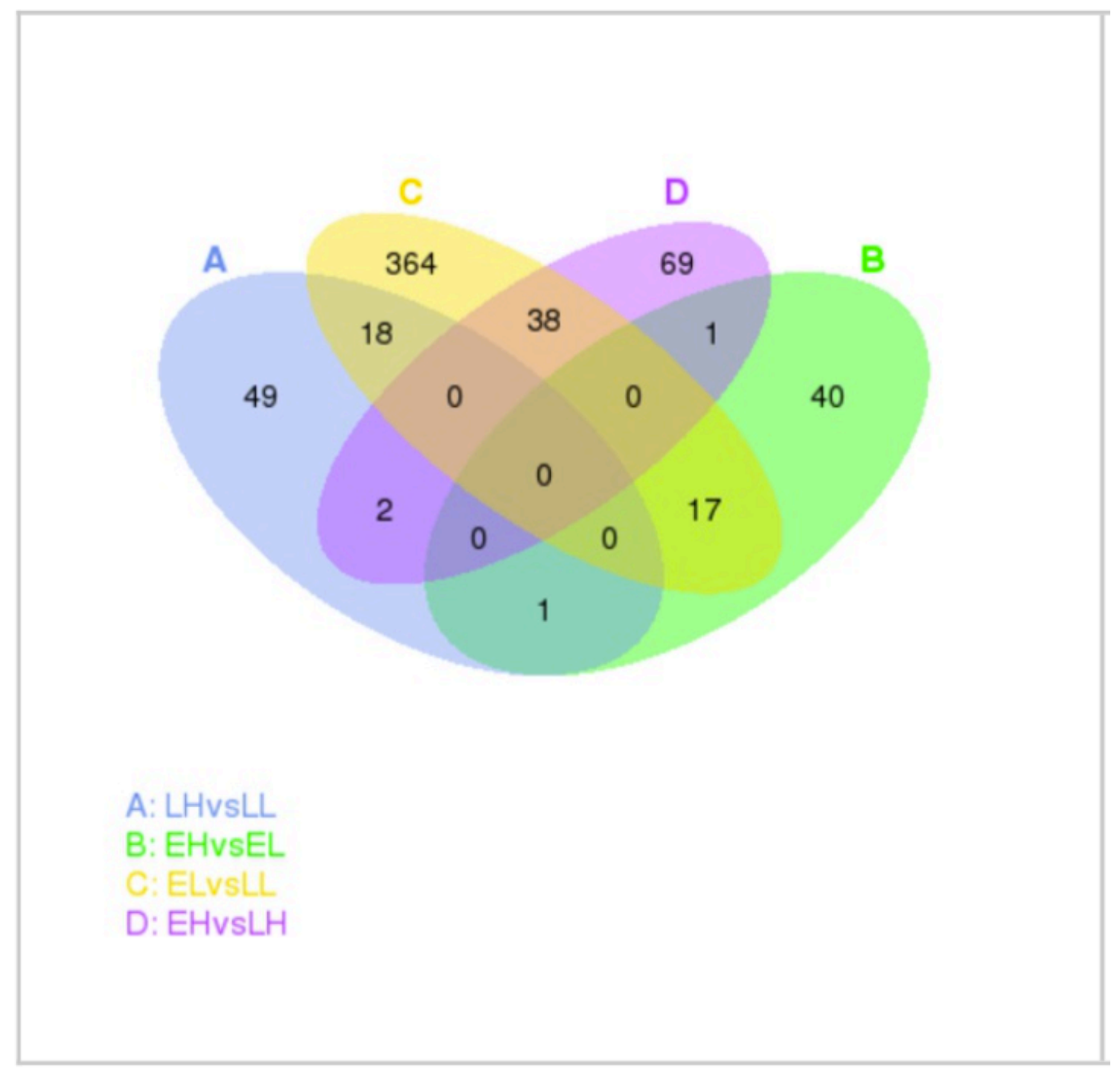

Appendix .Figure3-6. Venn diagram of differentially expressed genes. The sum of the numbers in each circle is the total number of genes expressed within a group, and the overlap represents the genes expressed in common between groups. 


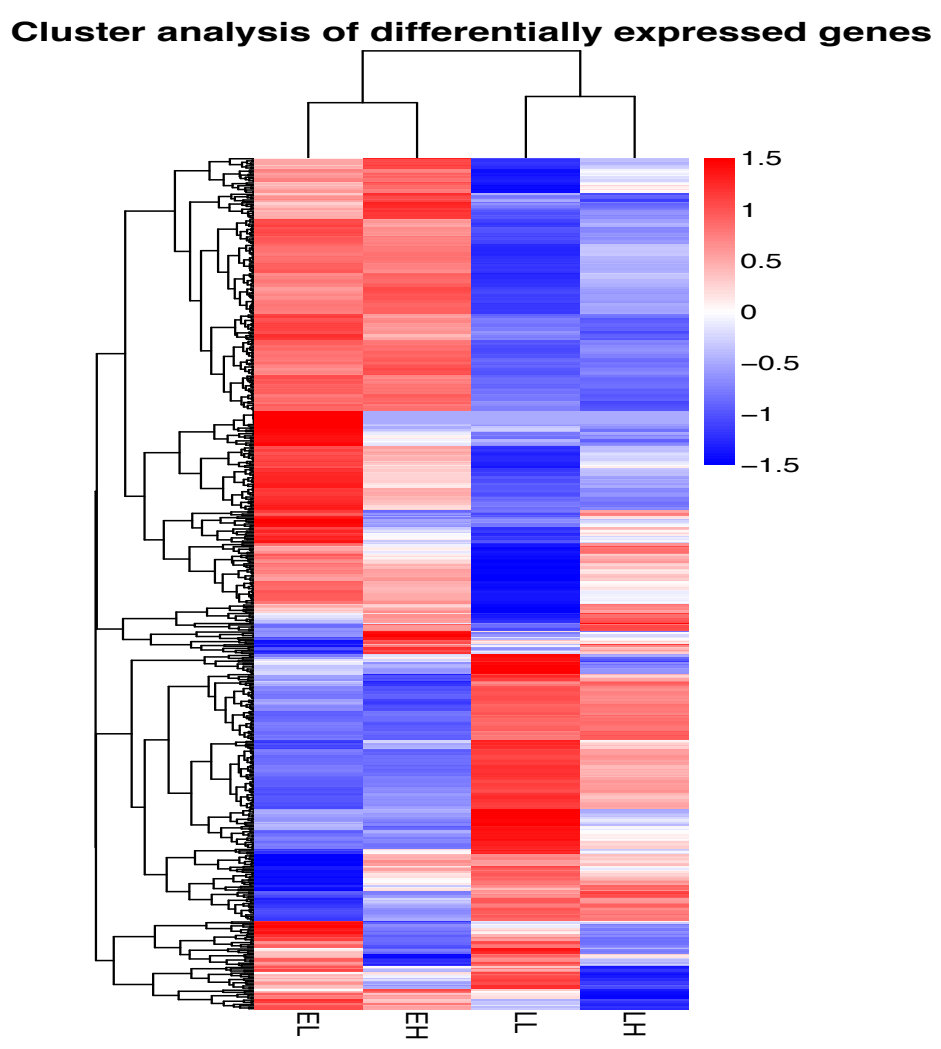

Appendix. Figure3-7. FPKM cluster analysis.

A. The overall results of FPKM cluster analysis, clustered using the $\log 10(\mathrm{FPKM}+1)$ value. Red denotes genes with high expression levels, and blue denotes genes with low expression levels. The color range from red to blue represents the $\log 10(\mathrm{FPKM}+1)$ value from large to small. B. MDH cluster includes another 7 genes C. Examples of PSII gene cluster. 


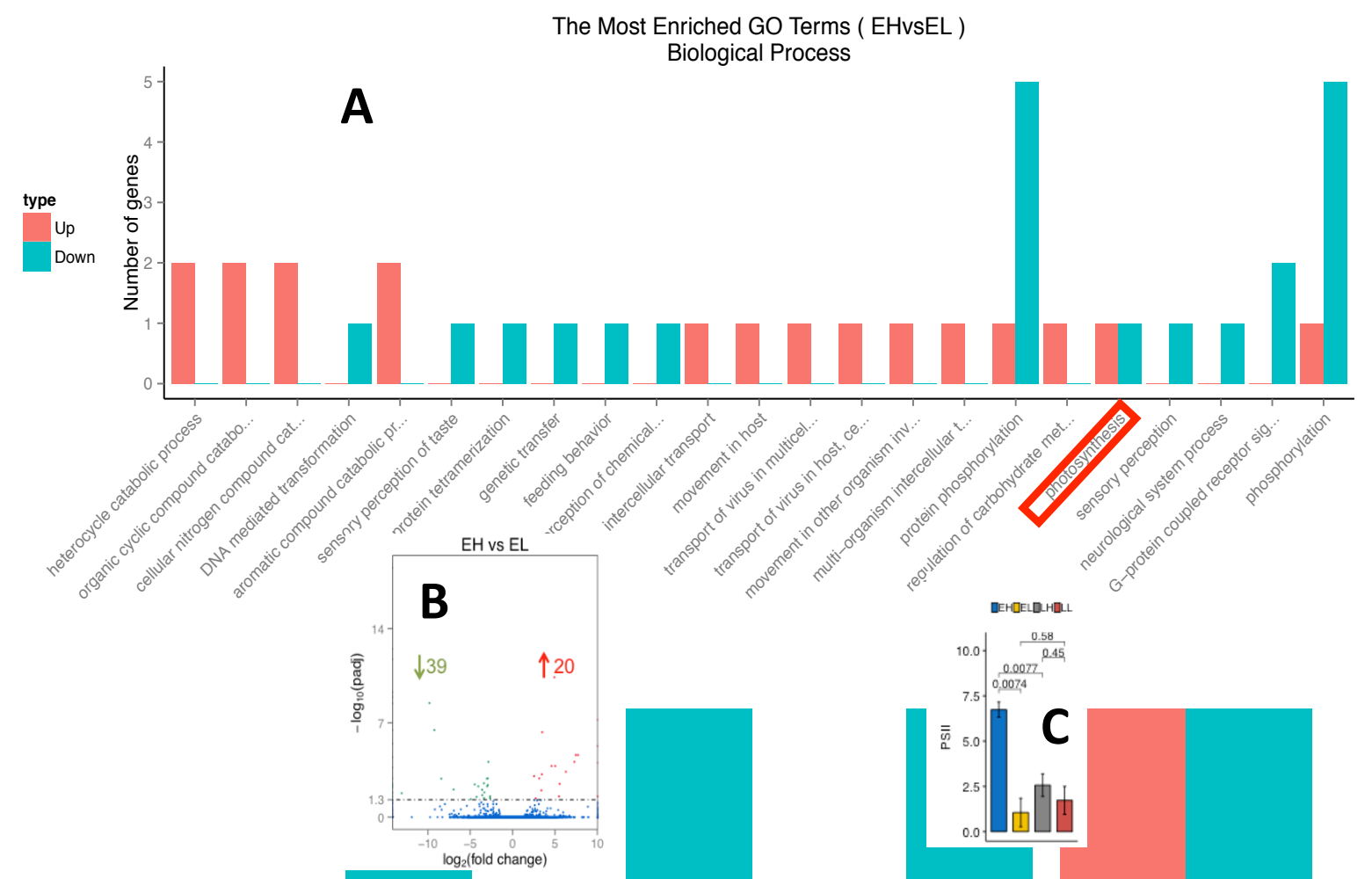

Appendix. Figure 3-8. Gene ontology analysis of gene expression differences. 


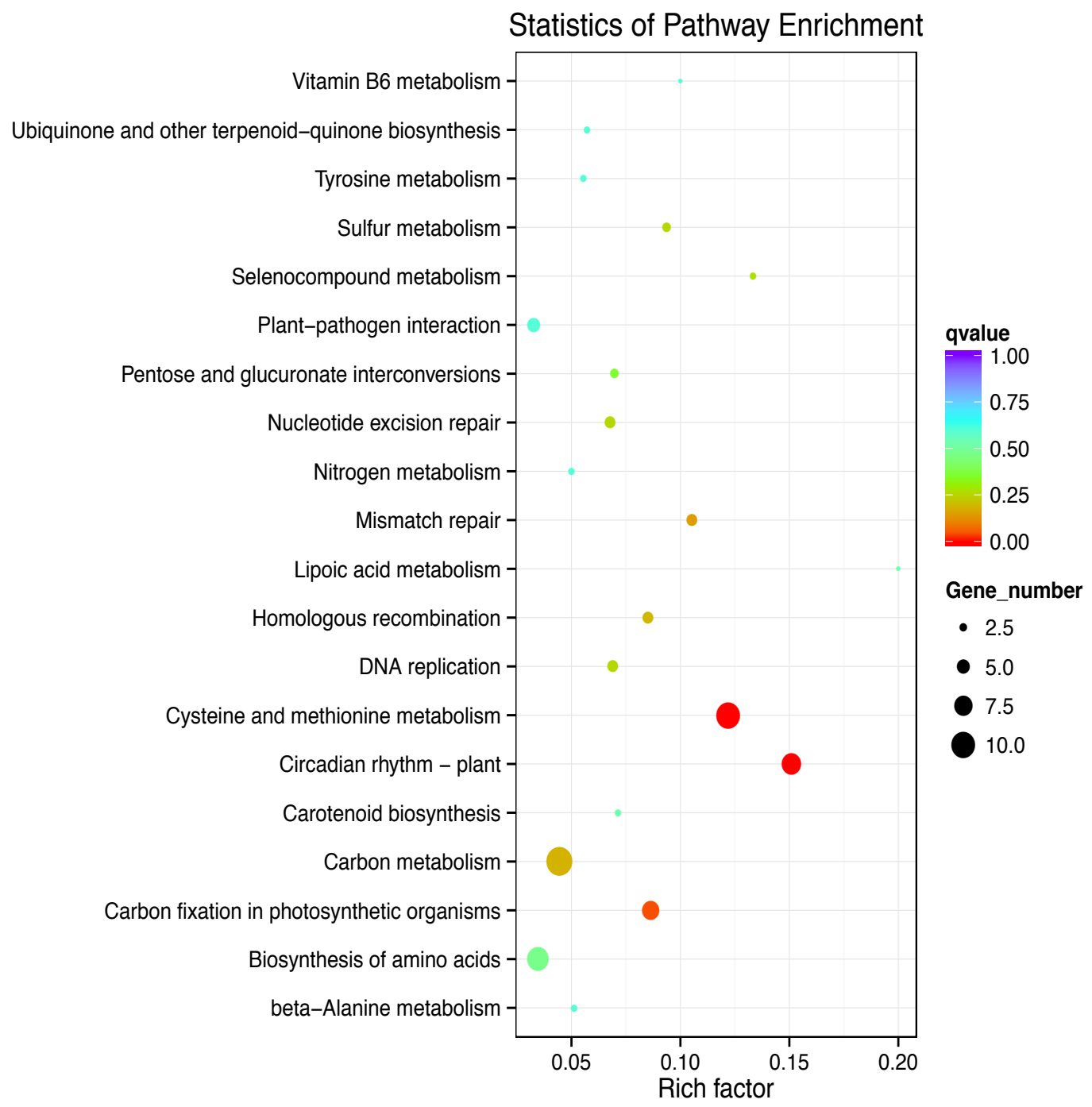

Appendix. Figure 3-9. KEGG enrichment scatter plot of DEGs, EL vs LL as an example to show the gene expression changes at different growth stages. The y-axis shows the name of the pathway and the $\mathrm{x}$-axis shows the Rich factor. Dot size represents the number of different genes and the color indicates the q-value. 


\section{VITA}

Ying Guo was born on June 23 ${ }^{\text {rd }}, 1978$ in Shandong, China. She completed her undergraduate studies and received a bachelor degree in agronomy (teacher) in 2003 and a master degree in crop cultivation and farming system in 2006 from Shandong Agricultural University, Shandong, China. She also taught plant physiology and inorganic chemistry as a teaching assistant professor in Weifang University of Science \& Technology, Shandong, China from 2006 to 2011. Before starting her PhD program, she worked at University of Missouri as a research technicianon soybean transformation in Dr. Zhanyuan Zhang's Lab from 2012 to 2013. She joined Dr. Felix Fritschi's lab in the Division of Plant Sciences at the University of Missouri-Columbia in the summer of 2013and received her PhD in Plant, Insect and Microbial Sciences in May 2019. Ying will be working as a biologist at Bayer Crop Science in St. Louis, Missouri starting in May 2019. 